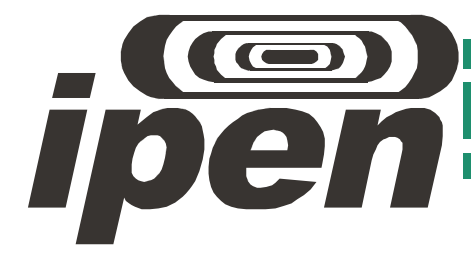

AUTARQUIA ASSOCIADA À UNIVERSIDADE DE SÃO PAULO

DESENVOLVIMENTO E IMPLEMENTAÇÃO DE UM NOVO

SISTEMA PNEUMÁTICO DE TRANSFERÊNCIA PARA

IRRADIAÇÃO DE MATERIAIS NO REATOR IEA-R1

ALBERTO DE JESUS FERNANDO

Dissertação apresentada como parte dos requisitos para obtenção do Grau de Mestre em Ciências na Área de Tecnologia Nuclear - Aplicações

Orientador:

Prof. Dr. Tufic Madi Filho 
INSTITUTO DE PESQUISAS ENERGÉTICAS E NUCLEARES

Autarquia associada à Universidade de São Paulo

\section{DESENVOLVIMENTO E IMPLEMENTAÇÃO DE UM NOVO SISTEMA PNEUMÁTICO DE TRANSFERÊNCIA PARA IRRADIAÇÃO DE MATERIAIS NO REATOR IEA-R1}

ALBERTO DE JESUS FERNANDO

Dissertação apresentada como parte dos requisitos para obtenção do Grau de Mestre em Ciências na Área de Tecnologia Nuclear - Aplicações.

Orientador:

Dr. Tufic Madi Filho 
Aos meus pais Luciano e Inês (in memoriam) pela oportunidade, à minha esposa Elisabeth e filhos Allan e Thiago pela dedicação, apoio $e$ carinho, em toda realização deste trabalho. 


\section{AGRADECIMENTOS}

Expresso meu sincero reconhecimento a todos que, direta ou indiretamente contribuíram com a elaboração deste presente trabalho, incluindo aqueles que porventura, não estejam aqui relacionados e especialmente:

Ao Instituto de Pesquisas Energéticas e Nucleares e à Comissão Nacional de Energia Nuclear pela oportunidade de execução deste trabalho e pela minha formação profissional, apoio científico e tecnológico ao projeto de pesquisa.

Ao Dr. Tufic Madi Filho, pela inestimável e valiosa orientação durante toda as etapas do trabalho. Sem a motivação e o incentivo deste admirável profissional e amigo, este trabalho não teria sido iniciado.

Ao M.Sc Walter Ricci Filho, da gerência do CRO do IPEN, pelo incentivo e oportunidade, pela infra-estrutura necessária ao desenvolvimento deste trabalho e amizade.

À M.Sc Fernanda Bernardes Calvo pelo apoio sempre atuante, pela amizade e encorajamento durante o tempo de preparação deste trabalho.

Aos Colegas do Centro de Operação do Reator IEA-R1 (CRO) do IPEN pelo apoio e incentivo e especialmente ao Sr. Gilson de Freitas Maciel pela parceria no desenvolvimento e implementação da automação do sistema.

A todos os colegas do Departamento de Projeto e Fabricação (DPF) do IPEN, que contribuíram no desenvolvimento deste trabalho na elaboração e confecção dos dispositivos mecânicos. Em especial o Mcs Fabio Eduardo Campo, Sr. Sergio Augusto Sá, Sr. Sergio Antonio do Prado, Sr. José Carlos Sabino e sua equipe de Usinagem, Sr. Idacir Mantovani e sua equipe de Montagem.

À Equipe de Proteção Radiológica no $\boldsymbol{C R O}$ pelo empenho e monitorações constantes do sistema.

Aos Colegas dos Laboratórios LAN (de Análises por Ativação), LMN (de Metrologia Nuclear) e LEER (de Espectroscopia e Espectrometria das Radiações) do IPEN pela colaboração, como usuários, nas análises necessárias e elaboração dos resultados utilizados na validação do trabalho. 
" A mente que se abre a uma nova idéia, jamais volta ao seu tamanho original “

( Albert Einstein ) 


\title{
DESENVOLVIMENTO E IMPLEMENTAÇÃO DE UM NOVO SISTEMA PNEUMÁTICO DE TRANSFERÊNCIA PARA IRRADIAÇÃO DE MATERIAIS NO REATOR IEA-R1
}

\author{
Alberto de Jesus Fernando
}

\section{RESUMO}

Sistemas Pneumáticos de Transferência - "Pneumatic Transfer Systems" (PTS) são equipamentos mecânicos amplamente e mundialmente utilizados para o transporte, movimentação e transferência de diversos tipos de materiais, objetos e cargas entre dois ou mais terminais localizados em locais próximos ou distantes um do outro. Devido à sua versatilidade e rapidez, a aplicabilidade do sistema se faz presente em diversas áreas da sociedade tais como medicina (hospitais e laboratórios de análises clínicas); indústria (civil, automobilística, siderúrgica, metalúrgica, mineração, química, de alimentos); comércio (postos de gasolina, cinemas, supermercados, bancos, pedágios, empresas de venda de produtos por internet, cassinos); serviços públicos (repartições públicas, cortes de justiça, correios e telégrafos). $\mathrm{Na}$ área nuclear $\mathrm{O}$ PTS também tem uma vasta aplicabilidade nas diversas instalações nucleares, destacando-se a sua utilização como parte do processo de produção de radioisótopos e radiofármacos de meia vida curta tais como ${ }^{67} \mathrm{Ga},{ }^{201} \mathrm{TI},{ }^{18} \mathrm{~F}$ e ${ }^{123}$ I-ultra puro, instalações de eliminação e estocagem de resíduos radioativos e áreas de pesquisa que utilizam o método analítico de Análise por Ativação Neutrônica (AAN). O desenvolvimento deste trabalho foi direcionado para o projeto, construção, instalação e implementação de um novo Sistema de Transferência Pneumático para transporte e transferência de materiais que são irradiados no núcleo do reator IEA-R1, localizado no Instituto de Pesquisas Energéticas e Nucleares (IPEN), para aplicação da técnica de AAN. Para sua instalação foi calculado a carga sobre a placa matriz do núcleo do reator e os testes de envio e retorno da amostra em análise. O fluxo neutrônico na posição de irradiação foi determinado utilizando a técnica de folhas de Au (ativação) apresentando um valor de $3,70 \pm 0,26 \cdot 10^{12} \mathrm{n} \mathrm{cm}^{-2} \mathrm{~s}^{-1}$. 


\title{
DEVELOPMENT AND IMPLEMENTATION OF A NEW PNEUMATIC TRANSFER SYSTEM FOR MATERIALS IRRADIATION AT IEA-R1 REACTOR
}

\author{
Alberto de Jesus Fernando
}

\begin{abstract}
Pneumatic Transfer Systems (PTS) are classified as mechanical equipment largely operated all over the world for transport of a huge sort of objects, samples and materials located at nearly terminals or even at separated ones. System applicability is often recognized in many activities, such as medicine (hospital settings, clinical analysis labs), industry (steel, automobiles, mining, chemical, food, construction), trading (gas station, movies, supermarkets, banks, e-commerce) and federal agencies (post services, federal courts, public enterprises). In the nuclear settings, PTS shows also a vast array of applications, being a part of radioisotope production, as well as short-lived radiopharmaceuticals, including ${ }^{67} \mathrm{Ga},{ }^{201} \mathrm{TI},{ }^{18} \mathrm{~F}$ and ${ }^{123}$ I-ultra pure. Besides, PTS are also used at radioactive waste management plants and research institutes that apply neutron activation analysis (NAA). This work was directed toward the design and operation of a new PTS for the IEA-R1 nuclear research reactor settled at Instituto de Pesquisas Energéticas e Nucleares (IPEN) for NAA application. With this aim, it was calculated the charge of reactor core grid plate and sample transport testing. Neutron flux at irradiating position was determined as $3,70 \pm 0,2610^{12} \mathrm{n} \mathrm{cm}^{-2} \mathrm{~s}^{-1}$.
\end{abstract}




\section{SUMÁRIO}

Página

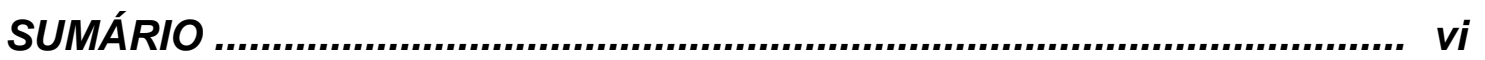

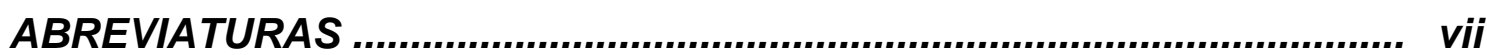

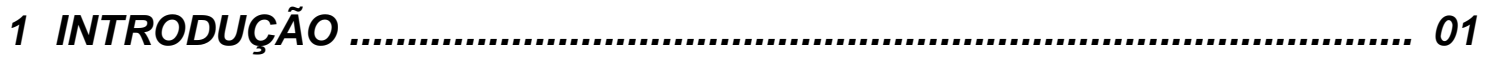

2 OBJETIVO

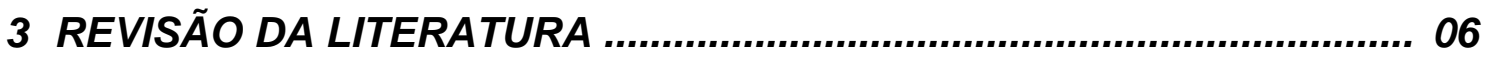

3.1 Sistemas PTS e PCP .......................................................... 06

3.2 Desenvolvimento e aplicações comerciais dos sistemas PTS e PCP. 06

3.2.1 Inglaterra (Origem) ........................................................... 06

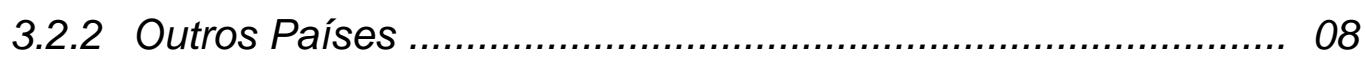

3.2.3 Aplicações Atuais ............................................................ 10

3.3 Desenvolvimento e aplicações na área nuclear dos sistemas PTS .... 11

3.3.1 Aplicações Diversas ........................................................ 12

3.3.2 Aplicação em AAN .......................................................... 14

4 MATERIAIS E MÉTODOS .............................................................. 19

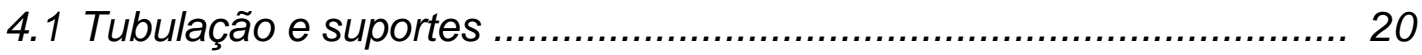

4.2 Elemento de Irradiação ............................................................. 25

4.3 Painel de comando e quadro de válvulas ........................................ 32

4.4 Porta Amostras (Coelho) ............................................................ 35

4.5 Estação de envio e recebimento das amostras irradiadas .................. 37

5 RESULTADOS E DISCUSSÃO .......................................................... 39

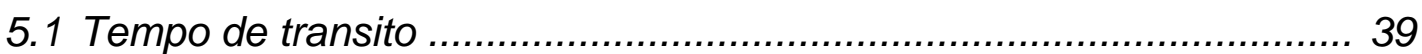

5.2 Medida de fluxo neutrônico (método folha de $A u$ ) .............................. 41

5.3 Avaliação estrutural da placa matriz do núcleo do reator .................... 41

5.4 Avaliação do risco de acidente e segurança do Reator IEA-R1 ......... 42

5.5 Avaliação da dose na cápsula irradiada (coelho) de PEAD ................ 43

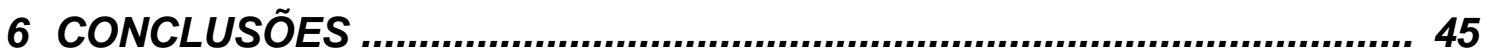

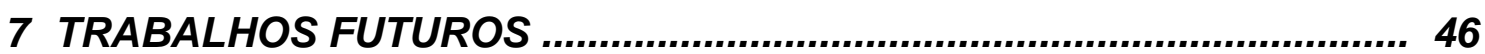

ANEXO A - Características técnicas-Mangueira da tubulação do novo PTS (Trecho-1).. 47

ANEXO B - Características técnicas-Mangueira da tubulação do novo PTS (Trecho-2).. 48

ANEXO C - Características técnicas - Suporte da tubulação do novo PTS .. 49

ANEXO D - Certificado de calibração do Lab. de Metrologia Nuclear ........... 50

ANEXO E - Análise e avaliação de risco operacional do Reator com o novo PTS ... 51

REFERÊNCIAS BIBLIOGRÁFICAS .................................................... 52 


\section{LISTA DE ABREVIATURAS}

AAN ANÁLISE POR ATIVAÇÃO NEUTRÔNICA

ABNT ASSOCIACAO BRASILEIRA DE NORMAS TECNICAS

AIEA AGÊNCIA INTERNACIONAL DE ENERGIA ATÔMICA

ASTM AMERICAN SOCIETY FOR TESTING AND MATERIALS

CEN CENTRO DE ENGENHARIA NUCLEAR

CENM CENTRO DE ENGENHARIA NUCLEAR - MECÂNICA

CNEN COMISSÃO NACIONAL DE ENERGIA NUCLEAR

CRPq CENTRO DO REATOR DE PESQUISAS

FNAA FAST NEUTRON ACTIVATION ANALYSIS

IEA-R1 INSTITUTO DE ENERGIA ATÔMICA REATOR 1

INAA INSTRUMENTAL NEUTRON ACTIVATION ANALYSIS

IPEN INSTITUTO DE PESQUISAS ENERGÉTICAS E NUCLEARES

LAN LABORATÓRIO DE METROLOGIA NUCLEAR

LOCA LOSS OF COOLANT ACCIDENT

NSCR NUCLEAR SCIENCE CENTER REACTOR

PCP PNEUMATIC CAPSULE PIPELINE

PEAD POLIETILENO DE ALTA DENSIDADE

PTS PNEUMATIC TRANSFER SYSTEM

RAS RELATÓRIO DE ANÁLISE DE SEGURANÇA

UTI UNIDADE DE TERAPIA INTENSIVA 


\section{INTRODUÇÃO}

\subsection{Considerações Gerais}

Sistemas pneumáticos de transferência, "Pneumatic Transfer Systems" (PTS), são equipamentos utilizados para transporte e movimentação de cargas e materiais entre dois ou mais pontos terminais. O principio deste transporte está baseado na teoria convencional da mecânica dos fluídos, ou seja, na circulação forçada de um fluído (gás), internamente e através de uma tubulação, onde o fluxo contínuo deste fluído irá impulsionar qualquer corpo ou carga material que seja colocado no interior desta tubulação, percorrendo o trecho que se faça necessário entre os pontos terminais estabelecidos para o transporte [1,2].

O sistema é complexo, constituído de vários componentes tais como: o equipamento que forçará a movimentação do fluído por sucção ("Blower" ou ventilador centrífugo) ou por pressurização (bomba ou compressor), o fluído propriamente dito (ar, gás pressurizado ou ar comprimido), um trecho de tubulação, pontos de carregamento da carga material a ser transportada e um terminal de utilização desta carga material. A carga material a ser transportada é colocada em um recipiente que a envolverá e será responsável por facilitar sua movimentação (além de protegê-la), no interior da tubulação (Figura-1.1). A cápsula pode ser feita em materiais plásticos ou metálicos [3,4,5,6].

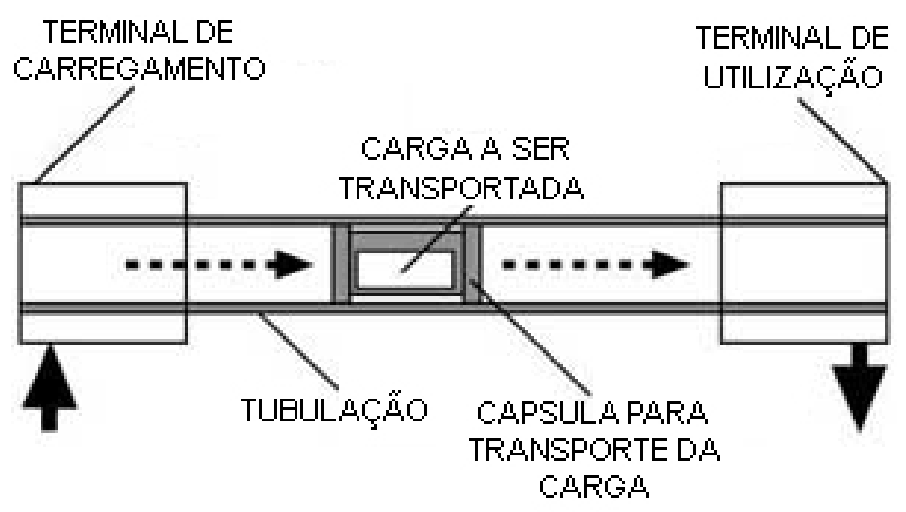

FIGURA 1.1 - Esquema básico de um sistema PTS 
Pela versatilidade e rapidez oferecida pelo PTS, este sistema é muito utilizado:

- em áreas de medicina como por exemplo hospitais (pronto atendimento, bancos de sangue, centros cirúrgicos, UTIs), farmácias e laboratórios de análises para transporte de documentos, relatórios, fichas de pacientes, raios-X, insumos laboratoriais, plasma, seringas e instrumentos e amostras de material biológico e medicamentos (Figura-1.2) [7];

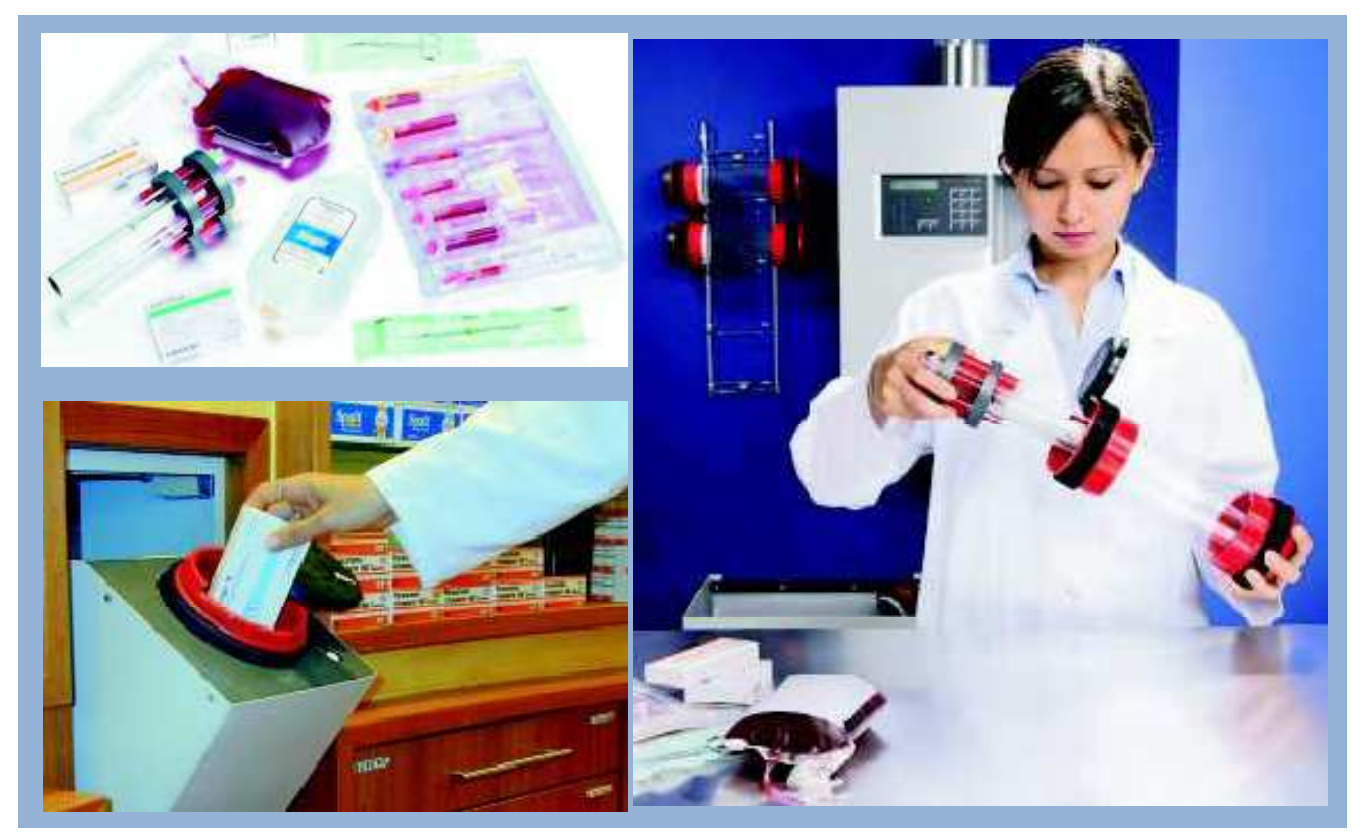

FIGURA 1.2 - Uso de um sistema PTS na área da medicina [7]

- em áreas industriais como por exemplo a indústria automobilística, de siderurgia, metalúrgica, química, alimentícia para transporte de peças e ferramentas entre departamentos e linhas de montagem melhorando a performance produtiva e transporte entre 0 laboratório de análise e os setores de produção permitindo o envio imediato de amostras quentes ou frias, sólidas ou líquidas tornando possível a correção do processo produtivo em tempo real reduzindo o transito de funcionários em ambientes agressivos (Figura-1.3) [7]; 


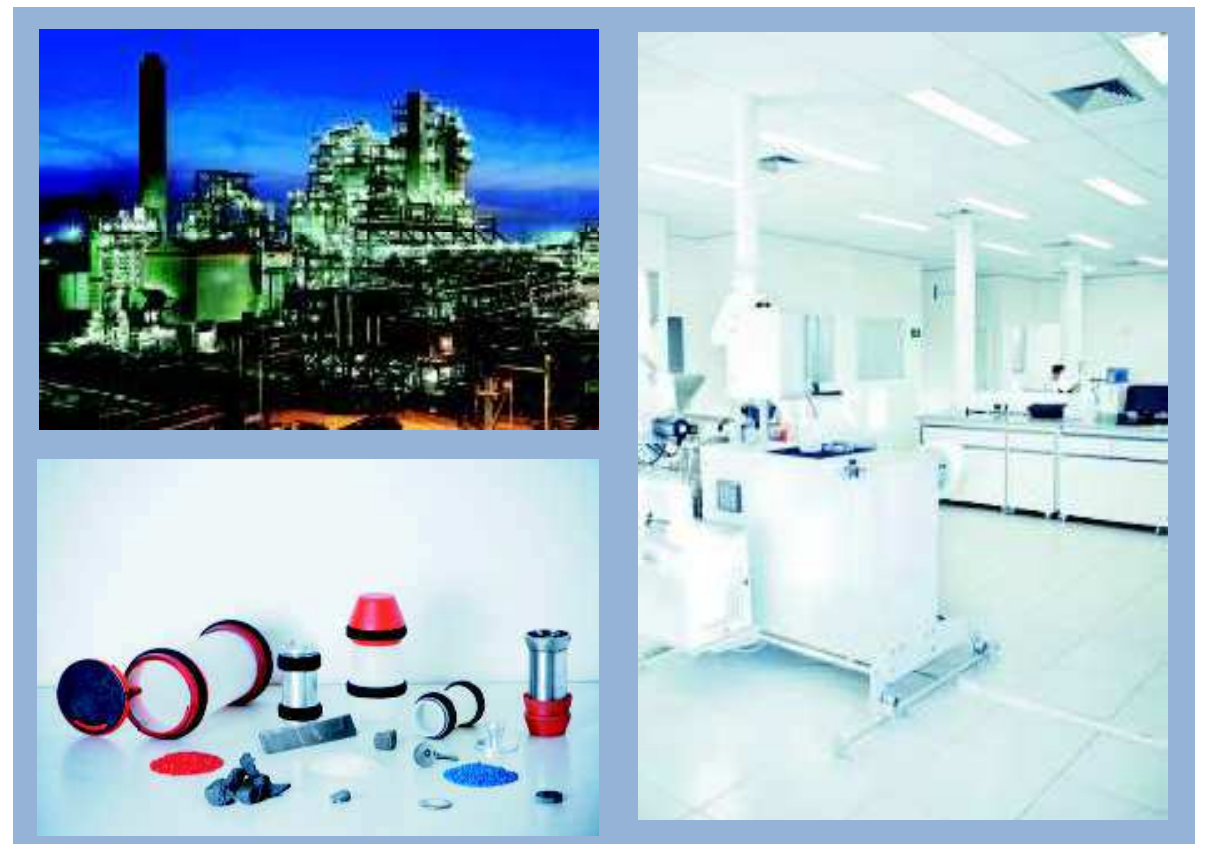

FIGURA 1.3 - Uso de um sistema PTS na área da indústria [7]

- áreas de comércio varejista e serviços como por exemplo postos de gasolina, cinemas, supermercados, bancos, pedágios, cassinos, empresas de distribuição e venda de produtos por internet para transporte constante de valores, arrecadados com vendas, para a tesouraria ou direto para o cofre reduzindo o acúmulo de grandes quantias em áreas de circulação e transporte de documentos e distribuição de correspondências, ou seja, notas fiscais e relatórios com total confiabilidade, confidencialidade e rapidez entre departamentos e gabinetes da área pública governamental, cortes de justiça, empresas de correios e telégrafos (Figura-1.4) [7];

- e finalmente na área nuclear como por exemplo nos centros de fabricação de radioisótopos (para transporte de radioisótopos de meia vida curta tais como lodo-123 ultra-puro, Flúor-18, Gálio-67 e Tálio-201) e nos laboratórios de pesquisa e análises que realizam o método de Análise por Ativação Neutrônica (AAN) [8]. 


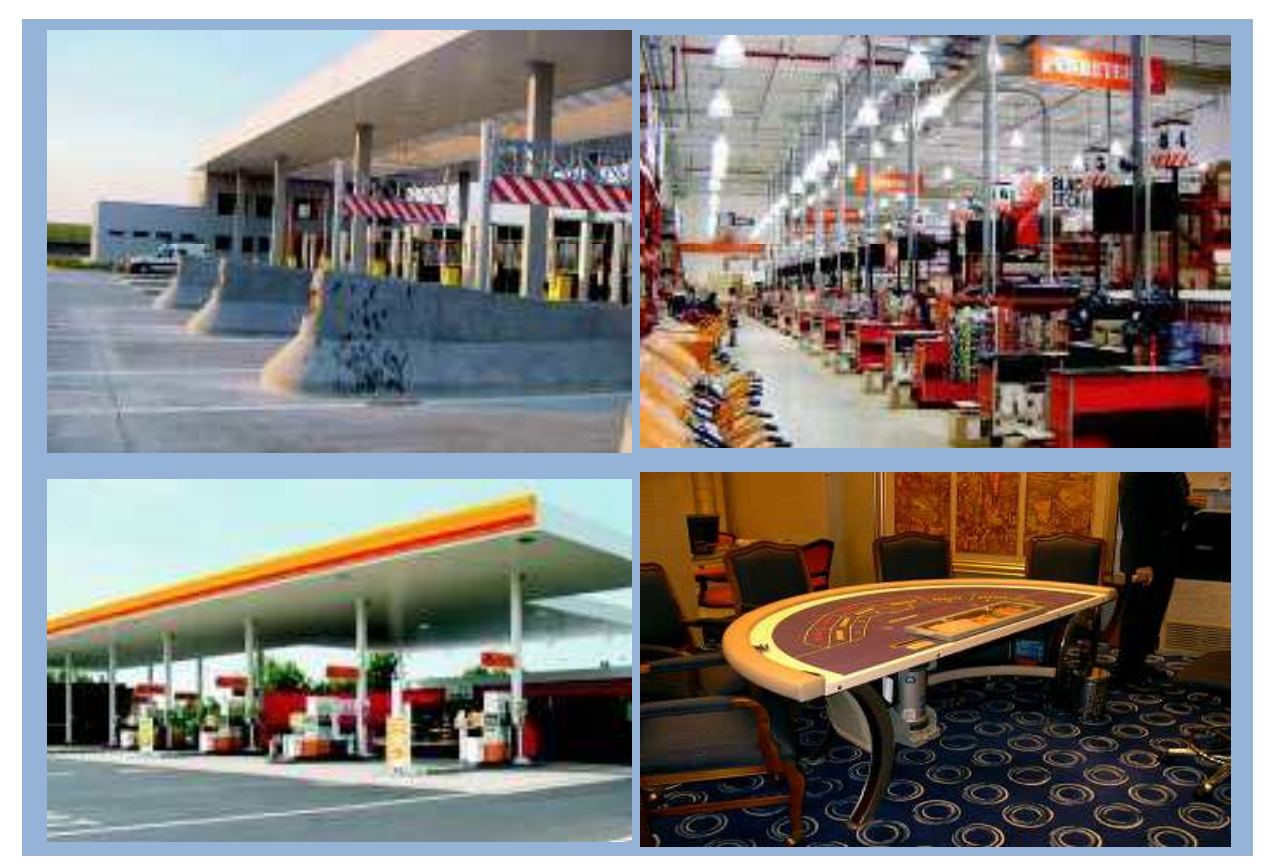

FIGURA 1.4 - Uso de um sistema PTS na área comercial [7]

O PTS também é muito utilizado em reatores de pesquisa. Sua aplicação é muito importante nas irradiações de materiais alvos com a finalidade de serem analisados pela aplicação da técnica de AAN para isótopos de meia vida curta [9].

O método AAN foi desenvolvido em 1936 por Hevesy e Levi quando estudavam amostras de terras raras submetidas à fonte de nêutrons. Por observação concluíram que era possível o emprego das reações nucleares em materiais, seguidas das medidas da radioatividade induzida para identificação qualitativa e quantitativa de elementos presentes em amostras desses materiais [9]. 


\section{OBJETIVO}

Este trabalho teve como objetivo o "Desenvolvimento do projeto, construção, instalação (montagem) e implementação de um Novo Sistema Pneumático de Transferência para Irradiação de Materiais no Reator IEA-R1", no Centro do Reator de Pesquisas - CRPq, do Instituto de Pesquisas Energéticas e Nucleares - IPEN-CNEN/SP. Com capacidade de irradiação de diversos tipos de materiais utilizados por grupos de pesquisas que aplicam o método analítico de Análise por Ativação Neutrônica (AAN). 


\section{REVISÃO DA LITERATURA}

\subsection{Sistemas PTS e PCP}

A tecnologia de transporte de cargas é utilizada nos atuais e modernos sistemas, onde as cargas são inseridas em cápsulas e estas se deslocam através de tubos, impulsionadas por um fluxo de ar no interior do tubo, e são conhecidos como "Pneumatic Transfer System" (PTS) e "Pneumatic Capsule Pipeline" (PCP). Apesar de utilizarem o mesmo principio de funcionamento os dois sistemas diferem nas características construtivas e nas áreas de aplicação $[10,11]$.

O sistema PTS utiliza-se de tubos de pequeno calibre ou tubos inferiores a $406 \mathrm{~mm}$ (16") de diâmetro e ainda utiliza-se de cápsulas sem rodas para conter e transportar a carga através da tubulação. Transportam cargas da ordem de quilogramas $(\mathrm{kg})$ [2].

O sistema PCP utiliza-se de tubos de grandes calibres com diâmetros superiores a $406 \mathrm{~mm}$ (16”), podendo ter secções circulares ou retangulares e as cápsulas, de grandes dimensões, possuem rodas para garantir a estabilidade da cápsula, na posição de equilíbrio, dentro do tubo sem derramar a carga e ainda as rodas minimizam o ruído, atrito e evitam o desgaste do tubo. Transportam cargas da ordem de toneladas (ton) [1,2].

\subsection{Desenvolvimento e aplicações comerciais dos sistemas PTS e PCP}

\subsubsection{Inglaterra (Origem)}

A tecnologia de transporte pneumático de cargas e materiais via tubo, teve origem em 1810, na Inglaterra, quando o industrial George Medhurst escreveu e publicou um panfleto informativo à população e sociedade propondo a utilização do método para transmissão de cartas e mercadorias de pequeno porte com grande segurança e rapidez através de uma via aérea de tubos. $O$ industrial afirmava que "A pressão necessária será de acordo com o quadrado da 
velocidade" e com isto as cartas poderiam ser enviadas através do tubo atingindo velocidades de $161 \mathrm{~km} / \mathrm{h}$ (100 mph). Neste curto documento Medhurst descreveu a tecnologia que permaneceu praticamente inalterada por mais de 150 anos [2, 10].

Em 1824, John Vallance, na cidade de Brighton, com base nas idéias contidas no panfleto de Medhurst, patenteou e construiu experimentalmente 0 primeiro sistema PCP para transporte de passageiros. Usando tábuas de madeira construiu uma tubulação com 45,7 m (150 pés) de comprimento e 2,44 m (8 pés) de diâmetro. A cápsula de transporte, que possuía rodas, foi construída com 6,71m (22 pés) de comprimento e 1,68 m (5.5 pés) de diâmetro para uma capacidade de 20 passageiros. O sistema era alimentado por um gerador de vapor [2, 10] que produzia o fluído responsável por impulsionar a cápsula carregada movimentando-a, com sucesso, pelo tubo a uma velocidade de $3,2 \mathrm{~km} / \mathrm{h}$ (2 mph).

Em 1853, Josias Latimer Clark desenvolveu a primeira aplicação prática da tecnologia PTS. sob a direção de Clark a empresa "Electric and International Telegraph Company" construiu o primeiro telégrafo comercial por sistema de transporte pneumático (Figura-3.1), interligando os escritórios centrais da empresa aos escritórios da Bolsa de Valores da cidade de Londres. Tubos de 206 m (675 pés) de comprimento e 38,1 mm (1,5 pol) de diâmetro constituíam o sistema. As mensagens eram enviadas pela tubulação em sacos de feltro por diferença de pressão gerada por um motor de 6 hp de potência [2, 10].

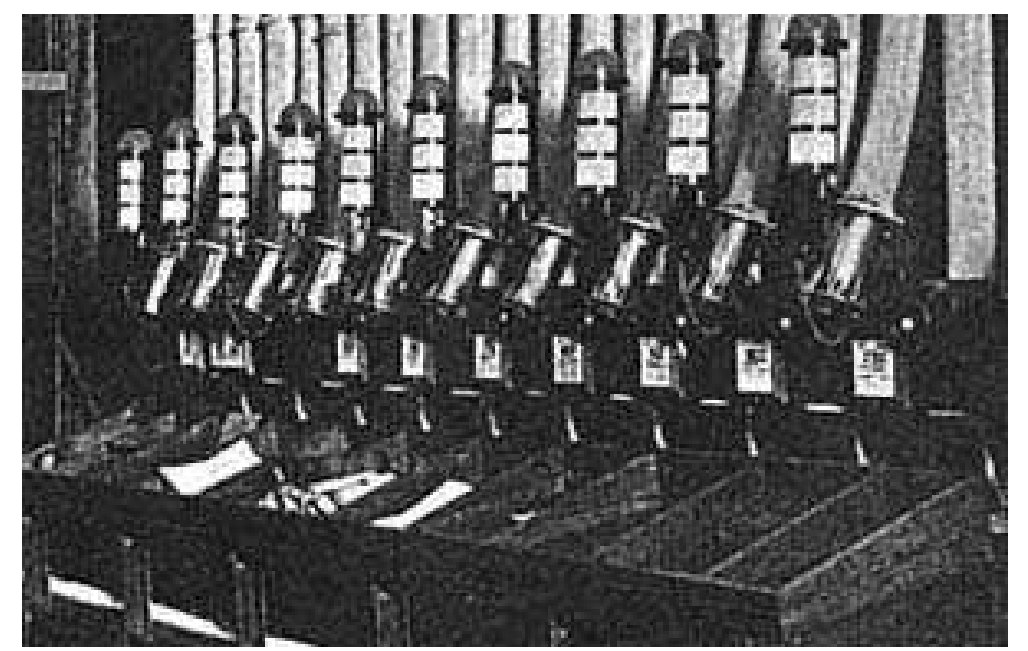

FIGURA 3.1 - Mesa operacional do PTS nos escritórios da central de telégrafos de Londres [11] 


\subsubsection{Outros Paises}

Em 1865 em Berlim, sob a coordenação de J. L. Clark, a empresa Siemens lançou seu primeiro sistema PTS de correios com 865 km (2,835 pés) de comprimento de tubos e $89 \mathrm{~mm}$ (3,5 pol) de diâmetro interligando a Bolsa de Valores e a estação central de telégrafos [2, 10].

Em 1866 a cidade de Paris lançou seu primeiro sistema PTS interligando primeiramente os escritórios de telégrafo do "Grand Hotel" e a Bolsa de Valores, (Figura-3.2). O sistema trazia como inovação o transporte das correspondências em uma única direção, mas o sistema interligava os prédios em redes circulares (poligonal ou hexagonal) permitindo um grau de liberdade maior possibilitando o transporte em todos os movimentos possíveis. Depois de um século, 1966, a França tinha um comprimento total de linhas de tubulações PTS em torno de $452 \mathrm{~km}$ (281 milhas) e diâmetros variando de 65 a 300 mm $(2,5$ a 12 pol) $[2,10]$.

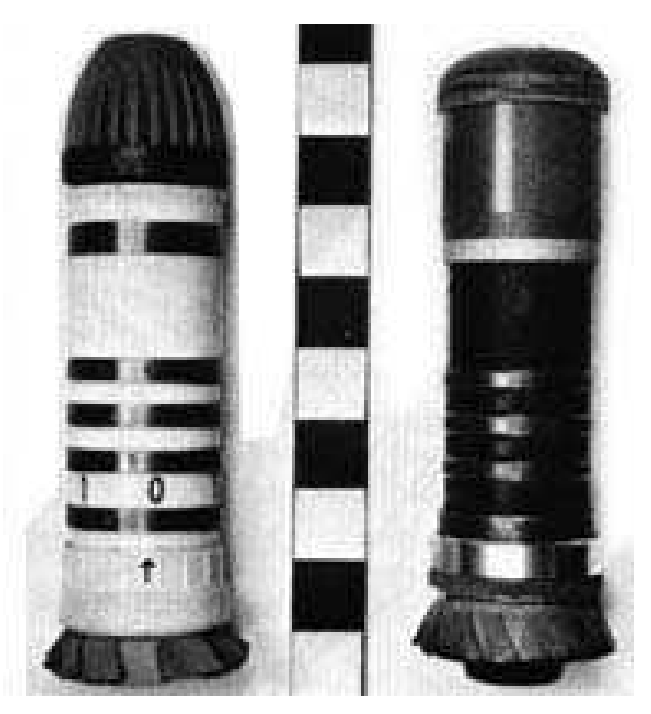

FIGURA 3.2 - Cápsulas utilizadas nos transportadores PTS de Paris [11]

Em 1876 a empresa americana "Western Union Telegraph Company" construiu na cidade de Nova York o primeiro PTS nos Estados Unidos para transporte telegráfico utilizando tubos com 76 mm (3 pol) de diâmetro. Em 1893 foi a vez da Filadélfia ganhar seu PTS de correio pneumático com uma tubulação de $885 \mathrm{~m}$ (0,55 milhas) de comprimento e $152 \mathrm{~mm}$ (6 pol) de diâmetro. Com a eficácia do sistema, o transporte de correio aumentou e se espalhou para as cidades de Boston, Chicago e St. Louis. De acordo com Cohen [11] o Congresso 
dos Estados Unidos autorizou em 1898 os primeiros $26 \mathrm{~km}$ (16,2 milhas) e em 1916 outros $182 \mathrm{~km}$ (113 milhas) totalizando, para as cinco cidades, um comprimento do correio pneumático de cerca de 209 km (130 milhas). As linhas de correio foram montadas com tubos de 203 mm (8 pol) de diâmetro em linhas duplas, possibilitando uma capacidade de transportar 200 mil cartas por hora, à velocidade de 48 km/h (30 mph). As cápsulas foram denominadas como "Carriers" ou "Containers", possuindo dupla banda de vedação (Figura-3.3). A cápsula tinha $610 \mathrm{~mm}$ (2 pés) de comprimento pesando 9,5 kg (21 lbs) com capacidade de levar cerca de 500 cartas por cápsula.
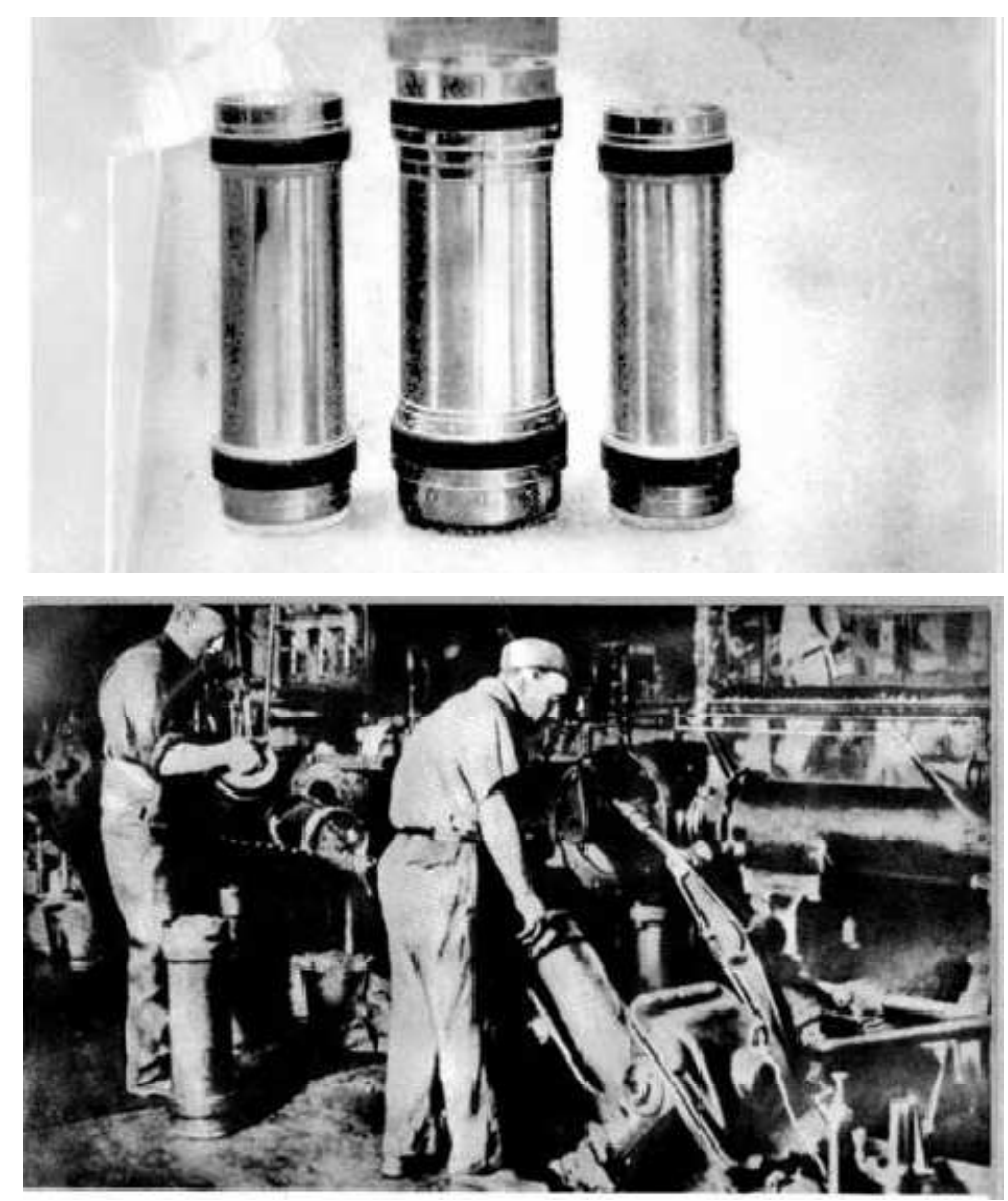

FIGURA 3.3 - Antes de 1953, os trabalhadores dos correios da cidade de Nova York, conhecidos como fogueteiros, "rocketeers", são mostrados alimentando os tubos pneumáticos com as cápsulas, "carriers", com o carregamento de cartas [11]

Em 1953 os serviços postais dos correios pneumáticos foram paralisados por ordem do governo que optou por substituir o serviço de entrega por PTS pelo serviço de entrega por caminhões. O que motivou esta atitude foi o 
fato do sistema pneumático vir operando por muito tempo, 50 anos, e já apresentava vários problemas mecânicos operacionais e a sua não automatização o tornara complicado para o uso e manutenção. Além do que a cidade de Detroit desenvolveu e montou uma frota nova de caminhões para o serviço de transporte de correio [2].

\subsubsection{Aplicações atuais}

Em 1971 foram construídos e postos em operação dois sistemas de PCP utilizando tubos de grandes diâmetros e cápsulas com rodas para transporte de cargas pesadas nos Estados Unidos e na ex-União Soviética.

O PCP dos Estados Unidos utilizava uma tubulação de $915 \mathrm{~mm}$ (3 pés) de diâmetro e $427 \mathrm{~m}$ (1,400 pés) de comprimento. O sistema foi construído pela empresa TubeExpress e liderada pelo professor M.R. Cartens do "Georgia Institute of Technology" (Figura-3.4).

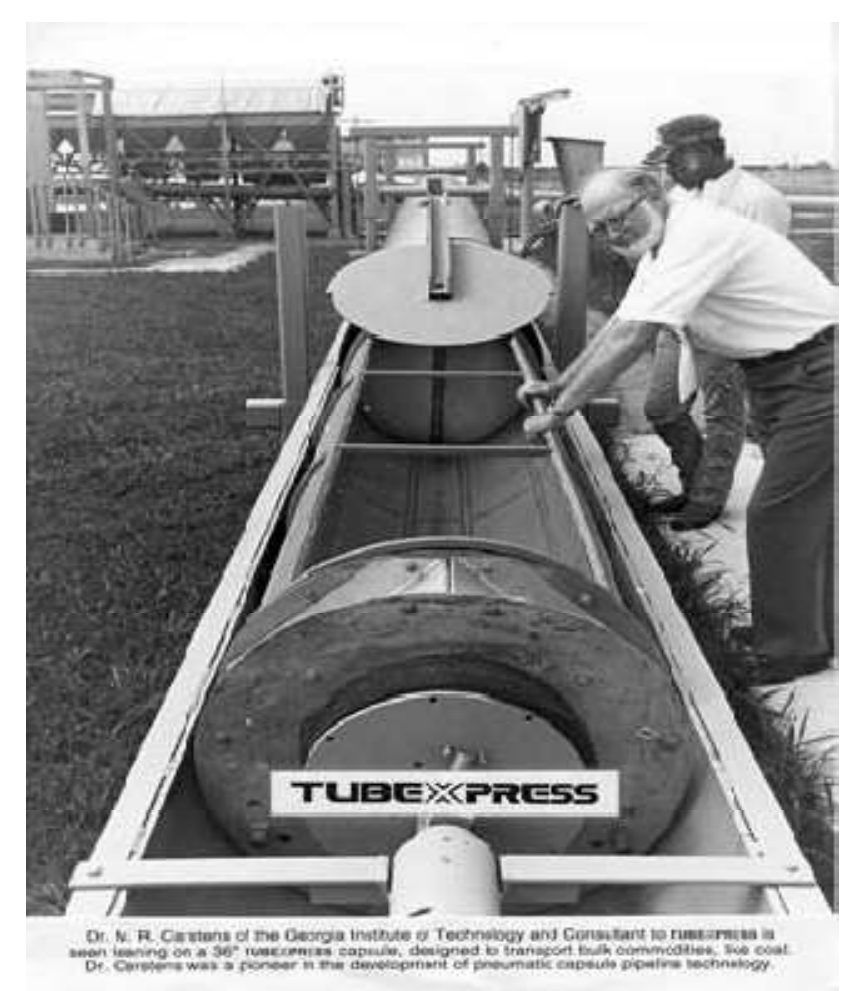

FIGURA 3.4 - Professor M.R. Carstens do Georgia Tech ao lado do seu PCP [02]

A ex-União Soviética construiu e testou um PCP de $1.020 \mathrm{~mm}$ (40 pol) de diâmetro e 2,1 km (1,5 milhas) de comprimento. Denominado de "Lilo-1" localizado na República da Geórgia era composto por seis cápsulas conectadas 
em forma de trem que comportavam transportar 25 ton de areia e cascalho com uma velocidade de $30 \mathrm{~km} / \mathrm{h}$ (20 mph) em cápsulas com carga plena. O "Lilo-2" foi construído posteriormente aumentando a capacidade de transporte para 8.000.000 ton/ano tendo este PCP o seu diâmetro aumentado para $1,27 \mathrm{~m}$ (50 pol) para o comprimento de $8 \mathrm{~km}$ (5 milhas).

Em 1980 o primeiro sucesso comercial no uso dos sistemas PCP de grandes dimensões aconteceu no Japão, onde a empresa "Sumitomo Metal Industries" construiu e operou o PCP com diâmetro de $1 \mathrm{~m}$ (3.3 pés) [2].

Em 1997, com a tecnologia da "Sumitomo Metal Industries", o Japão constrói o Túnel Akima, com $83 \mathrm{~km}$ de comprimento e $90 \mathrm{~m}^{2}$ de secção transversal, para o complexo ferroviário de seus trens-bala. Após análise técnica/econômica definiu-se o sistema PCP para transporte dos materiais escavados, como solo e rochas, para fora do túnel e para o transporte do material de pavimento e revestimento para dentro do túnel, substituindo assim o transporte por caminhões e ferrovias temporárias que inserem problemas de segurança e poluição dentro do túnel durante sua construção [24, 25].

Em 1997, com a tecnologia da "Sumitomo Metal Industries", o Japão construiu o Túnel Akima, com $83 \mathrm{~km}$ de comprimento e $90 \mathrm{~m}^{2}$ de secção transversal, para o complexo ferroviário de seus trens de alta velocidade. Após análise técnica/econômica definiu-se o sistema PCP para transporte dos materiais escavados, como solo e rochas, para fora do túnel e para o transporte do material de pavimento e revestimento para dentro do túnel, substituindo assim o transporte por caminhões e ferrovias temporárias que inserem problemas de segurança e poluição dentro do túnel durante sua construção $[24,25]$.

\subsection{Desenvolvimento e aplicações na área nuclear dos sistemas PTS}

Os sistemas de transferência pneumáticos estão sendo muito utilizados em diversas instalações nucleares devido a sua versatilidade, confiabilidade e rapidez como um meio de movimentação e manuseio dos materiais radioativos gerados nos processos de cada instalação contribuindo para a baixa exposição dos trabalhadores dessas áreas. 


\subsubsection{Aplicações Diversas}

No Japão muitos sistemas de transporte foram estudados para movimentação de Embalagens com Rejeitos Radioativos desde a superfície para o repositório geralmente instalado à uma profundidade no subsolo. Um novo método de transporte foi apresentado no Japão utilizando-se de um PTS construído e funcionando como um elevador (tipo eixo vertical) juntamente a um veículo (cápsula porta amostras) transporta os materiais da superfície ao subsolo (Figura-3.5) [26, 27].

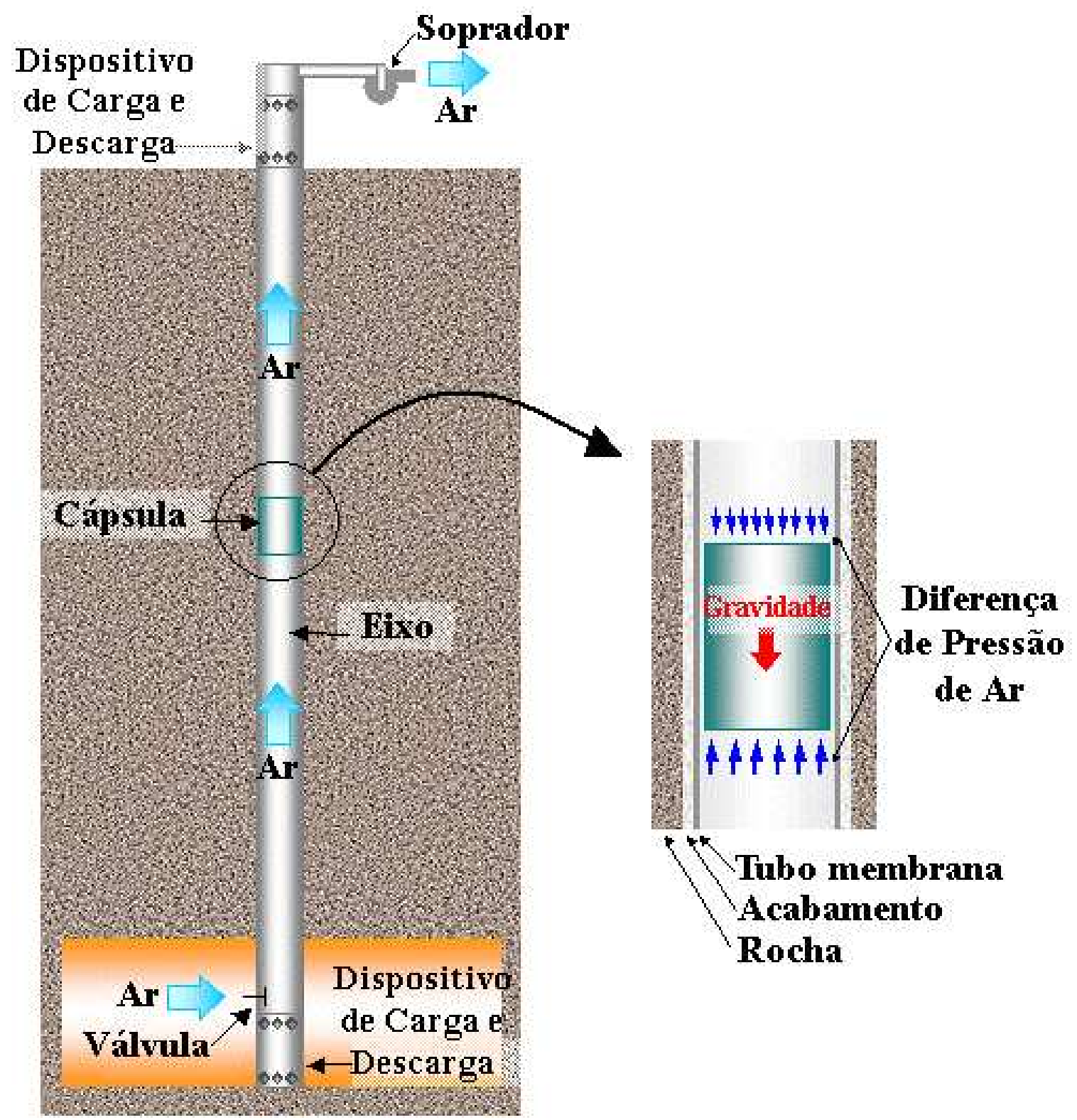

FIGURA 3.5 - Conceito Básico do Sistema PTS como Elevador [26] 
$\mathrm{Na}$ universidade "Texas A\&M University Nuclear Science Center Reactor" (NSCR) foi instalado um sistema de PTS para viabilizar o estudo dos efeitos na saúde, em longo prazo, por doses provenientes de exposições à nêutrons rápidos avaliando os mecanismos biológicos de danos nas células cultivadas e em animais vivos, como ratos e camundongos. O PTS foi instalado em uma célula de irradiação fornecendo um sofisticado sistema de controle de transferência de amostra, que podem ser os animais vivos ou tecidos recebendo a dose mínima enquanto estão em trânsito no ambiente de nêutrons não filtrados, prevenindo de danos que poderiam ser feitos por uma parada brusca. Um PTS especialmente concebido é capaz de enviar uma cápsula de nove centímetros (diâmetro externo) com a amostra em seu interior até a caverna de exposição em poucos segundos e de trazê-lo de volta à parte superior no laboratório da investigação. $O$ sistema foi instalado para conseguir a transferência rápida de amostras sem ferimentos. A caixa de carregamento da cápsula com a amostra localizada no nível superior de investigação foi projetada para sustentar a pressão negativa e minimizar as fugas de material radioativo no ar. Uma tubulação "bypass" foi instalada também para reduzir a velocidade de viagem do porta amostra e aproximar a amostra na caixa de descarga da célula de irradiação. Um sistema informatizado de controle gerencia a coleta de dados e do sistema de transporte pneumático. Os dados de acompanhamento foram coletados por meio de portas RS-232 de comunicação serial no computador. Valores predefinidos de tempo de exposição ou dose absorvida de nêutrons podem ser usados para iniciar a obtenção da amostra pelo PTS [20]. Na seqüência é apresentado um esquema geral da instalação (Figura-3.6). 


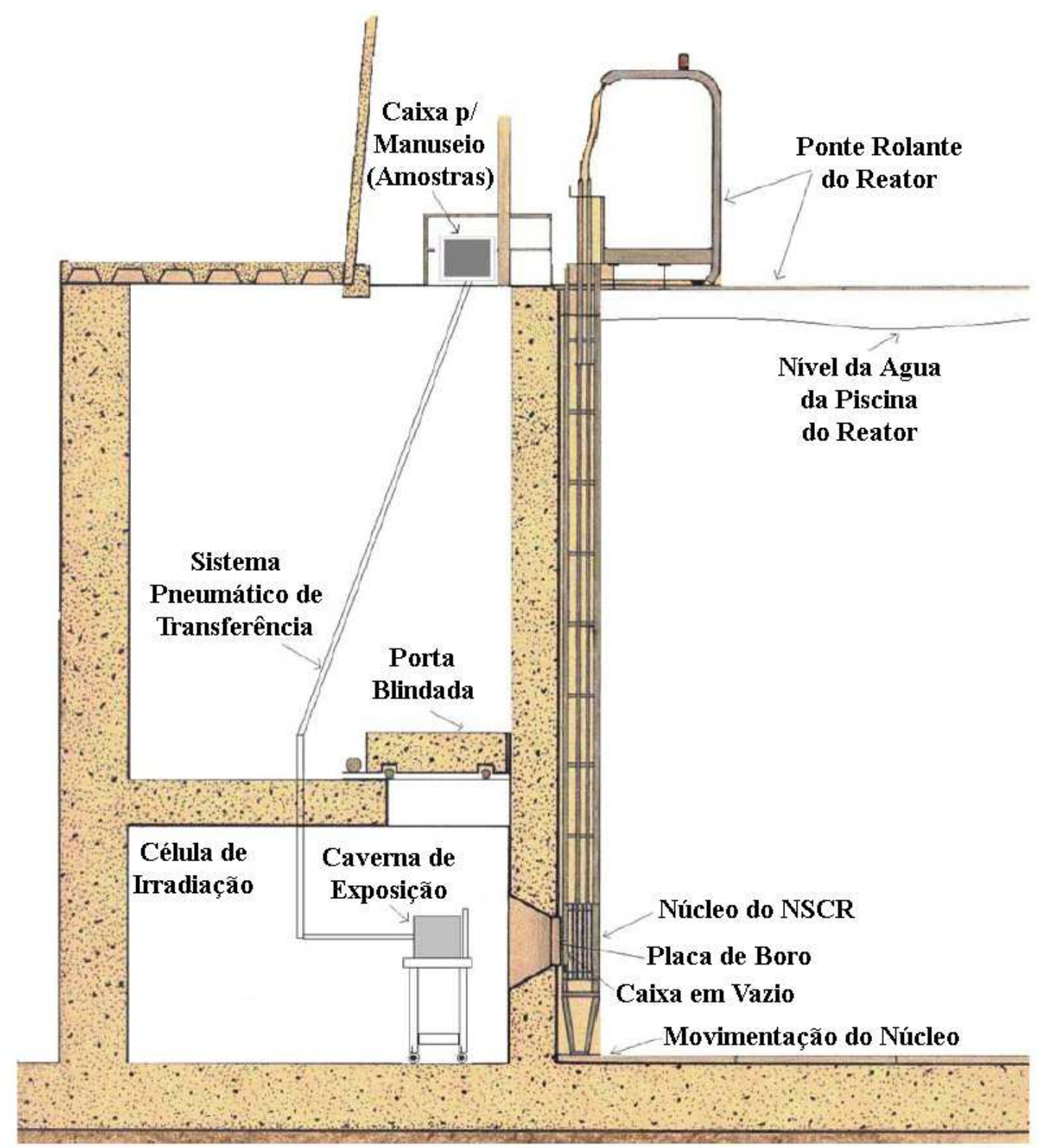

FIGURA 3.6 - Esquema do Sistema PTS e da Célula de Irradiação [26]

\subsubsection{Aplicação em AAN}

Outra importante aplicação do sistema PTS na área nuclear é sua utilização como parte nas técnicas de análise por ativação de amostras com nêutrons. Essa técnica foi aplicada em estudos para quantificação e qualificação de elementos químicos presentes no leite, e avaliações da presença de lodo na dieta e no sal consumido pela população brasileira. As amostras e padrões foram irradiados por dois minutos cada, no reator IEA-R1, para determinação dos elementos sódio, potássio, manganês, magnésio e cálcio. A quantificação da irradiação e contagem de emissões gama permitiram determinar o potencial nutritivo do leite analisado [12, 62]. 
A AAN é utilizada como técnica auxiliar na detecção de poluição ambiental, a seguir apresentamos dois exemplos de seu uso:

a) em estudos para quantificação e qualificação de elementos químicos considerados poluentes na monitoração da qualidade das águas dos rios Sorocaba e Ipanema em 6 pontos da região de Iperó, SP, com relação aos metais tóxicos Alumínio, Cádmio, Cromo, Cobre, Ferro, Manganês, Níquel, Chumbo e Zinco. Os sedimentos coletados ao longo dos rios foram preparados em amostras de referência e padrões de 100 a 150 mg e irradiados por cinco minutos cada no reator IEA-R1 [13].

b) em estudos para quantificação e qualificação de elementos químicos presentes e acumulados em amostras de líquen Canoparmelia Texana para determinação dos níveis de poluição da região metropolitana de São Paulo. As amostras coletadas em áreas livres de poluição e poluídas foram irradiadas por cinco minutos no reator IEA-R1 [14].

c) em análises de elementos traço $\mathrm{Br}, \mathrm{Cl}, \mathrm{K}, \mathrm{Mg}, \mathrm{Mn}$ e $\mathrm{Na}$ em amostras de mexilhão Perna perna que apresentam grande interesse para o uso na monitoração da poluição ambiental da região costeira pelo aporte de substâncias tóxicas geradas por atividades agrícolas e industriais. O material foi coletado ao longo do litoral paulista, preparados em amostras de cerca de $180 \mathrm{mg}$ que foram irradiadas por 10 min no reator IEA-R1 [15].

d) em análises para estabelecer procedimento adequado para a obtenção de resultados confiáveis na determinação do elemento tóxico Vanádio em mexilhões Perna perna para biomonitoramento da poluição litorânea próximo aos terminais petrolíferos. O material coletado em São Sebastião/llha Bela foi preparado em amostras de 200 mg e então submetidas por 8 segundos ao fluxo de nêutrons do reator IEA-R1 [16, 17].

Pesquisas realizadas no IPEN em conjunto com bancos de sangue e laboratórios hematológicos de diferentes regiões do Brasil, forneceram resultados destinados a elucidar o metabolismo dos organismos vivos, tanto em condições 
de normalidade (organismos saudáveis) como em situações de disfunções (organismos com patologia). Com a aplicação do método AAN em amostras de sangue, detectaram-se quantitativamente os metais $\mathrm{Br}, \mathrm{Cl}, \mathrm{K}, \mathrm{Na}, \mathrm{Ca}, \mathrm{Mg}, \mathrm{Fe}, \mathrm{Rb}$, Se, Zn com a finalidade de permitir uma avaliação clínica quanto ao bom funcionamento das várias funções que regulam a fisiologia dos orgãos. Dessa forma procurou-se relacionar as possíveis disfunções com alterações desses elementos no sangue. O método AAN foi aplicado na investigação de sangue de individuos da população brasileira e de diversos animais de pequeno porte usados atualmente como modêlos animais para testes in vivo de formulação de novos medicamentos e vacinas (hamster, coelhos, camundongos, ratos). A técnica AAN também foi utilizada em amostras de sangue retiradas de cavalos utilizados para produção de antiveneno no Instituto Butantã. Para determinar a concentração dos elementos $\mathrm{Br}, \mathrm{Cl}, \mathrm{K}, \mathrm{Na}, \mathrm{Ca}, \mathrm{Mg}, \mathrm{Fe}, \mathrm{Rb}, \mathrm{Se}, \mathrm{Zn}$ no sangue, auxiliando no diagnóstico de pacientes, amostras de sangue coletadas em diversos bancos de sangue brasileiros, foram irradiadas individual e juntamente com o monitor $\mathrm{Au}$ (folha metálica pequena de aproximadamente $1 \mathrm{mg}$ ) utilizado para a medição do fluxo de nêutrons, por alguns minutos na estação de pneumática no reator IEA-R1, permitindo a ativação simultânea destes materiais [18, 31, 32, 33, 34, 35, 36, 37,38, 39, 40, 41, 42, 43].

Para fazer a análise por ativação de nêutrons rápidos (FNAA) de amostras com meia-vida curta a Thermo Electron atualizou e modernizou o seu sistema de transferência pneumática automática para laboratórios de ativação. Por exemplo, com uma separação de $10 \mathrm{~m}$ da estação de contagem e uma velocidade de trânsito de $15 \mathrm{~m} / \mathrm{s}$, o oxigênio pode ser analisado com maior precisão. $\mathrm{O}$ tempo de trânsito rápido é necessário devido à curta meia-vida de ${ }^{16} \mathrm{~N}$ e ${ }^{19} \mathrm{O}, 7 \mathrm{~s}$ e $27 \mathrm{~s}$, respectivamente, e frascos de amostras de oxigênio livre de polietileno são utilizadas para permitir a contagem rápida e diminuir as contagens de fundo. Foram incorporados ao sistema um compressor axial duplo sentido na estação de irradiação para a amostra e padrão, estações de carregamento e recebimento e contagem juntamente com uma fonte de nêutrons químicas, tais como Cf-252 [19].

No estudo dos efeitos na saúde, em longo prazo, por doses provenientes de exposições à nêutrons rápidos avaliando os mecanismos 
biológicos de danos nas células cultivadas e em animais vivos, como ratos e camundongos [20].

Concentrações de elementos traço em fragmentos cerâmicos de dois sítios arqueológicos situados nas planícies de inundação do Rio Paraguai e no Pantanal. Ambos os locais foram caracterizados como assentamentos de grande importância para o estudo das populações antigas que habitavam esta região. Os elementos foram medidos $\mathrm{Na}$, Lu, U, Yb, La, Th, Cr, Cs, Sc, Rb, Fe, Eu, Ce, Hf, e Tb. Preparadas as amostras e os padrões de $100 \mathrm{mg}$ foram irradiadas no reator IEA-R1 por 5 min [21].

Um experimento foi aplicado ao estudo de recuperação de uma degradada pastagem de grama, tipo Brachiaria Decumbens, da região de São Carlos analisando os efeitos do calcário, fertilizantes e minerais aplicados durante três anos ao solo do local. Foram preparadas 24 amostras e juntamente com os padrões ( $\mathrm{Ca}, \mathrm{Cl}, \mathrm{K}, \mathrm{Mg}$. Mn e V) foram irradiados no PTS em um porta amostras de polietileno por um tempo de 2,5 minutos. Após irradiação a técnica de análise por ativação neutrônica, seguido por espectrometria de raios gama foi o método analítico utilizado para determinar o conteúdo mineral [22, 23].

A AAN foi utilizada na avaliação de concentração de oito elementos de terras raras em folhas de plantas do cerrado brasileiro. Os resultados visaram estabelecer fatores de transferência solo-planta [28].

Para estudos de análises de cabelos humanos utilizado na avaliação de níveis de elementos traço no corpo humano verificando-se intoxicação e/ou envenenamento por metais tóxicos (monitoração de exposição ambiental ou ocupacional), avaliação do estado nutricional e diagnose de doenças. Amostras de $500 \mathrm{mg}$ foram irradiadas por 5 minutos no reator IEA-R1 [29].

Outro estudo teve como objetivo a caracterização química dos solos superficiais adjacentes à Marginal do Rio Tietê, na Região Metropolitana de São Paulo, por meio da técnica de análise por ativação com nêutrons instrumental (INAA), para determinar elementos de interesse ambiental como As, Ba, Co, Cr, $\mathrm{Sb}$ e $\mathrm{Zn}$ em amostras de solos coletadas ao longo de seu curso. As amostras e padrões foram preparados de modo que 32 irradiações foram realizadas no reator IEA-R1 por tempos de 5 min por irradiação [30].

O método AAN foi aplicado em estudos realizados pelo Laboratório de Estrutura Nuclear do IPEN para determinação dos parâmetros nucleares de 
importantes nuclídeos envolvidos em aplicações nucleares gerando um grau de conhecimento desses parâmetros garantindo a confiabilidade dos resultados e a segurança da experiência. A Meia-Vida de decaimento, que é um parâmetro de grande importância para cálculos relativos à inventários de radioisótopos em acidentes com núcleos de reatores, foram determinadas para isótopos ${ }^{155} \mathrm{Sm}$, ${ }^{101} \mathrm{Mo},{ }^{101} \mathrm{Tc},{ }^{127} \mathrm{Te},{ }^{193} \mathrm{Os}$ e ${ }^{193}$ Ir onde os materiais base foram submetidos à irradiação no fluxo neutrônico do reator IEA-R1 [44, 45, 46, 47, 48, 49, 50, 51].

O método AAN foi também aplicado pelos profissionais do Laboratório de Estrutura Nuclear na investigação de outros parâmetros tais como estudos do nível de energia recem identificado do ${ }^{193}$ Ir pelo decaimento $\beta$ do ${ }^{193}$ Os; estudos das secções de choque para neutrôns térmicos dos nuclídeos ${ }^{48} \mathrm{Ca}$ e ${ }^{81} \mathrm{Br}$; estudos descrevendo métodos semelhantes para cálculo das intensidades de transição gama de medições de coincidência com multidetectores e novos procedimentos para análise de correlação angular de dados experimentais; estudos de procedimentos para identificação quantitativa de isótopo ${ }^{235} \mathrm{U}$ em amostras de material enriquecido; desenvolvimento de software para cálculo e determinação da intensidade do fluxo de neutrôns gerado no núcleo do reator IEA-R1; estudo de procedimento semi-paramétrico de ativação de nêutrons aplicado para determinar a concentração de elementos químicos em materiais de referência padrão. Para todos os estudos as amostras dos materiais base foram submetidos à irradiação no fluxo neutrônico do reator IEA-R1 $[52,53,54,55,56$, $57,58,59,60,61]$. 


\section{MATERIAIS E MÉTODOS}

Os materiais desenvolvidos e utilizados neste Sistema de Transferência Pneumática são apresentados neste capítulo. A Figura-4.1 esquematiza o sistema completo desenvolvido com os dispositivos que 0 compõem:
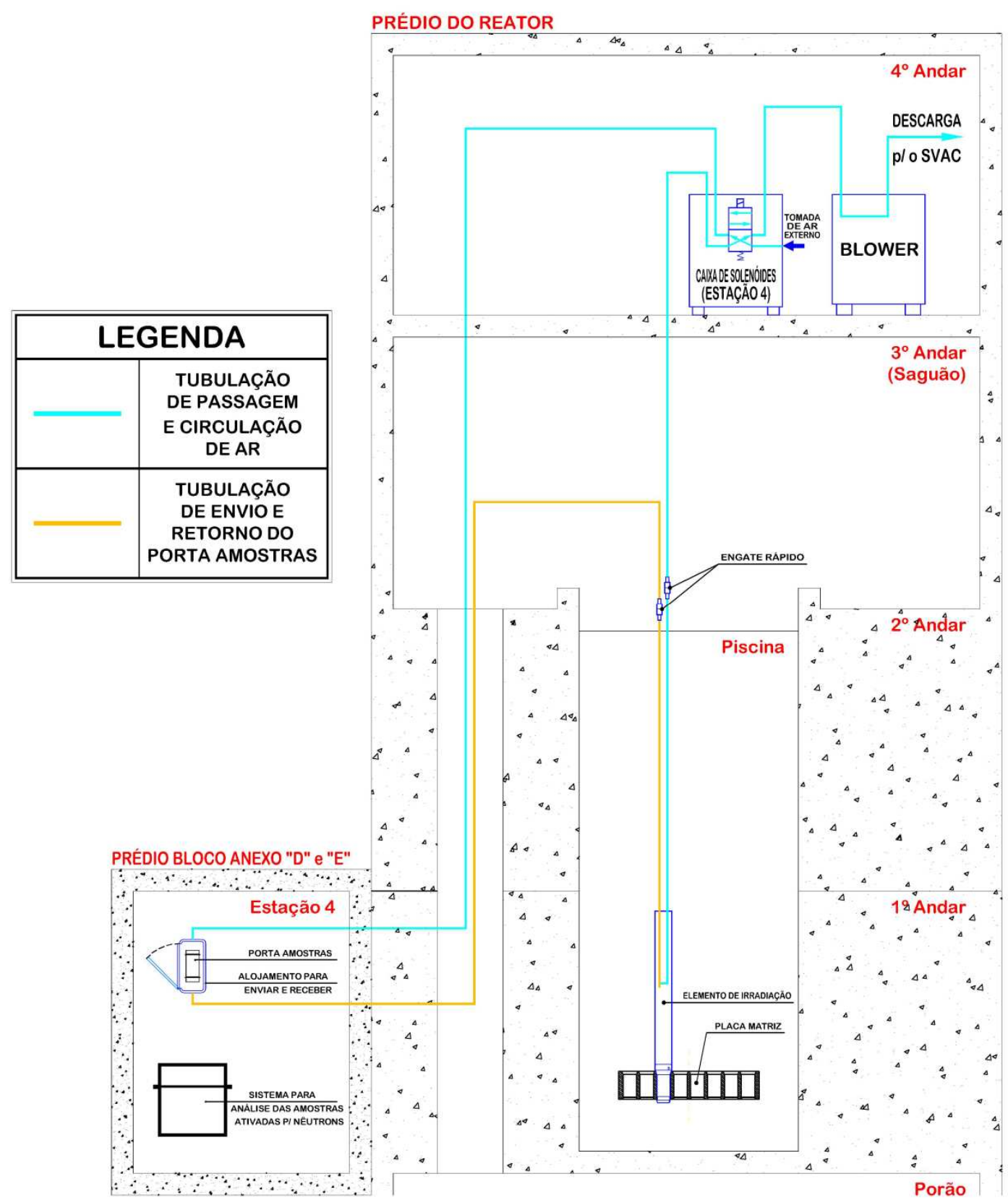

FIGURA 4.1 - Diagrama do PTS Desenvolvido e Implementado 
O desenvolvimento deste trabalho divide-se em 3 etapas: 1) Etapa de Projeto Mecânico de componentes e dispositivos; 2) Etapa de Projeto da Automação operacional do sistema; etapa de execução dos trabalhos de Fabricação, Montagem e Instalação dos componentes e dispositivos; 3) Etapa de Testes Operacionais do Sistema Pneumático para transporte de material ativado com os nêutrons produzidos no núcleo do Reator Nuclear de Pesquisas IEA-R1. $O$ projeto dos componentes mecânicos do PTS enfoca o desenvolvimento e modernização do sistema de tubulação incluindo toda a parte mecânica de sustentação, desenvolvimento de um sistema inédito de elemento de irradiação, desenvolvimento e modernização do painel de comando do sistema por válvulas solenóides, desenvolvimento e modernização do novo porta amostras (coelho) para acondicionamento e transporte do material a ser irradiado.

\subsection{Tubulação e suportes}

4.1.1A tubulação foi definida tecnicamente de modo a resolver problemas existentes nos sistemas PTS anteriores. Os problemas se apresentavam devido aos materiais dessa tubulação. $O$ modelo de mangueira definido (Figura-4.2) é do tipo flexível em PVC Trançada Cristal PT250 com uma trama interna trançada de fio de polyester, nas dimensões de diâmetro interno de 50,8 mm (2") e diâmetro externo de 60,8 mm (2,3937") não apresentou o comportamento desejado.

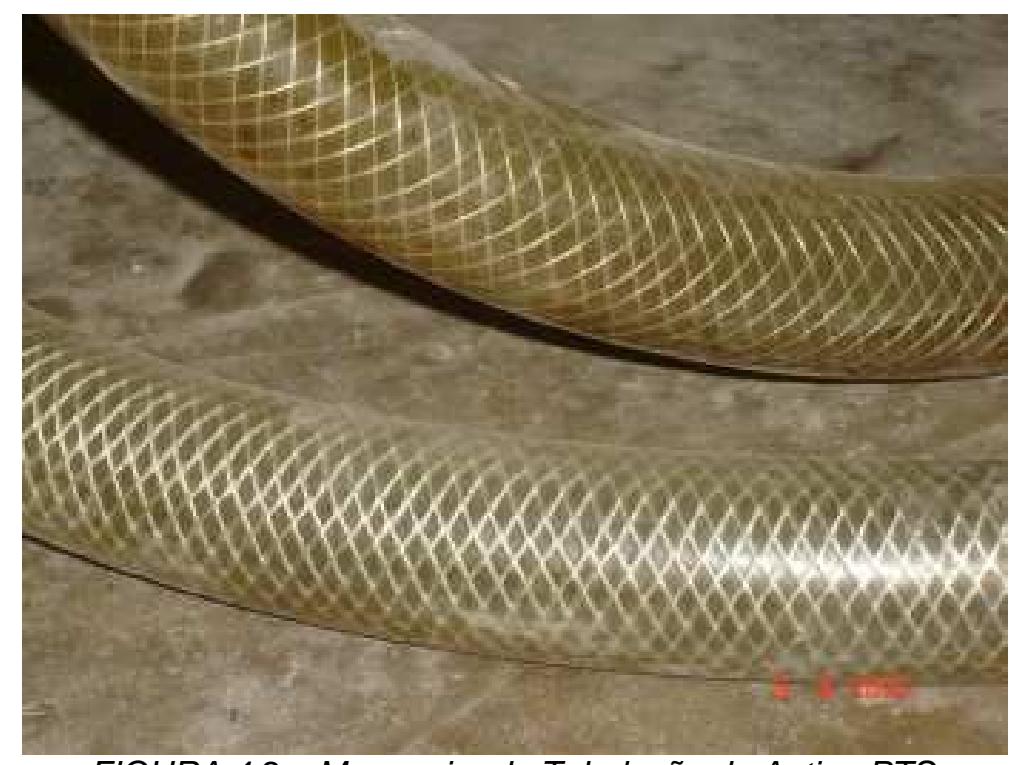

FIGURA 4.2 - Mangueira da Tubulação do Antigo PTS 
A mangueira apresentava deformações dimensionais ao longo do seu comprimento, principalmente nos trechos curvados, ocasionando com freqüência a parada do porta amostras nestes pontos já que a dimensão do diâmetro interno se alterava e o porta amostras não ultrapassava estes trechos. Fato que ocasionava a interrupção do sistema até que o porta amostras, em uma operação manual fosse retirado. Caso o porta amostra não tivesse chegado ao núcleo a operação de retirada era feita sem problemas maiores, mas caso o porta amostras tivesse voltando ao laboratório, saído do núcleo, ele estaria já irradiado e ativo o que ocasionava uma operação muito complicada com exposição de dose ao profissional que executaria a operação de desobstrução da linha.

Outro problema avaliado no sistema antigo foi a falta de suportes de sustentação das mangueiras ao longo de todo seu comprimento (Figura-4.3) desde a saída do laboratório (Estação 4) até a chegada ao núcleo. A falta de suportes forçava a mangueira a seguir um trajeto totalmente disforme e não linear o que ocasionava a deformidade nas dimensões diametrais das mangueiras, nestes trechos, já que estas se estendiam de qualquer maneira pelas paredes e solo.

A falta de suportes e proteção ocasionava também a rápida deterioração do material PVC trançado.

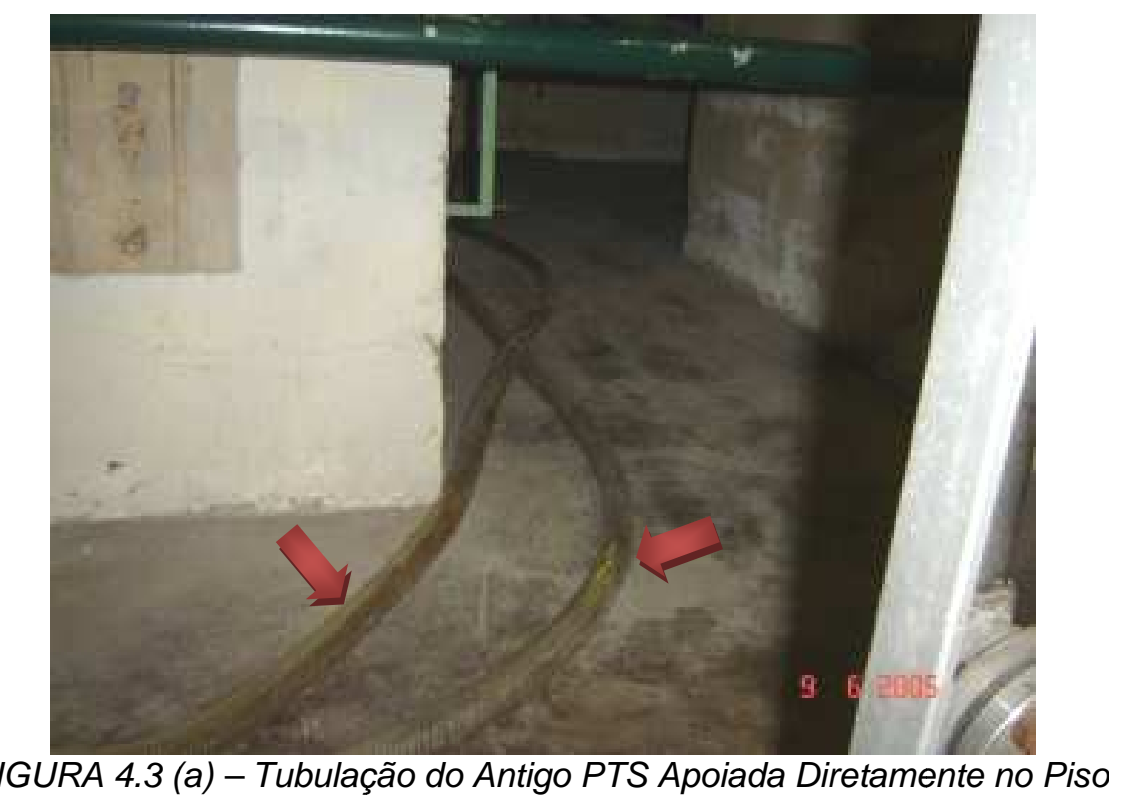




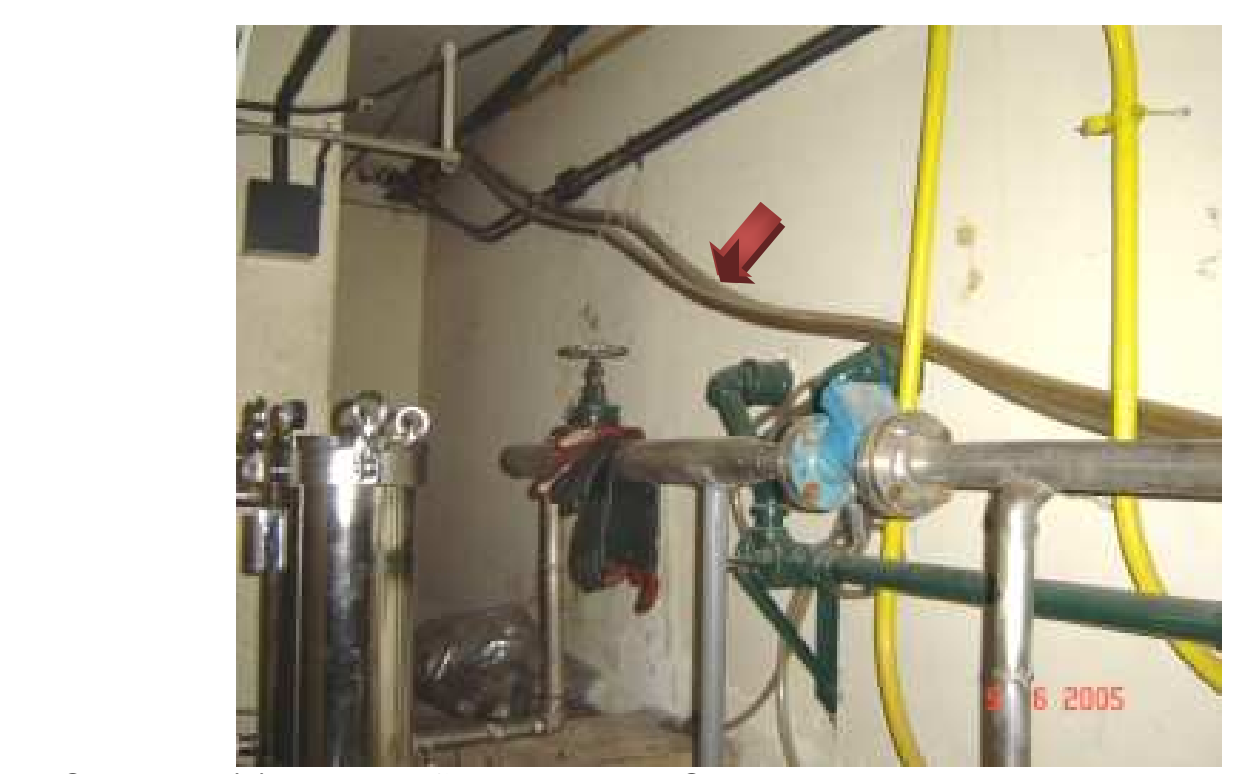

FIGURA 4.3 (b) - Tubulação do Antigo PTS Apoiada Diretamente na Parede sem Suportes

Com o objetivo de melhorar a funcionalidade da tubulação no sistema, utilizaram-se mangueiras de material flexível, capaz de se adaptar ao trajeto irregular desde o laboratório ao núcleo, e que mantivesse as medidas dimensionais ao longo do seu comprimento total, ou seja, nos trechos de curvas a dimensão do diâmetro interno se mantém.

A tubulação está dividida em 2 trechos. Visando identificar o trecho de circulação do porta amostras, as mangueiras foram selecionadas de modo a identificar por cores os dois trechos. O Trecho-1, por onde o porta amostras se movimenta impulsionado pela circulação do ar teve a mangueira selecionada com a cor branca e o Trecho-2 onde circula somente o ar que alimenta o sistema, teve a mangueira selecionada com a cor azul.

A mangueira especificada, para compor a tubulação do Trecho-1, tem medidas comerciais padrões de fácil aquisição comercial proporcionando baixo custo na aquisição e tem as características técnicas a relacionadas a seguir e também no ANEXO A:

- Mangueira espiralada flexível de PVC;

- Fabricante: Kanaflex

- Modelo: KA - Transparente com espiral branco - Tipo Atóxica;

- Diâmetro Externo de 39 mm;

- Diâmetro Interno de 31,75 mm (1 1/4");

- Face interna totalmente lisa; 
- Pressão de Trabalho de $8 \mathrm{kgf} / \mathrm{cm}^{2}\left(114 \mathrm{lb} / \mathrm{pol}^{2}\right)$ à $25^{\circ} \mathrm{C}$;

- Pressão de Ruptura de $24 \mathrm{kgf} / \mathrm{cm}^{2}\left(341 \mathrm{lb} / \mathrm{pol}^{2}\right)$ à 25우

- Raio de curvatura mínimo para transporte de $92 \mathrm{~mm}$ à $25^{\circ} \mathrm{C}$;

- Raio de curvatura mínimo para trabalho de $460 \mathrm{~mm}$ à $25^{\circ} \mathrm{C}$;

A mangueira especificada, para compor a tubulação do Trecho-2, tem medidas comerciais padrões de fácil aquisição comercial proporcionando baixo custo na aquisição e tem as características técnicas relacionadas a seguir e também no ANEXO B:

- Mangueira espiralada flexível de PVC Transparente (azul);

- Fabricante: Kanaflex

- Modelo: KM - Transparente com espiral azul - Tipo Sucção e Descarga;

- Diâmetro Externo de 37 mm;

- Diâmetro Interno de 31,75 mm (1 1/4");

- Face interna totalmente lisa;

- Pressão de Trabalho de $7,3 \mathrm{kgf} / \mathrm{cm}^{2}\left(104 \mathrm{lb} / \mathrm{pol}^{2}\right)$ à $25^{\circ} \mathrm{C}$;

- Pressão de Ruptura de $22 \mathrm{kgf} / \mathrm{cm}^{2}\left(313 \mathrm{lb} / \mathrm{pol}^{2}\right)$ à 25우 $\mathrm{C}$;

- Raio de curvatura mínimo para transporte de $92 \mathrm{~mm}$ à 25우

- Raio de curvatura mínimo para trabalho de $450 \mathrm{~mm}$ à $25^{\circ} \mathrm{C}$;

Visando solucionar os problemas da montagem da antiga tubulação, projetou-se para a tubulação deste novo PTS suportes para todo o percurso da mesma desde o laboratório, na saída da glove Box, até a chegada ao elemento de irradiação, sobre o núcleo do reator. Definimos tecnicamente que as eletro calhas comerciais, utilizadas para montagens elétricas, tem as características mecânicas funcionais ideais para suportação. Alta resistência mecânica, alta durabilidade, de fácil instalação, ampla variedade de fabricantes nacionais o que possibilita fácil aquisição ou reposição.

Os dispositivos especificados, para suportar a tubulação, têm medidas comerciais padrões de fácil aquisição comercial proporcionando baixo custo na aquisição e tem as características técnicas relacionadas a seguir e também no ANEXO C:

- Eletrocalha Perfurada Tipo "C" - EPC;

- Tampa Aparafusada para Eletrocalha - TAE; 
- Fabricante: J.E.A. - Indústria Metalúrgica

- Modelo: EPC;

- Largura de $300 \mathrm{~mm}$;

- Aba $75 \mathrm{~mm}$;

- Chapa perfurada de aço SAE 1020;

- Galvanizado a fogo tratado por imersão em zinco a quente;

Para facilitar a montagem da tubulação do novo PTS foi simplesmente apoiada internamente às calhas. As calhas estão montadas desde o laboratório (estação 4) até a chegada ao elemento de irradiação por sobre o núcleo do reator. Este percurso totaliza um comprimento de 60 metros, passando por diversos ambientes do prédio do reator definidos por serem ambientes restritos à circulação de pessoas de modo a evitar exposições a doses do material irradiado circulando pela tubulação. As calhas estão fixadas nas paredes por apoios padrões presos com parafusos e chumbadores. O percurso está formado por derivações, trechos retos, curvas laterais, curvas ascendentes, curvas descendentes. As dimensões das calhas em curva foram selecionadas de maneira a manter o raio mínimo para a mangueira flexível garantindo o perfeito funcionamento na passagem do porta amostras pelo interior da mesma (Figura-4.4).

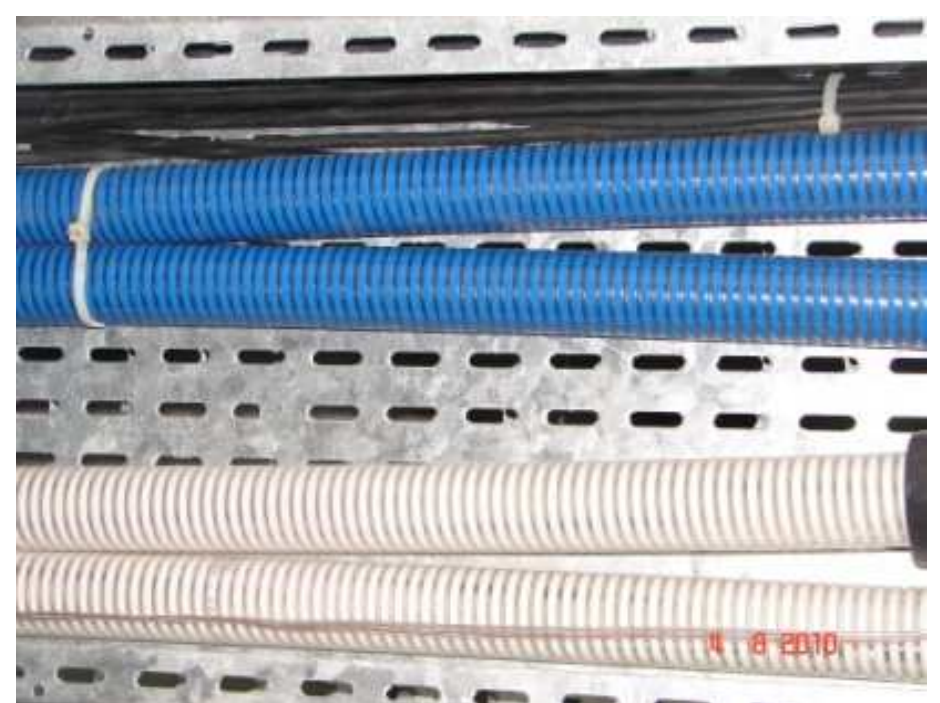

FIGURA 4.4 (a) - Tubulação Branca e Azul Apoiadas Internamente às Calhas de Suportes 
FIGURA 4.4 (b) - Vista dos Suportes para Tubulação do Novo PTS Fixado nas Paredes
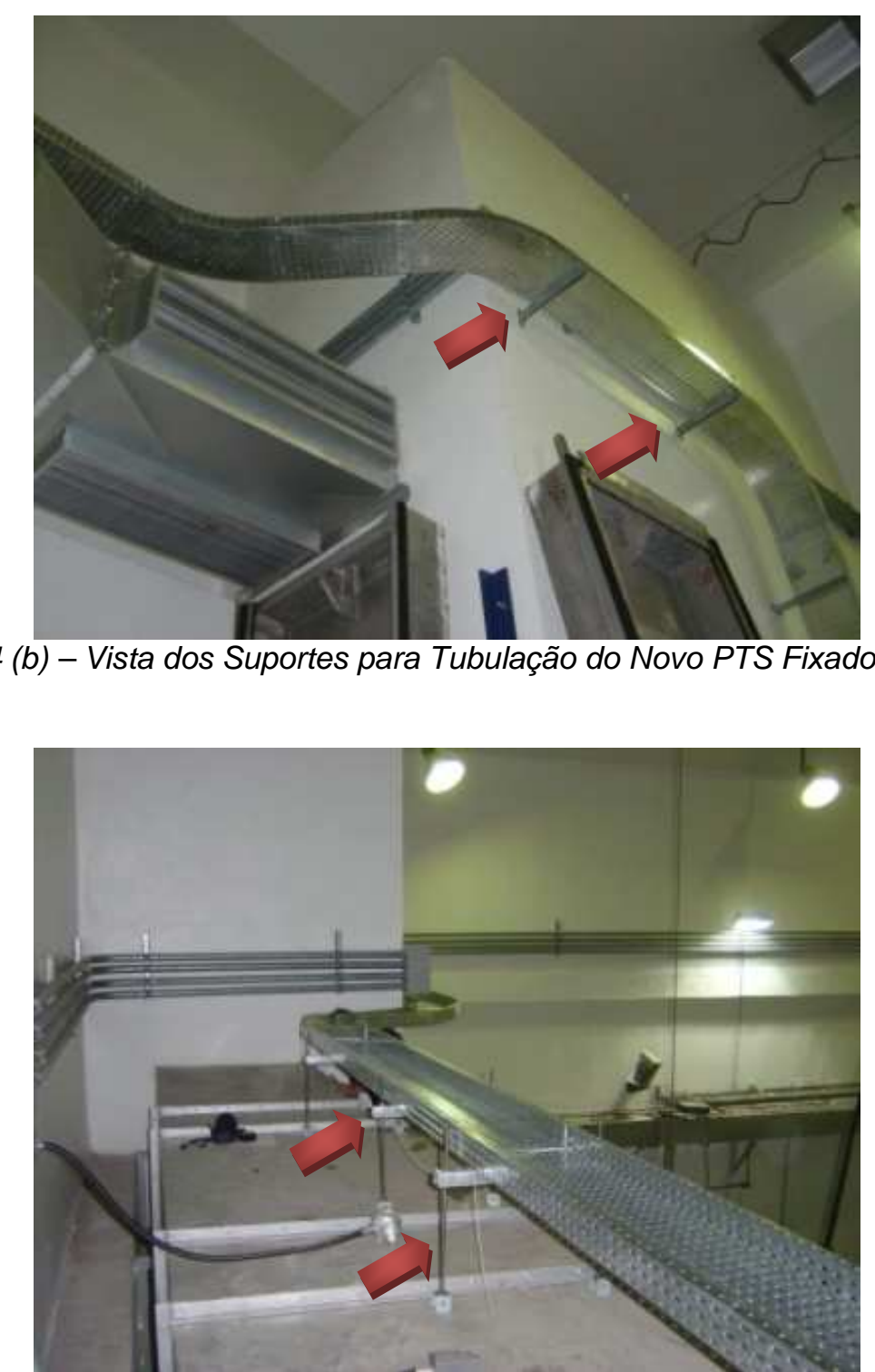

FIGURA 4.4 (c) - Vista dos Suportes para Tubulação do Novo PTS Fixado nos Dutos de Ventilação

\subsection{Elemento de Irradiação}

O elemento de irradiação foi projetado e implementado neste sistema, pois no antigo não existia este conceito. O PTS antigo possuía tubos rígidos e fixos em uma única posição (Figura-4.5) com relação ao núcleo do reator, ou seja, uma única posição de irradiação. Havia riscos com relação a segurança da operação do reator visto que o rompimento de um desses tubos rígidos ocasionaria um acidente denominado Loss of Coolant Accident (LOCA) pois os tubos entravam pelo fundo da piscina. 


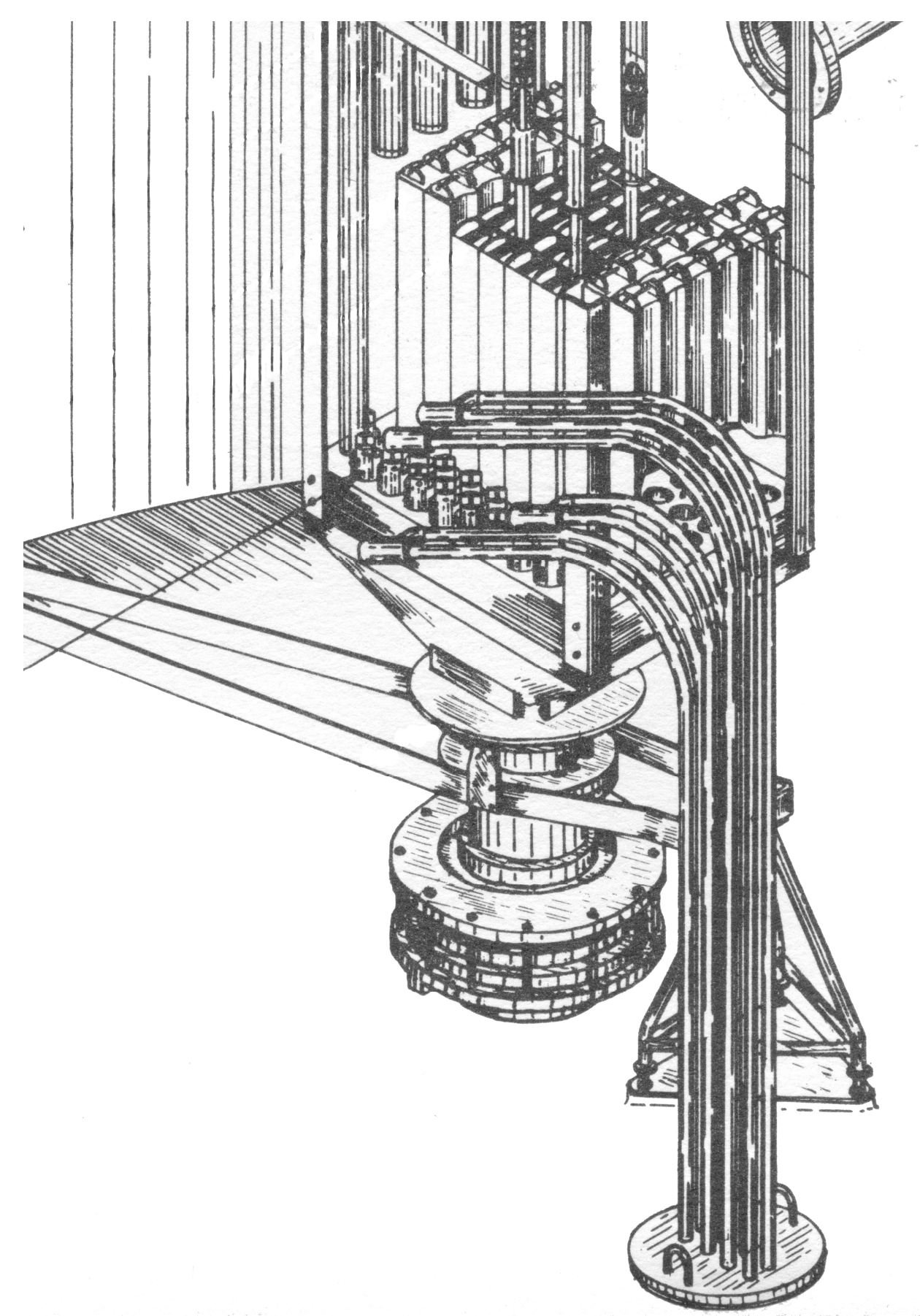

FIGURA 4.5 - Sistema de Irradiação do Antigo PTS

A montagem do sistema pelo fundo da piscina era complexo, o sistema necessitava de flanges e juntas de chumbo montadas e fixadas por parafusos pelo interior e pelo exterior da piscina (Figura-4.6). 


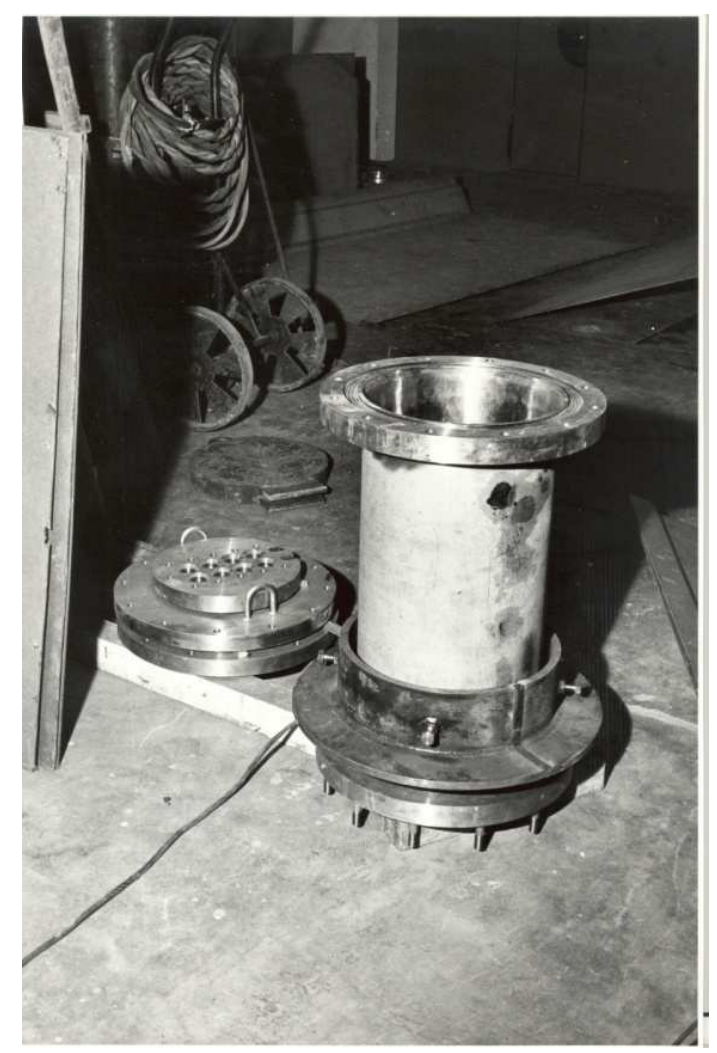

FIGURA 4.6 (a) - Tubulação do Sistema de Irradiação do Antigo PTS Dispositivo de Passagem do Porão para o Fundo da Piscinar

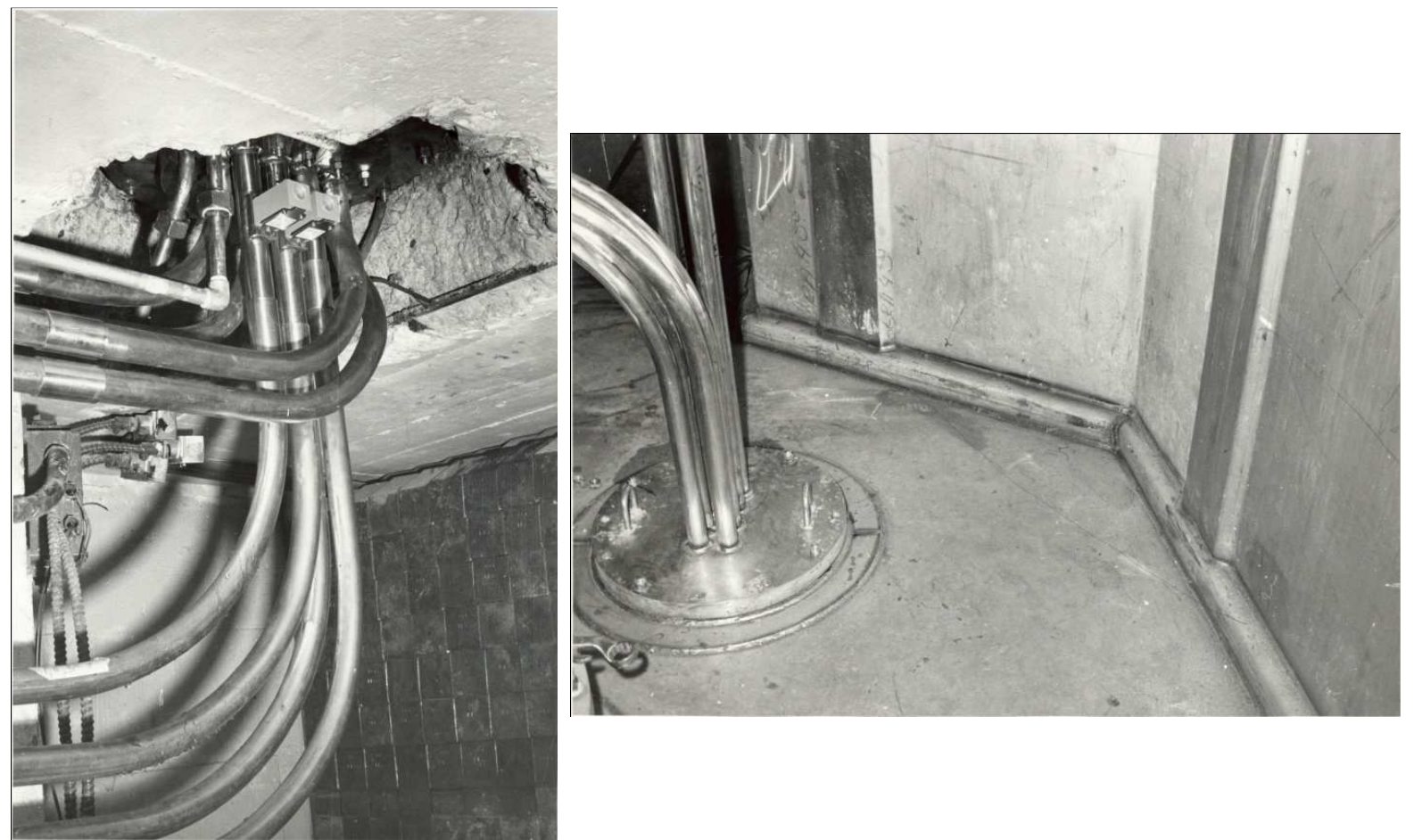

FIGURA 4.6 (b) - Tubulação Metálica no Interior da Piscina do Reator 
A posição de irradiação do antigo sistema estava localizada próxima ao núcleo de modo a receber o fluxo de nêutrons gerados pelas fissões, responsáveis pela ativação do material. O ponto de chegada (Figura-4.7) do porta amostras teve alguns problemas verificados ao longo do tempo de uso do sistema. A falta de um sistema de amortecimento causou por diversas vezes a quebra do porta amostras no momento que o mesmo chegava ao ponto de irradiação, causando a contaminação do sistema. Devido ao difícil acesso pelo seu posicionamento e complexidade de montagem e desmontagem não houve como realizar manutenção para descontaminação do sistema e este teve suas atividades paralisadas.

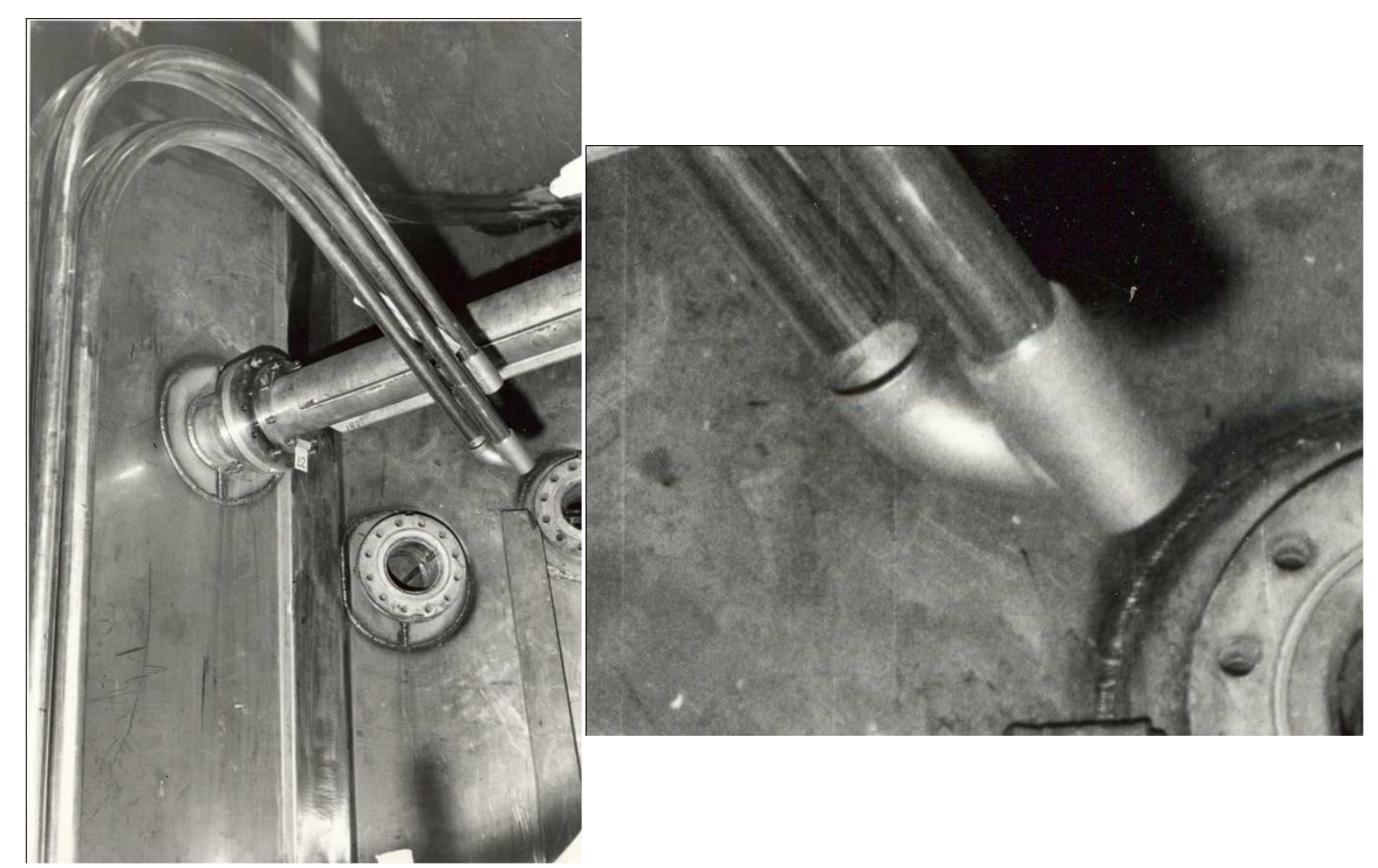

FIGURA 4.7 - Dispositivo de Irradiação do Antigo PTS

O elemento de irradiação novo (Figura-4.8) foi projetado de modo poder ser encaixado em qualquer posição da placa matriz, portanto aproveitando vários níveis de fluxo neutrônico e eliminou os riscos de esvaziamento da piscina provocando o LOCA já que sua montagem é pelo topo da piscina. 


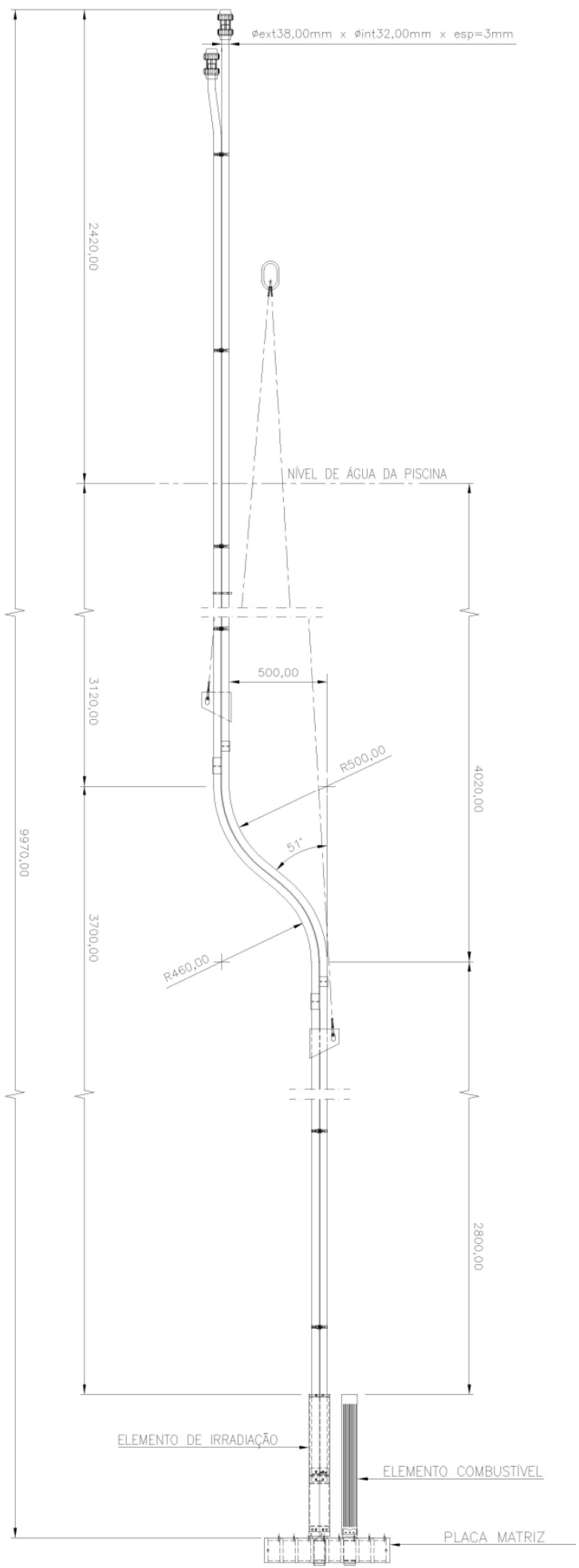

FIGURA 4.8 - Elemento de Irradiação do Novo PTS (medidas em mm)

A concepção do novo elemento visa posicionar o ponto de irradiação em uma estrutura padrão intercambiável facilitando sua montagem em qualquer posição de irradiação na placa matriz. Mantendo as características usadas nos materiais estruturais do núcleo do reator, definiu-se que o material a ser utilizado 
na fabricação do elemento de irradiação é o Alumínio em sua liga de classificação ASTM-6061 ou ABNT-6061. A qualidade principal deste material, tornando-o ideal para fabricação de dispositivos utilizados no núcleo do reator é a sua alta resistência à corrosão e mecânica e boa corformabilidade e soldabilidade. $\mathrm{O}$ alumínio escolhido apresenta as seguintes características, Tabela-4.1:

TABELA 4.1 - Características e Aplicações da Liga ASTM/ABNT-6061 de Alumínio

\begin{tabular}{|l|l|l|}
\hline LIGA & \multicolumn{1}{|c|}{ CARACTERÍSTICAS } & \multicolumn{1}{|c|}{ APLICAÇÕES } \\
\hline 6061 & $\begin{array}{l}\text { Alta resistência mecânica e à corrosão. } \\
\text { Boa corformabilidade e soldabilidade }\end{array}$ & $\begin{array}{l}\text { Estruturas, } \\
\text { construção naval, } \\
\text { veículos, indústria } \\
\text { moveleira, rebites, } \\
\text { móveis, oleodutos. }\end{array}$ \\
\hline
\end{tabular}

$\mathrm{Na}$ seqüência são apresentados, Tabela-4.2 e Tabela-4.3, as propriedades mecânicas e físicas características da liga ASTM-6061 selecionada para fabricação e aquisição de toda parte estrutural do elemento de irradiação:

TABELA 4.2 - Propriedades Mecânicas da Liga ASTM/ABNT-6061 de Alumínio

\begin{tabular}{|c|c|}
\hline Propriedades Mecânicas & LIGA ASTM/ABNT-6061 \\
\hline Equivalente Norma DIN & Al Mg Si Cu \\
\hline Tempera & T6 \\
\hline $\begin{array}{l}\text { Limite de Resistência à Tração } \\
\qquad \mathrm{MPa}\left(\mathbf{N} / \mathbf{m m}^{2}\right)\end{array}$ & 260 \\
\hline $\begin{array}{l}\text { Limite de Escoamento } \\
\qquad \mathrm{MPa}\left(\mathbf{N} / \mathbf{m m}^{2}\right)\end{array}$ & 240 \\
\hline $\begin{array}{l}\text { Alongamento Mínimo } 50 \mathrm{~mm} \\
\text { (\%) }\end{array}$ & 6 \\
\hline Dureza Brinell (HB) & 95 \\
\hline
\end{tabular}


TABELA 4.3 - Propriedades Físicas da Liga ASTM/ABNT-6061 de Alumínio

\begin{tabular}{|c|c|}
\hline Propriedades Mecânicas & LIGA ASTM/ABNT-6061 \\
\hline $\begin{array}{c}\text { Densidade a } 20^{\circ} \mathrm{C} \\
(\rho=\text { Peso específico) } \\
\left(\mathrm{g} / \mathrm{cm}^{3}\right)\end{array}$ & 2,71 \\
\hline $\begin{array}{c}\text { Temperatura de Fusão } \\
\left({ }^{\circ} \mathrm{C}\right)\end{array}$ & $580-650$ \\
\hline $\begin{array}{l}\text { Calor Específico } \\
0 \text { a } 100^{\circ} \mathrm{C} \\
\text { (cal/g }{ }^{\circ} \mathrm{C} \text { ) }\end{array}$ & 0,22 \\
\hline $\begin{array}{l}\text { Coeficiente de Expansão Térmica } \\
\qquad \begin{array}{c}20 \text { a } 10^{\circ} \mathrm{C} \\
\left(10^{-6} 0^{\circ} \mathrm{C}\right)\end{array}\end{array}$ & 24 \\
\hline $\begin{array}{c}\text { Condutibilidade Térmica a } 25{ }^{\circ} \mathrm{C} \\
\left.\text { (cal } / \mathrm{cm}^{2} \mathrm{~cm}^{2} / \mathrm{seg}^{\circ} \mathrm{C}\right)\end{array}$ & 0,37 \\
\hline $\begin{array}{c}\text { Condutibilidade Elétrica a } 20^{\circ} \mathrm{C} \\
\text { (\% IACS) }\end{array}$ & 43 \\
\hline $\begin{array}{l}\text { Módulo de Elasticidade } \\
\text { (MPa) }\end{array}$ & 70.000 \\
\hline $\begin{array}{l}\text { Módulo de Rigidez } \\
\text { (MPa) }\end{array}$ & 26.500 \\
\hline
\end{tabular}

O ponto de irradiação está fixado em uma estrutura equivalente ao elemento combustível, um tubo de seção quadrada e um "plug" fazem com que o elemento de irradiação se fixe na placa matriz em um de seus furos. O corpo do elemento de irradiação é fabricado de tubos. Ambos estão fabricados na liga de alumínio caracterizada anteriormente. O elemento se compõe de tubo quadrado e tubo redondo. As dimensões selecionadas para cada tubo selecionado estão demonstradas na Tabela-4.4 e Tabela-4.5: 
TABELA 4.4 - Propriedades Dimensionais da Tubulação Quadrada do Elemento de Irradiação

\begin{tabular}{|c|c|c|}
\hline \multicolumn{2}{|c|}{ Diâmetro Externo } & $\begin{array}{c}\text { Espessura da Parede }(\mathrm{mm}) \\
\text { [Peso }(\mathrm{kg} / \mathrm{m})]\end{array}$ \\
\hline pol. & $\mathrm{mm}$ & $\begin{array}{c}\mathbf{3 , 1 7} \\
{[\mathbf{2 , 8 0 5}]}\end{array}$ \\
\hline 3
\end{tabular}

TABELA 4.5 - Propriedades Dimensionais da Tubulação Quadrada do Elemento de Irradiação

\begin{tabular}{|c|c|c|}
\hline Día & mo & $\begin{array}{l}\text { Espessura da Parede (mm) } \\
\text { [Peso }(\mathrm{kg} / \mathrm{m})]\end{array}$ \\
\hline $11 / 2^{\prime \prime}$ & 38,1 & $\begin{array}{c}3,17 \\
{[0,939]}\end{array}$ \\
\hline
\end{tabular}

Ao conjunto do elemento de irradiação foi incorporada uma curva na meia altura do corpo tubular do conjunto. Esta curvatura na tubulação tem o objetivo de evitar que o fluxo de nêutrons seja colimado pelo tubo atingindo o ambiente do saguão da piscina e causando doses de radiação aos trabalhadores da área.

\subsection{Painel de comando e quadro de válvulas solenóides}

O painel de comando operacional e o painel de válvulas solenóides (Figura-4.9) foi totalmente modernizado. Materiais e equipamentos eletro/mecânicos de tecnologias atuais constituem os sistemas de comando (Figura-4.10) possibilitando com relação aos sistemas do antigo PTS uma maior confiabilidade operacional do sistema bem como proporcionando uma automação total do novo PTS.

O conjunto painel mais o quadro de válvulas é o responsável pela operacionalidade do sistema. Foram implementados dois modos operacionais:

a.) Operação manual: $O$ usuário do sistema aciona o envio da amostra no painel ( Figura-4.10 (a) ) mandando o conjunto do porta amostras para o núcleo, controla manualmente o tempo de irradiação e após esse tempo aciona o retorno, no painel, da amostra irradiada para a estação de recebimento. 
b.) Operação automática: $O$ usuário antes de acionar o envio, estabelece no temporizador, instalado no painel, o tempo necessário para sua irradiação e a seguir aciona o botão de envio. O tempo de irradiação e o retorno acontecem automaticamente comandados pelo temporizador que faz o retorno da amostra irradiada para a estação.

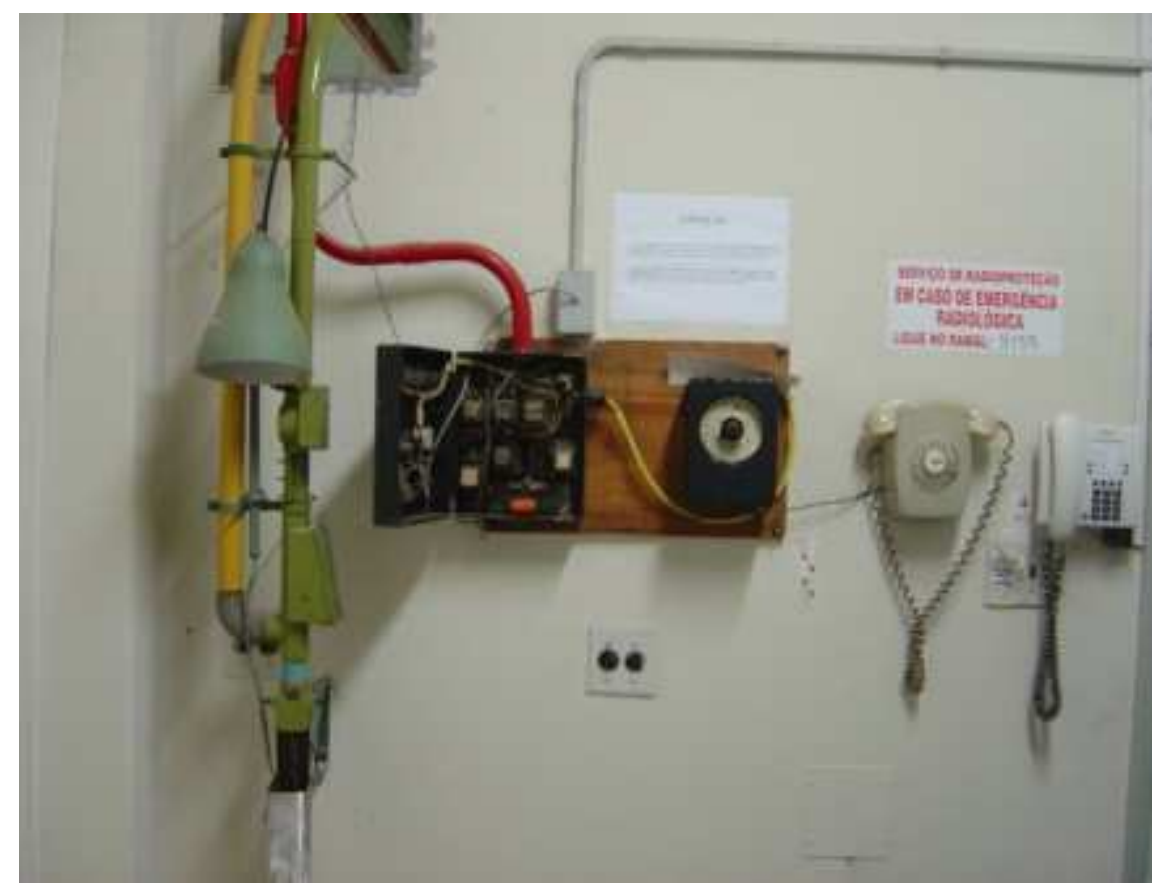

FIGURA 4.9 (a) - Painel de Comando do Antigo PTS

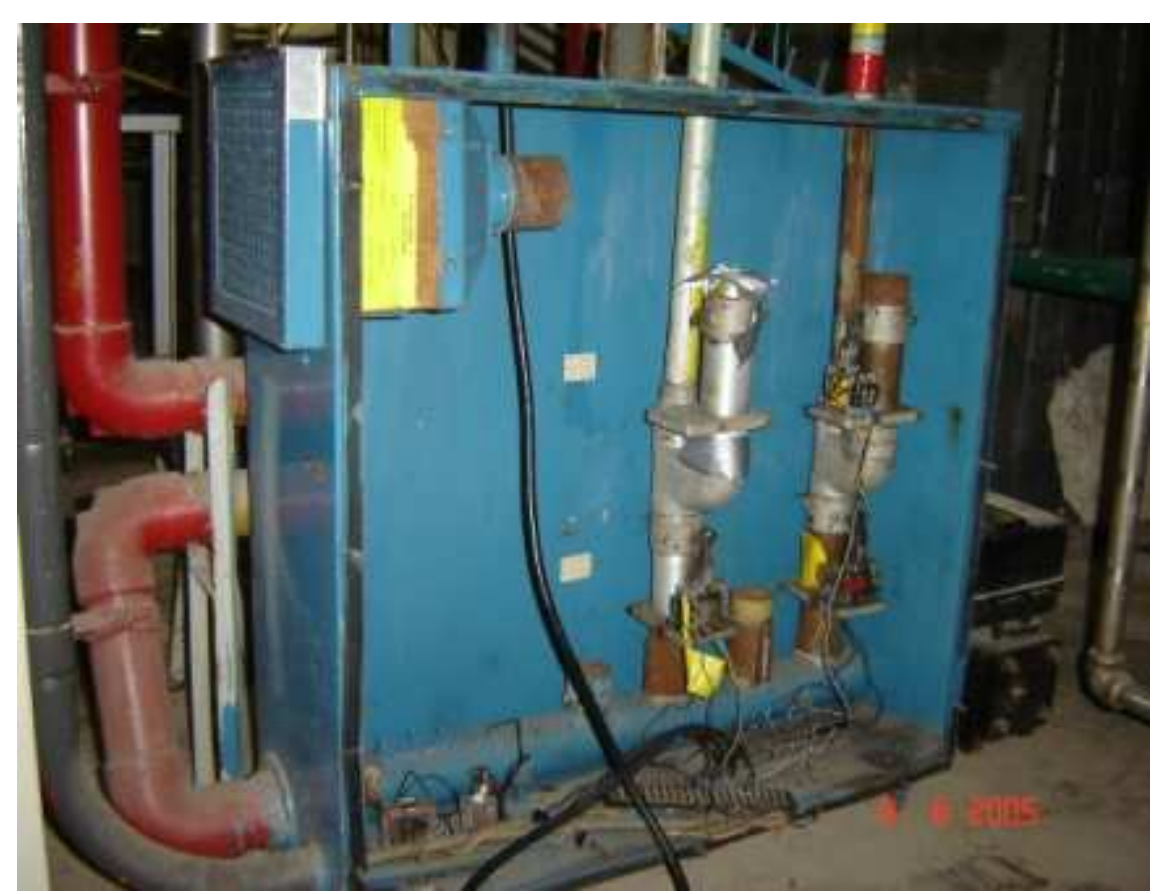

FIGURA 4.9 (b) - Painel de Válvulas Solenóides do Antigo PTS 

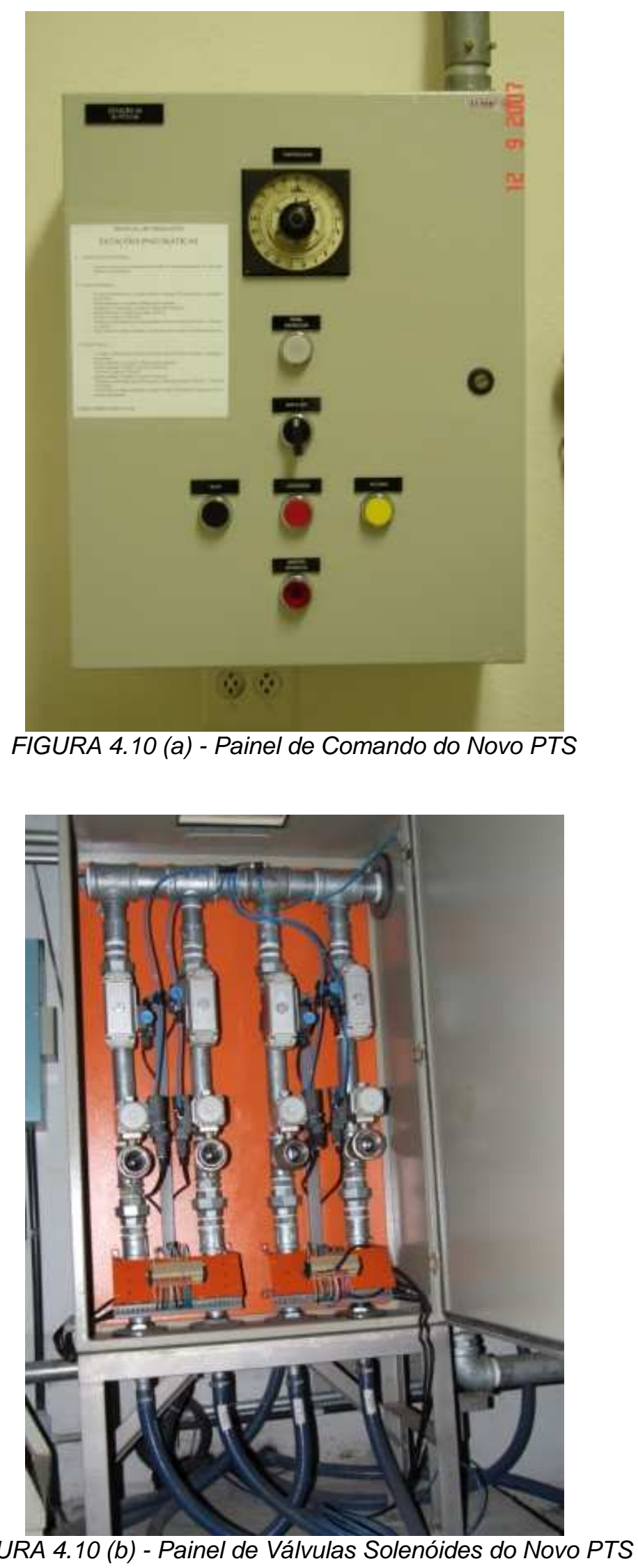


\subsection{Porta Amostras (Coelho)}

O projeto do porta amostras desenvolveu-se com o conceito de implementar inovações técnicas de fabricação, de materiais e de aerodinâmica. $O$ porta amostras do antigo PTS era fabricado com Nylon por processo de usinagem (Figura-4.11). O material e o processo mostraram-se não adequados à finalidade. O material apresentou um comportamento ao efeito da radiação pouco eficiente. Após alguns minutos de exposição à radiação o Nylon alterava suas características mecânicas tornando-se quebradiço e provocando por varias vezes a quebra do porta amostras dentro da tubulação, com perda da amostra irradiada. Outro ponto negativo é que a constituição química do Nylon possui alguns elementos, impurezas, que elevam a dose ao usuário durante sua manipulação para extração da amostra irradiada. O processo de fabricação por usinagem implementa um custo e tempo de fabricação incompatíveis com o produto.

$O$ projeto desenvolvido para o novo porta amostras (Figura-4.12) definiu o Polietileno de Alta Densidade (PEAD) como material construtivo e o processo de injeção plástica para fabricação.

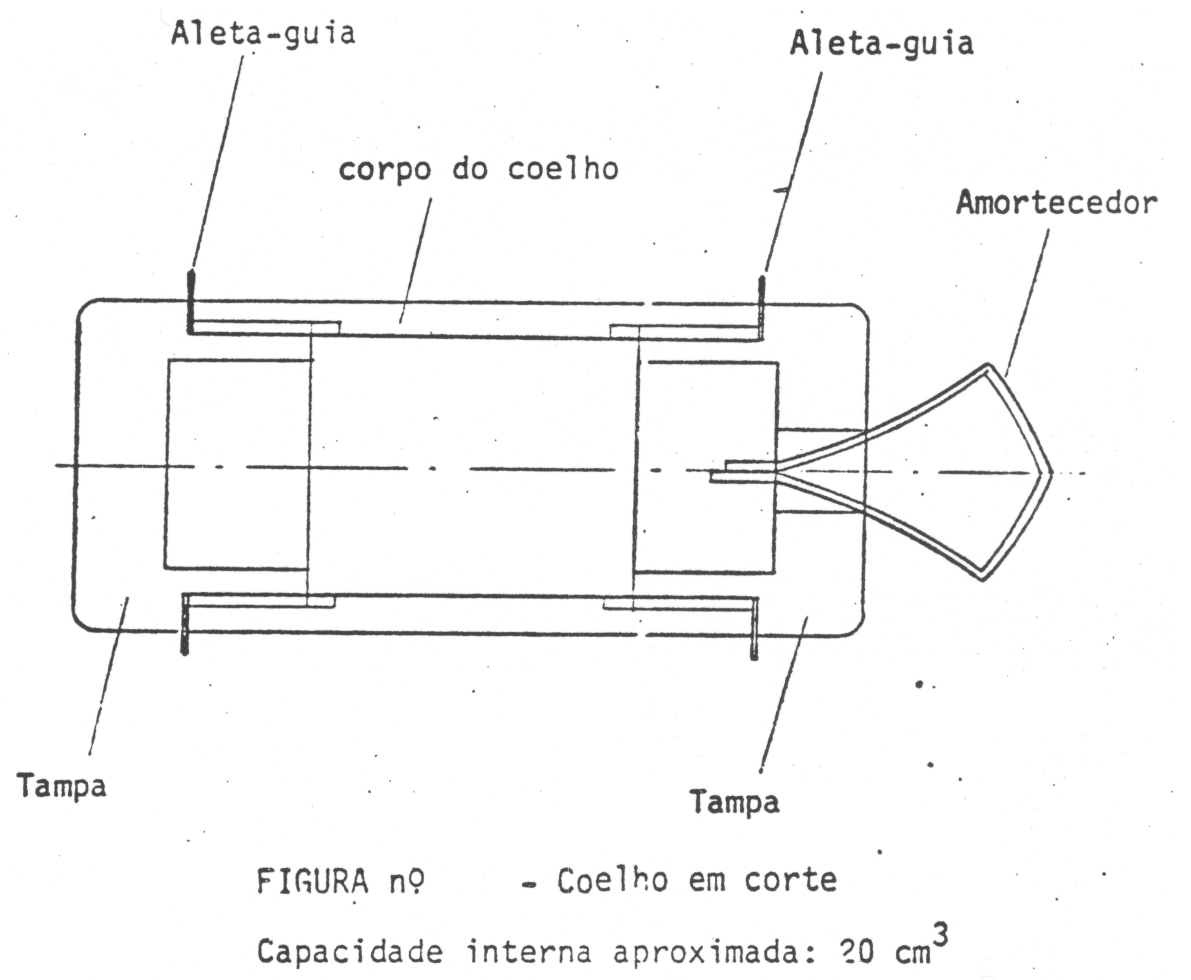

FIGURA 4.11 (a) - Características Dimensionais do Porta Amostras do Antigo PTS 


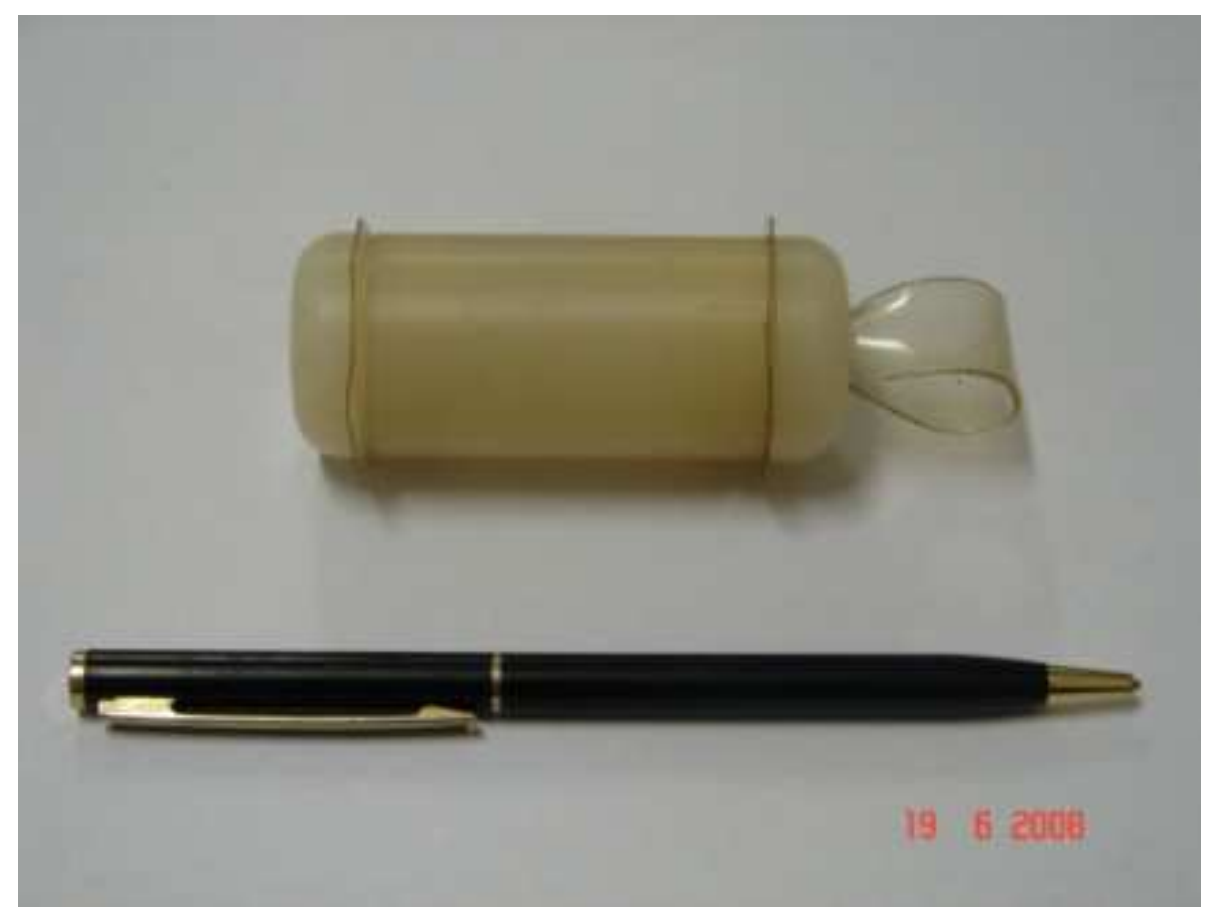

FIGURA 4.11 (b) - Comparativo Dimensional do Porta Amostras

PEAD teve resultados compatíveis nas avaliações de doses devido a manipulação após irradiação e o processo de injeção é de excelente desempenho.

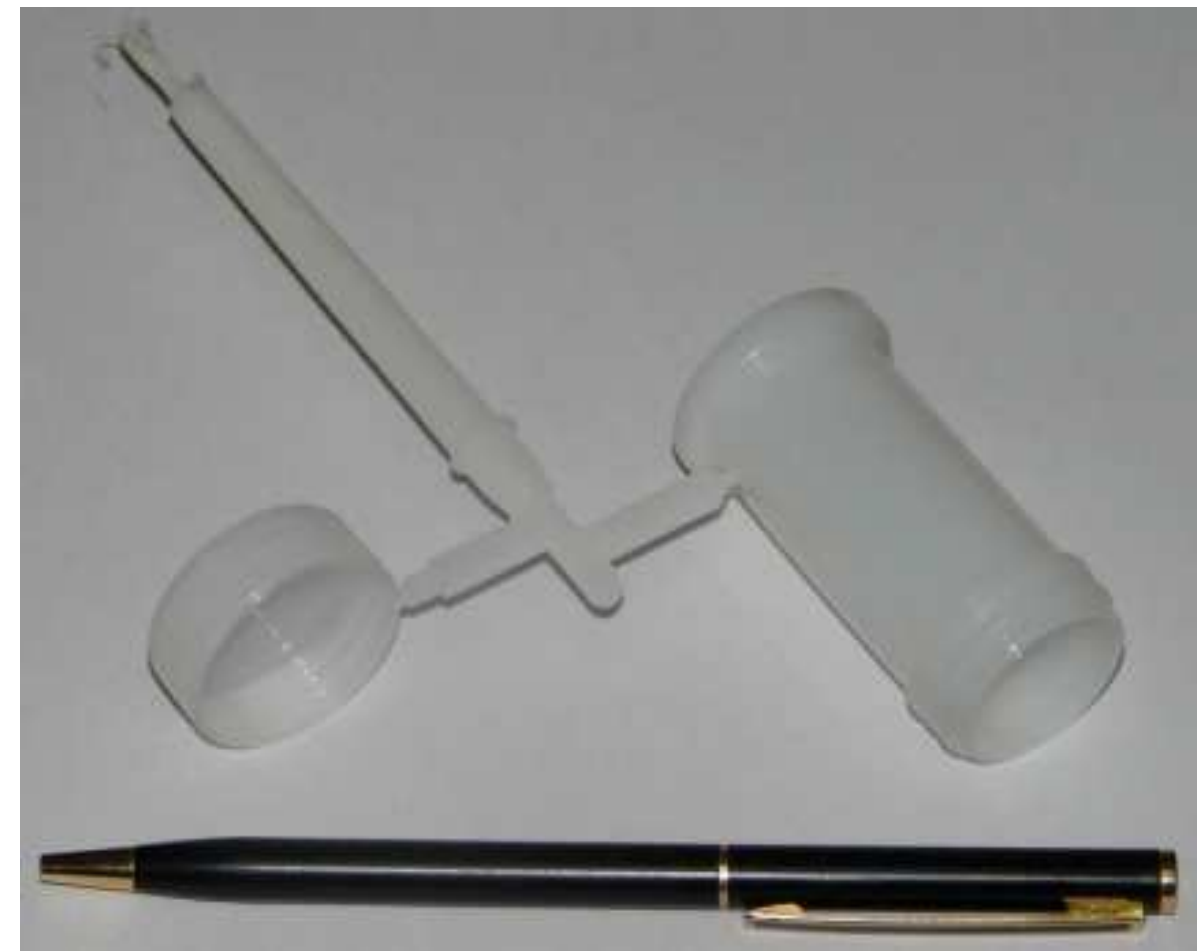

FIGURA 4.12 (a) - Características de Fabricação (Injeção Plástica) Porta Amostras do Antigo PTS 


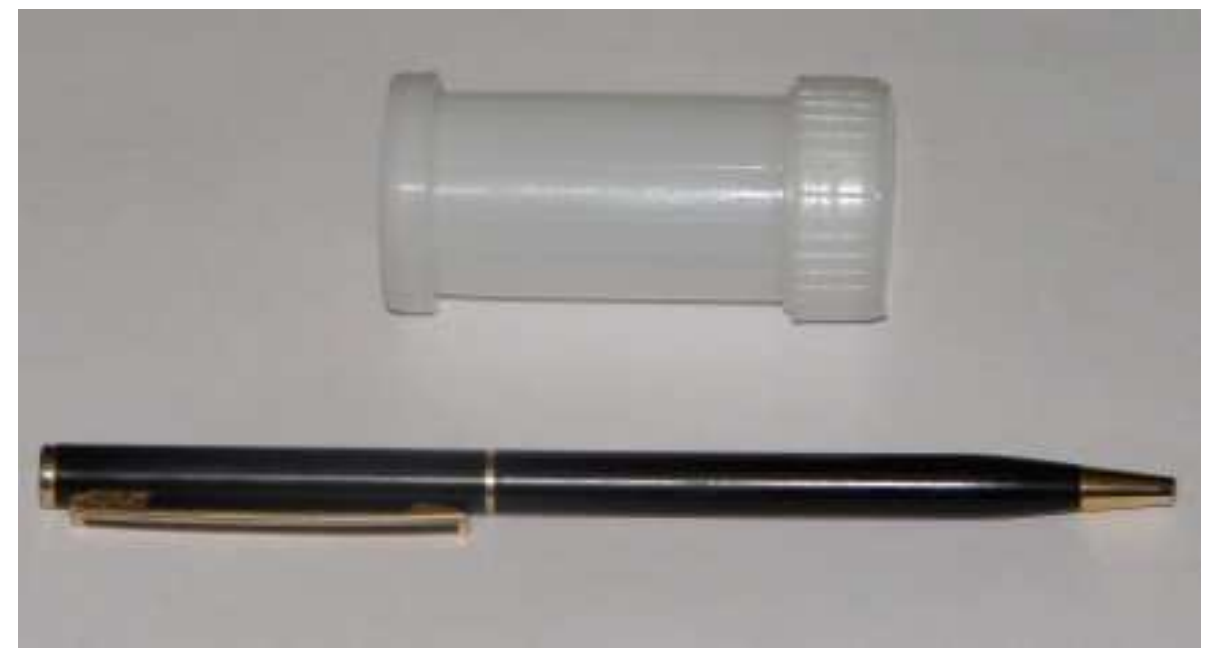

FIGURA 4.12 (b) - Comparativo Dimensional do Porta Amostras

\subsection{Estação de envio e recebimento das amostras irradiadas}

A estação é um conjunto de receptáculos de onde partem os porta amostras para irradiação, e para onde retornam, logo após. Compõem-se de dispositivos mecânicos dotados de um alojamento com uma portinhola, a qual deve ser aberta manualmente durante a operação de envio do porta amostras. Para esta operação, basta colocá-lo no alojamento e fechar a portinhola e o transporte é realizado, pois já existe fluxo de ar proporcionado pelo funcionamento do turbo compressor (Blower). Terminada a irradiação do porta amostras dá-se o retorno do mesmo, indo parar no receptáculo de retorno, que no caso do novo PTS é o mesmo que o receptáculo de envio.

O receptáculo de envio/retorno está montado em linha, solidariamente, formando um conjunto, o qual é conectado à tubulação de transporte do porta amostras até a posição de irradiação.

A antiga estação (Figura-4.13) não proporcionava ao pesquisador usuário uma atividade ocupacional segura causando um tempo excessivo de exposição aos materiais irradiados (porta amostra+amostra). O sistema não contava com blindagem apropriada para proteção do usuário que recebia 0 material irradiado e o manipulava de forma direta.

O laboratório, onde se localiza a estação, que serve aos usuários ganhou uma nova estação de trabalho que permite de maneira segura e ágil manipular os materiais base das pesquisas, desde seu envio sem alguma atividade até seu retorno depois de irradiado (Figura-4.14). 


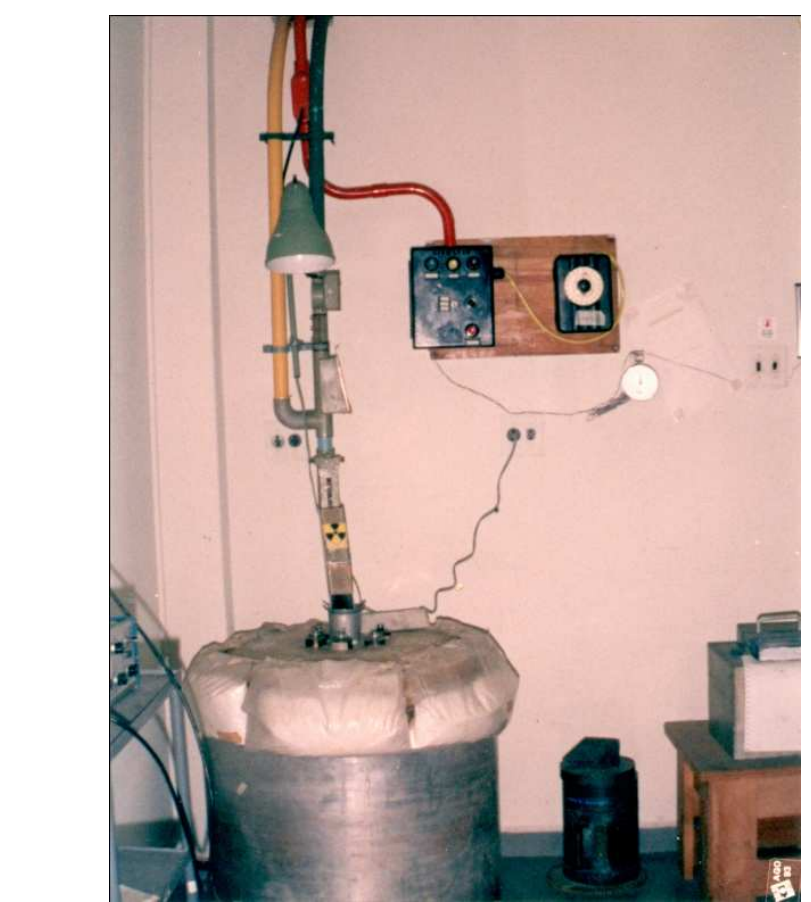

FIGURA 4.13 - Estação de Envio/Retorno do Antigo PTS

A estação do novo PTS é dotada de uma Glove-Box onde ao redor da área operacional está montada uma blindagem de chumbo e com o receptáculo de envio/retorno montado internamente à esta Glove-Box está garantindo a proteção do usuário quanto a exposição às doses dos materiais irradiados.

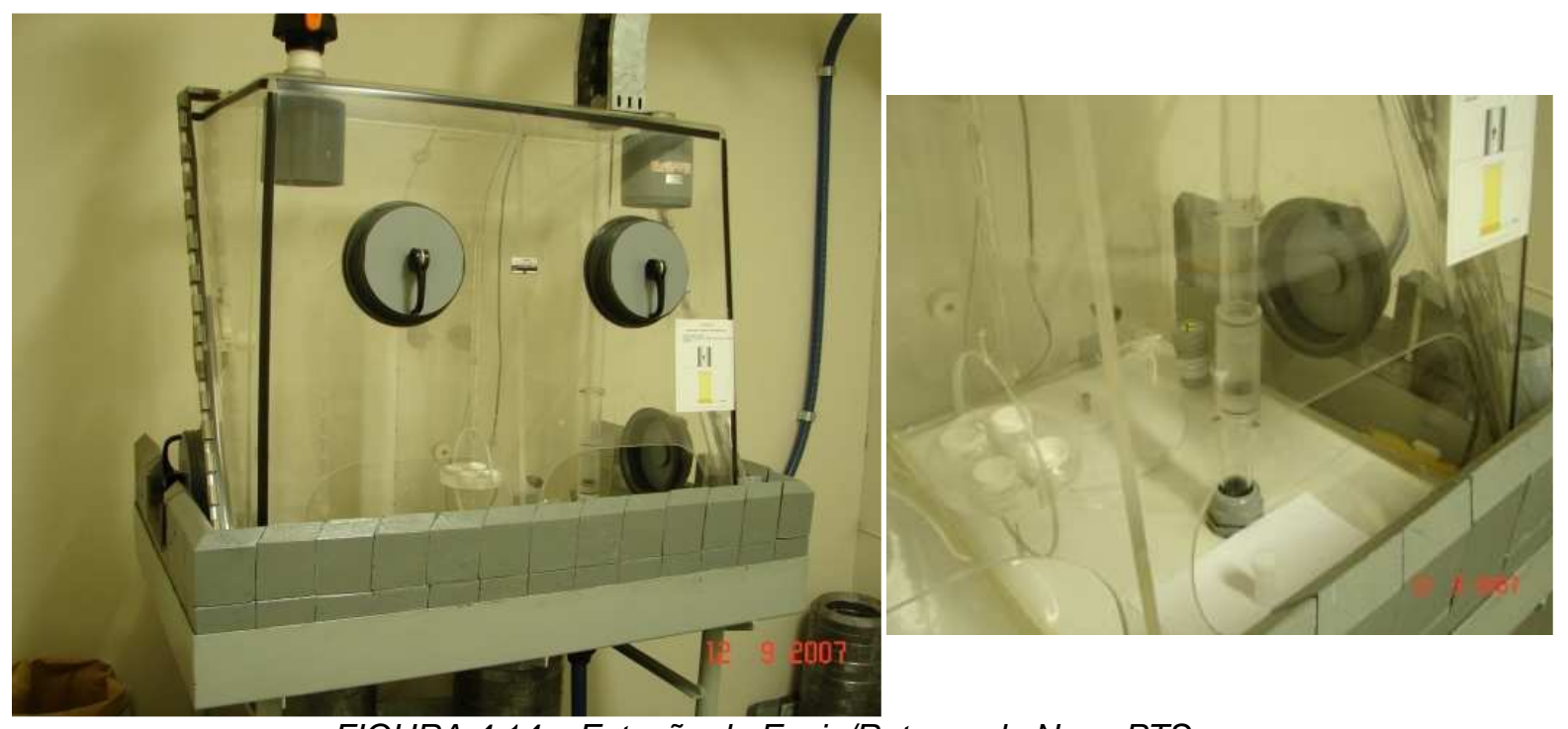

FIGURA 4.14 - Estação de Envio/Retorno do Novo PTS 


\section{RESULTADOS E DISCUSSÃO}

Neste capítulo serão apresentados os resultados e a discussão dos dados obtidos dos Testes operacionais do sistema referentes aos tempos de transito da cápsula dentro da tubulação; medidas de fluxo neutrônico (folha de Au) na posição de irradiação na placa matriz; avaliação estrutural da placa matriz do núcleo do reator quando submetida ao esforço do conjunto elemento de irradiação; avaliação do impacto da instalação do sistema pneumático na operacionalidade e segurança do Reator IEA-R1 com avaliação do risco de acidente provocado pelo sistema; Análise e avaliação de doses na cápsula (coelho) de polietileno de alta densidade e no de nylon.

\subsection{Tempo de transito}

O tempo de transito é um fator muito importante na funcionalidade e aplicação do sistema. O método analítico AAN é utilizado para qualificação e quantificação de elementos químicos presentes em determinadas amostras de materiais. Muitos desses elementos químicos, quando irradiados, possuem isótopos com tempos de meia-vida bastante curtos e para serem detectados e sensibilizarem a instrumentação necessitam que o intervalo de tempo entre o fim da irradiação e o início das medidas seja o menor possível. Portanto os tempos de transito dentro da tubulação desde o ponto de irradiação da amostra (núcleo do reator) e o ponto de abertura da cápsula e retirada da amostra (laboratório) para leitura ou contagem pelo equipamento instrumental, deve ser compatível com os tempos necessários para as diversas análises que são feitas no laboratório na detecção de elementos químicos específicos que necessitam ser investigados.

Testes de envio e retorno das cápsulas vazias, sem amostras, e com as cápsulas carregadas com o peso máximo permitido foram executados. 0 tempo de envio foi determinado desde o momento em que o sistema era acionado no painel de comando, localizado no laboratório, até o momento em que a 
amostra chegava na posição de irradiação indicada por uma sinalização luminosa no quadro de comando indicando que a amostra estava no núcleo do reator. $\mathrm{O}$ tempo de retorno foi determinado desde o momento em que a amostra, após o tempo de irradiação, saiu do núcleo, indicada pela desligamento da sinalização no painel de comando, até a sua chegada e parada total na posição de manipulação no laboratório. São apresentados na seqüência (Figura-5.1) os tempos de transito em várias situações, de vazio à carga máxima.

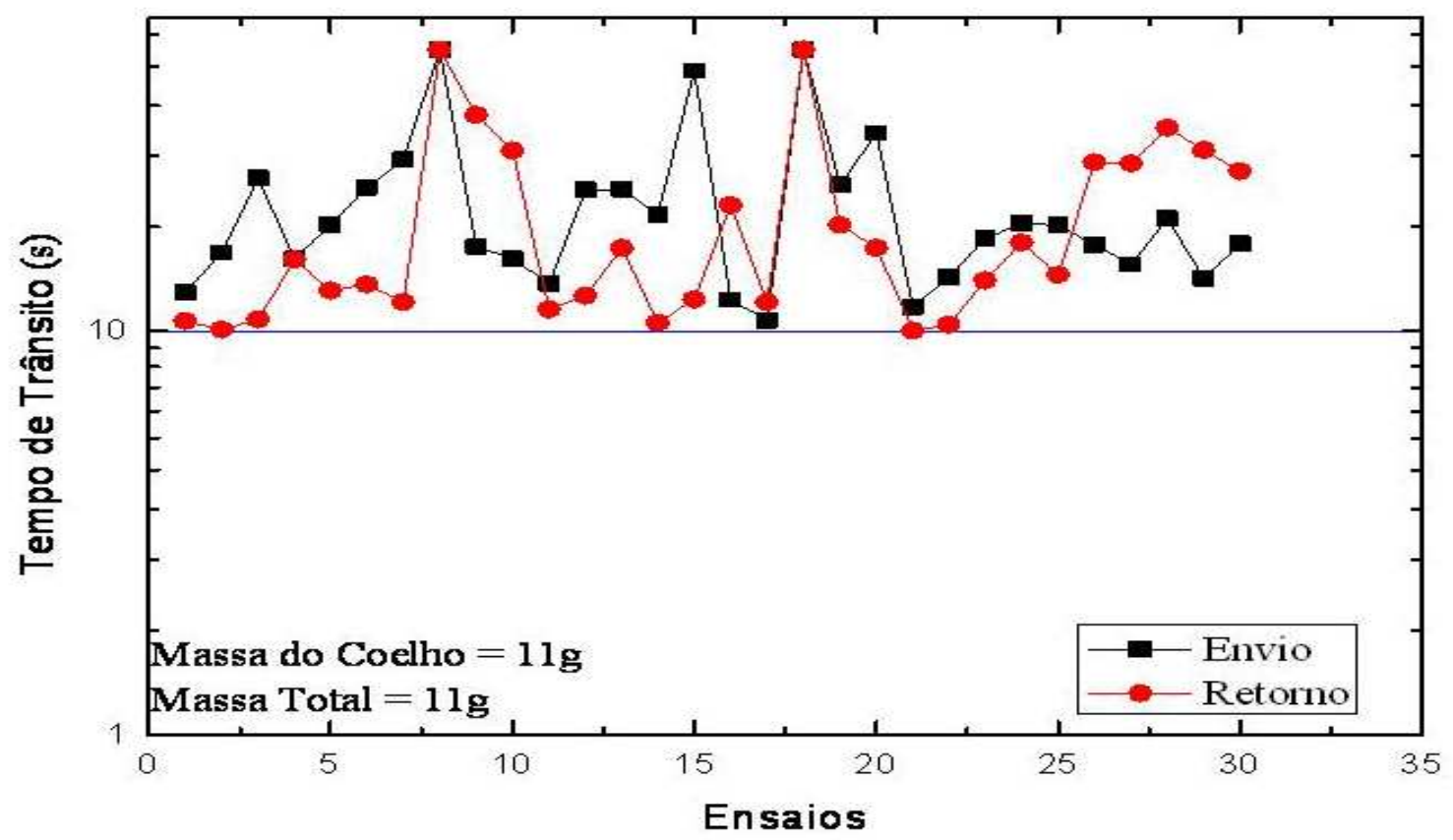

FIGURA 5.1 (a) - Ensaio do Tempo de Transito do Coelho Vazio

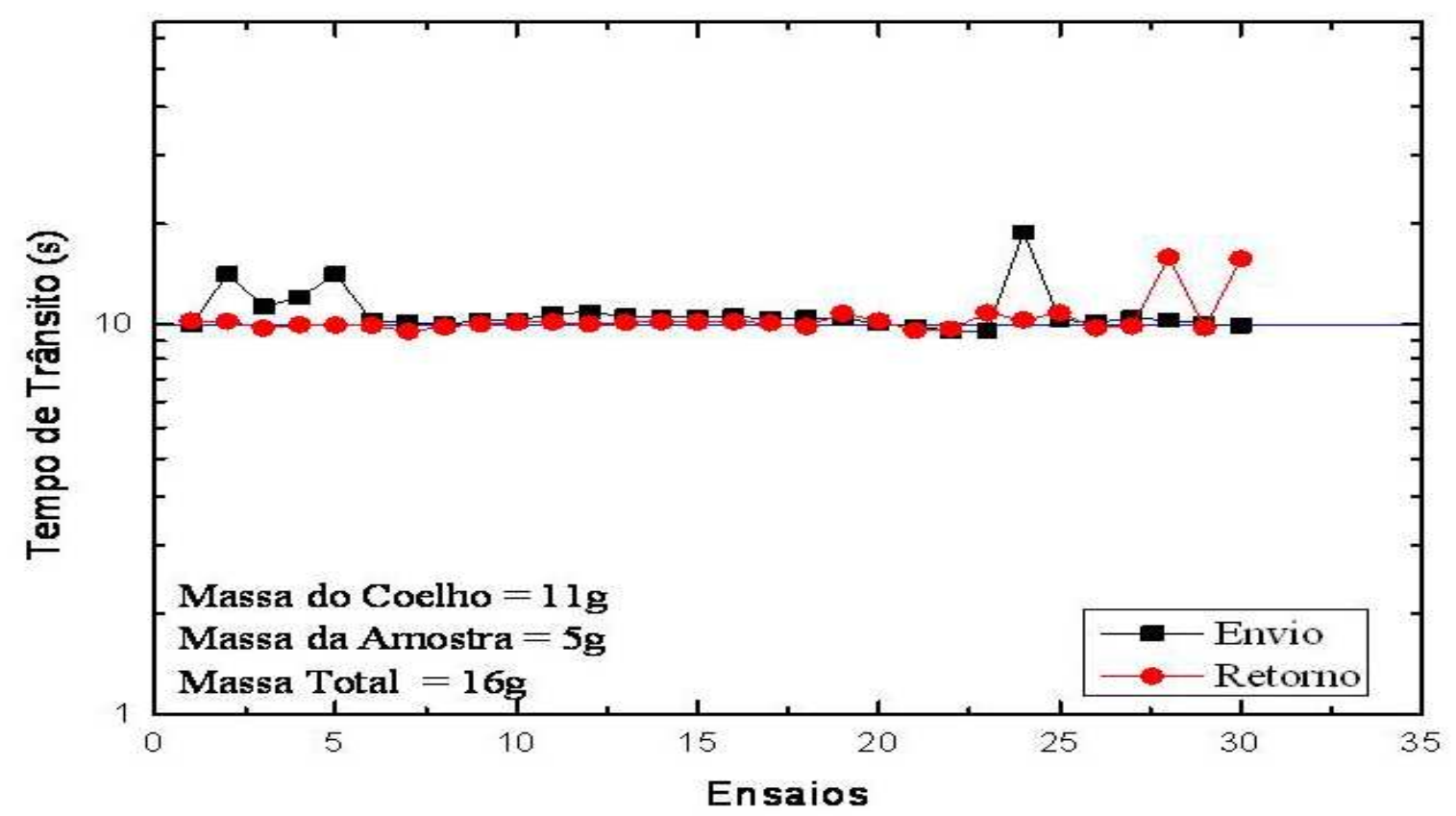

FIGURA 5.1 (b) Tempo de Transito do Coelho com amostra de $5 g$ 


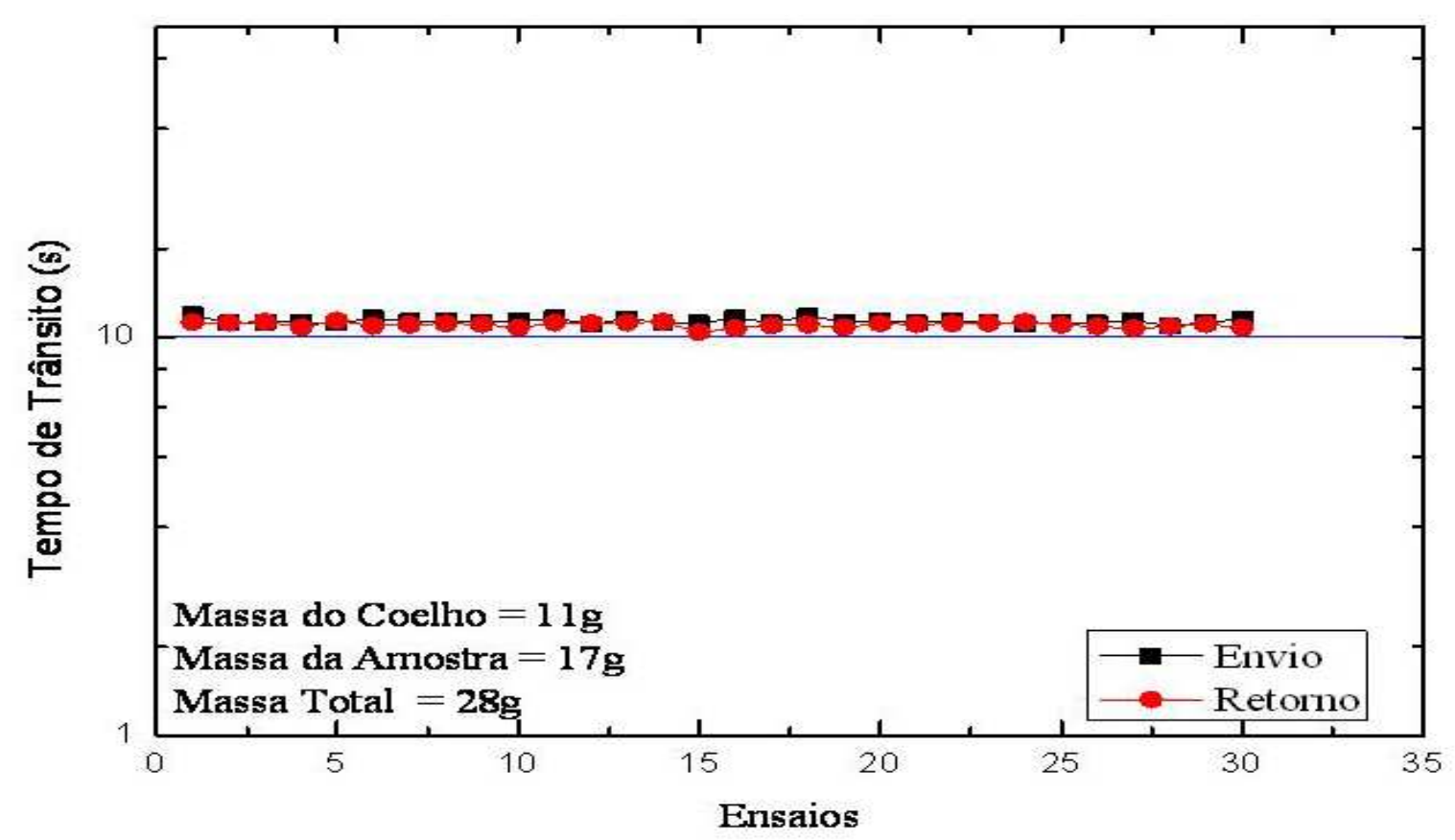

FIGURA 5.1 (c) Tempo de Transito do Coelho com Amostra de $17 g$ (Cápsula de Cádmio)

Pode ser observado das Figuras-5.1 (b) e 5.1 (c) que o incremento de massa no Porta-Amostras torna o tempo de trânsito mais estável e regular. 0 volume do Porta-Amostras limita a massa a ser irradiada evitando altas atividades alcançadas neste sistema de irradiação, o que é compatível com as características do processo de AAN.

\subsection{Medida de fluxo neutrônico (método de ativação de folha de $\mathrm{Au}$ )}

A medida de fluxo na posição de irradiação, ou seja, dentro do elemento de irradiação posicionado na posição 16 da placa matriz do reator, foi executada pelo Laboratório de Metrologia Nuclear (LAN) do IPEN usando o método de ativação de folhas de ouro. Os resultados obtidos e demonstrados no ANEXO D, confirmam os níveis de fluxo de $3,70.10^{12} \mathrm{n} \mathrm{cm}^{-2} \mathrm{~s}^{-1}$.

\subsection{Avaliação estrutural da placa matriz do núcleo do reator}

Devido à inclusão de um elemento de irradiação, do novo PTS, posicionado sobre a placa matriz do núcleo requereu-se a comprovação da resistência mecânica da placa matriz na nova configuração. Foi então desenvolvido um modelo de cálculo utilizando-se o programa de elementos finitos ANSYS, pela área de Mecânica Estrutural (CENM) do Centro de Engenharia Nuclear do IPEN avaliando as configurações possíveis para locação de até dois 
novos elementos de irradiação em posições determinadas e verificando as tensões para os casos avaliados.

Após simulações computacionais verificou-se que as tensões resultantes para as configurações avaliadas não são significativas, sendo que na configuração com os novos elementos de irradiação, as tensões atuantes na placa matriz e nos parafusos de ligação da placa matriz à estrutura de sustentação do núcleo ficaram cerca de $20 \%$ e $7 \%$, respectivamente, maiores que na configuração sem os novos elementos de irradiação conforme mostrado na Tabela-5.1 abaixo:

TABELA 5.1 - Tensões Resultantes e Limites da Placa Matriz à Esforços do PTS

\begin{tabular}{|c|c|c|c|c|}
\hline & \multicolumn{3}{|c|}{ Tensão (N/mm²) } & \multirow{2}{*}{$\begin{array}{c}\text { Nova } \\
\text { Situação } \\
\text { (2) / (1) } \\
(\%)\end{array}$} \\
\hline & $\begin{array}{l}\text { (1) } \\
\text { Sem novos } \\
\text { elementos } \\
\text { de } \\
\text { Irradiação }\end{array}$ & $\begin{array}{l}\text { (2) } \\
\text { Com novos } \\
\text { elementos } \\
\text { de } \\
\text { Irradiação }\end{array}$ & $\begin{array}{c}\text { Limites } \\
\text { Admissíveis }\end{array}$ & \\
\hline Placa Matriz & 2,56 & 3,08 & 25,0 & 20 \\
\hline $\begin{array}{c}\text { Contato } \\
\text { Placa-Parafuso }\end{array}$ & 1,94 & 2,10 & 37,5 & 8 \\
\hline Parafusos & 17,8 & 19,0 & 109 & 7 \\
\hline
\end{tabular}

\subsection{Avaliação do risco de acidente na operação e segurança do Reator IEA-R1}

O PTS anterior a este objeto da dissertação, devido à sua montagem e operação, foi sempre tratado no Relatório de Análise de Segurança (RAS) da instalação do reator como um sistema com potencial risco de provocar um esvaziamento da piscina, pelo rompimento da tubulação, ocasionando o acidente conhecido por Loss of Coolant Accident (LOCA) que é a perda do refrigerante do núcleo. Portanto o sistema mereceu sempre cuidados especiais como a colocação de válvulas solenóides especiais, para isolamento da tubulação, acionadas por sensores de níveis caso a piscina fosse esvaziando. O conceito do 
novo PTS foi avaliado quanto aos riscos de provocar qualquer tipo de acidente à operação do reator sendo que conforme relatório da equipe do Centro de Engenharia Nuclear (CEN) do IPEN relatado no ANEXO E, não existe neste sistema o risco do esvaziamento da piscina existente no sistema antigo. $O$ que propiciou isto foi o novo conceito de montagem do PTS cuja chegada ao ponto de irradiação no núcleo se faz por um duto aéreo ao saguão eliminando o risco de esvaziamento por rompimento da tubulação.

\subsection{Avaliação de dose na cápsula irradiada (coelho) de PEAD}

Um novo porta amostras foi projetado de material plástico apropriado para utilização em PTS conforme o documento técnico TECDOC-564 [8] da AIEA. O material novo, PEAD, juntamente com o material do antigo porta amostras, Nylon, foram submetidos a idênticas condições de irradiação e o grupo de proteção radiológica do reator fez a avaliação da dose de cada material observando que o comportamento do PEAD se mostrou mais adequado à aplicação que o comportamento do Nylon em termos de dose. Uma vez que para - PEAD as doses ficaram dentro dos limites compatíveis com a atividade profissional dos usuários e garantindo um reaproveitamento do porta amostras de PEAD após uma semana de decaimento da atividade devida á irradiação. Esse tempo para o antigo porta amostras chega ao tempo de 1 mês para que possa ser reutilizado.

As características mecânicas do novo porta amostras foram avaliadas visualmente, após irradiação, onde o de Nylon (Figura-5.4) mostrou-se mais deteriorado que o de PEAD (Figura-5.5). 

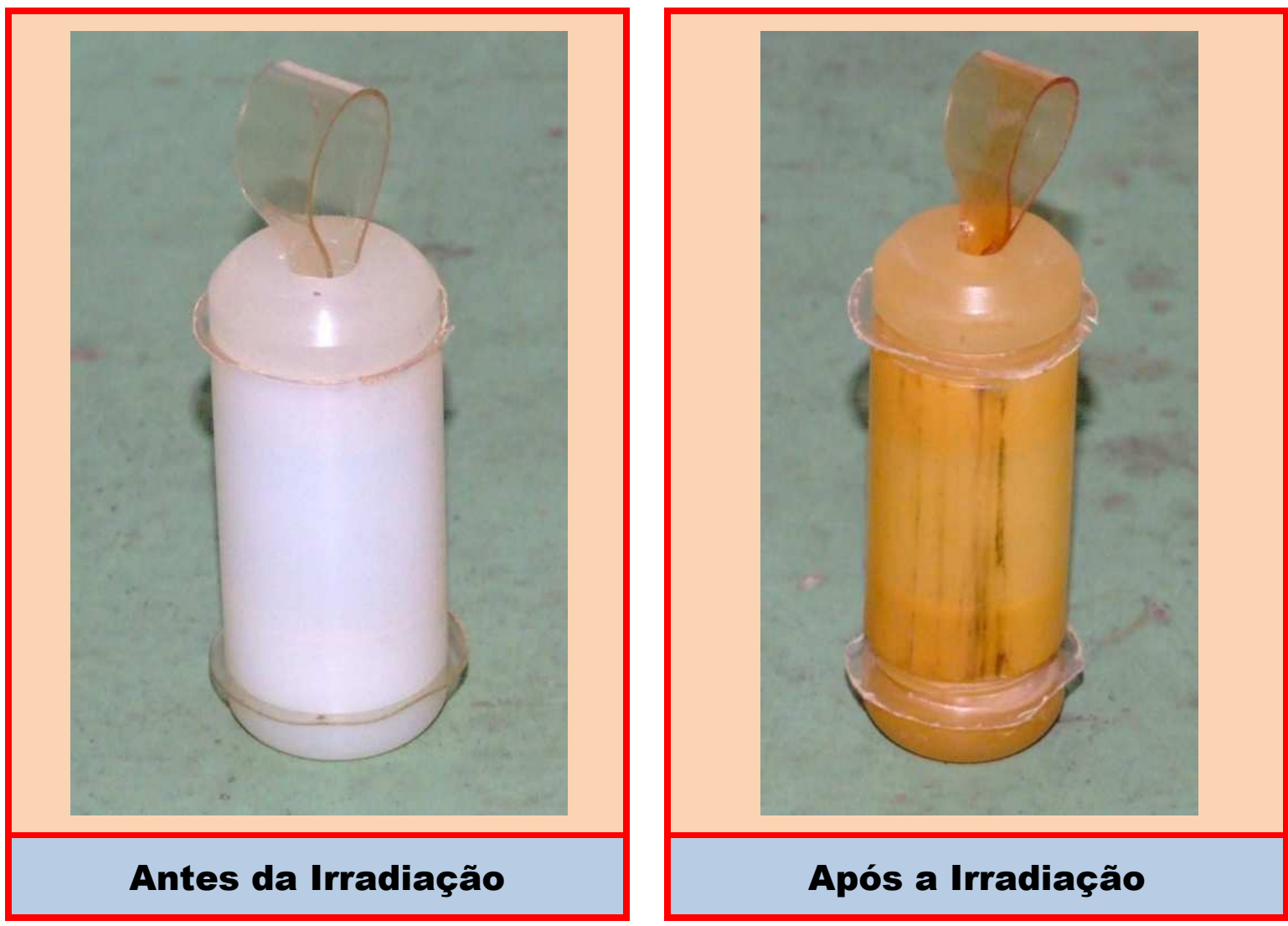

FIGURA 5.4 - Porta amostras de Nylon
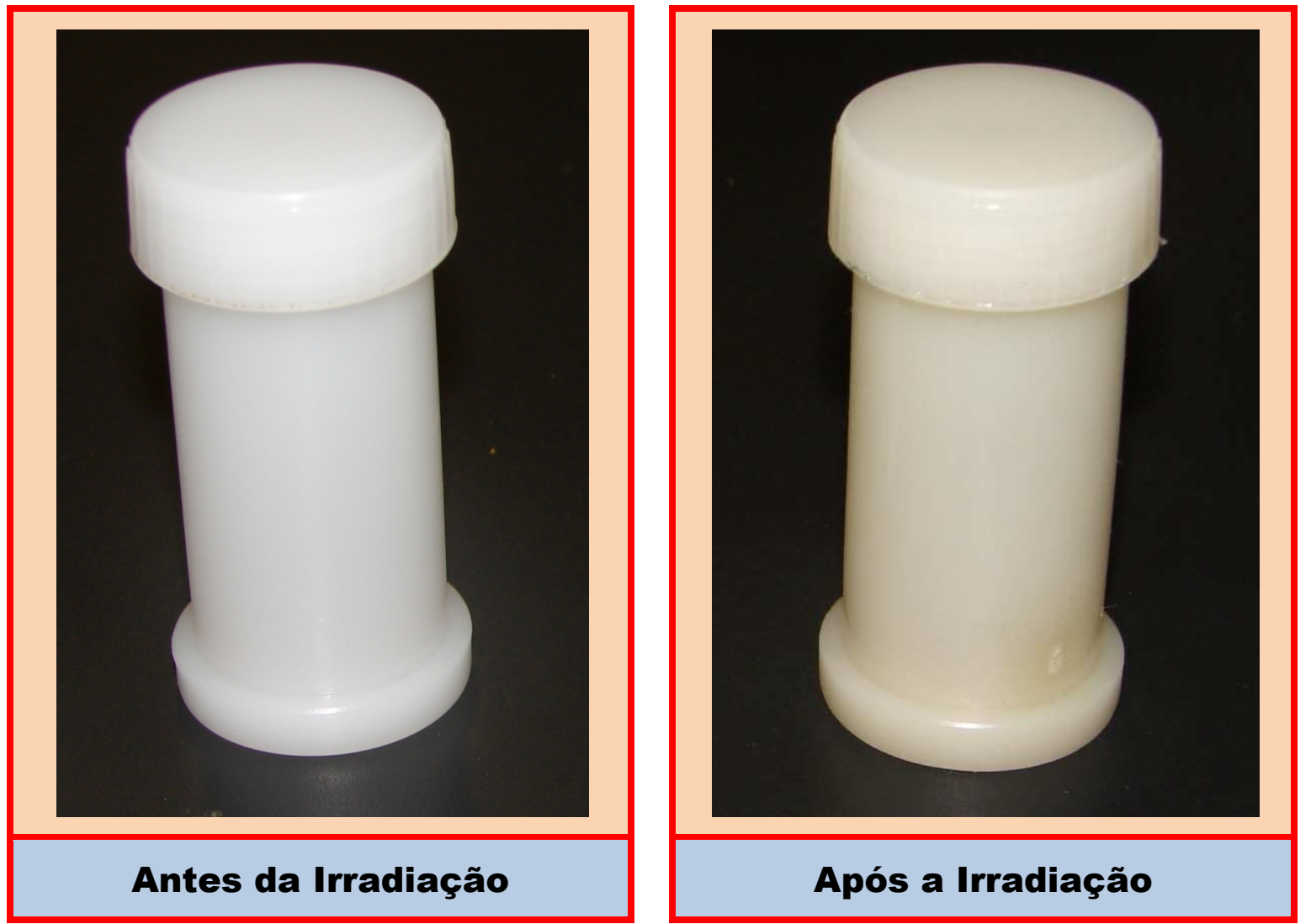

FIGURA 5.5 - Porta amostras de PEAD Antes da Irradiação 


\section{CONCLUSÕES}

O novo PTS melhora as condições de segurança na operacionalidade do reator. Evita o problema de LOCA e insere à placa matriz esforços dentro do permissível para uma condição segura.

O sistema novo insere uma maior segurança, ao usuário, quanto ao tempo de transito, tempo este muito importante em AAN.

O PTS implementado garante o nível de fluxo, na posição atual, ou seja, furo 16 da placa matriz do núcleo do reator, da ordem de $3,7 \times 10^{12} \mathrm{n} . \mathrm{cm}^{-2}$. $\mathrm{s}^{-1}$, com possibilidade de alterar esse fluxo com um reposicionamento do elemento de irradiação entre as posições disponíveis para irradiação da placa matriz do núcleo do reator.

O novo sistema pneumático já está em operação e tem sido utilizado por diferentes grupos. Pesquisadores que fazem análise de alimentos [12, 62]; análise de poluição ambiental atmosférica $[13,15,16,17]$ e de rios [14, 30]; análise e determinação de elementos de terras raras em plantas e solo [28]; análise de elementos traços em cabelo [29] e análise de amostras de sangue [18, 31, 32, 33, 34, 35, 36, 37, 38, 39, 40, 41, 42, 43]; investigação de parâmetros nucleares [44, 45, 46, 47, 48, 49, 50, 51, 52, 53, 54, 55, 56, 57, 58, 59, 60, 61].

O sistema em operação regular apresentou-se de simples manutenção e de fácil solução de problemas que ocasionalmente ocorrem durante sua utilização. A facilidade de manutenção evita a interdição, permitindo aos usuários a utilização contínua do sistema.

De acordo com os resultados obtidos pelos usuários o novo sistema está consolidado. 


\section{TRABALHOS FUTUROS}

Melhoria na aerodinâmica do porta amostras, mais especificamente a tampa, de modo a uniformizar o tempo de envio com o tempo de retorno.

Implementar ao sistema um painel sinótico de modo a monitorar o envio e o retorno do porta amostras. O painel será interligado a sensores de posição, instalados ao longo do trecho da tubulação, desde o laboratório até a posição de irradiação no núcleo.

Melhoria do sistema de alimentação (Blower), selecionando um equipamento de tecnologia mais atual. 
ANEXO A: Características Técnicas - Mangueira da tubulação do novo PTS (Trecho-1)

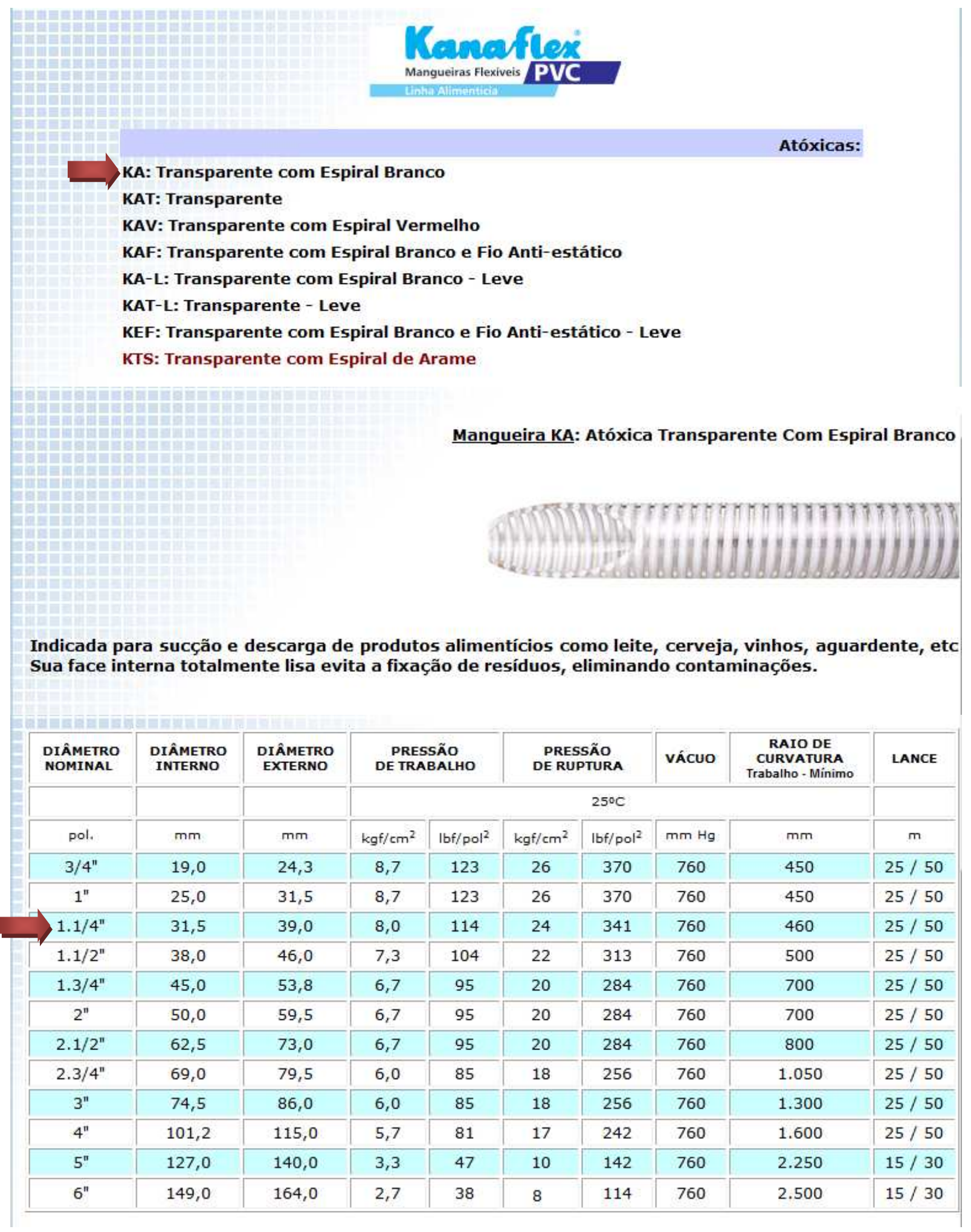


ANEXO B: Características Técnicas - Mangueira da tubulação do novo PTS (Trecho-2)

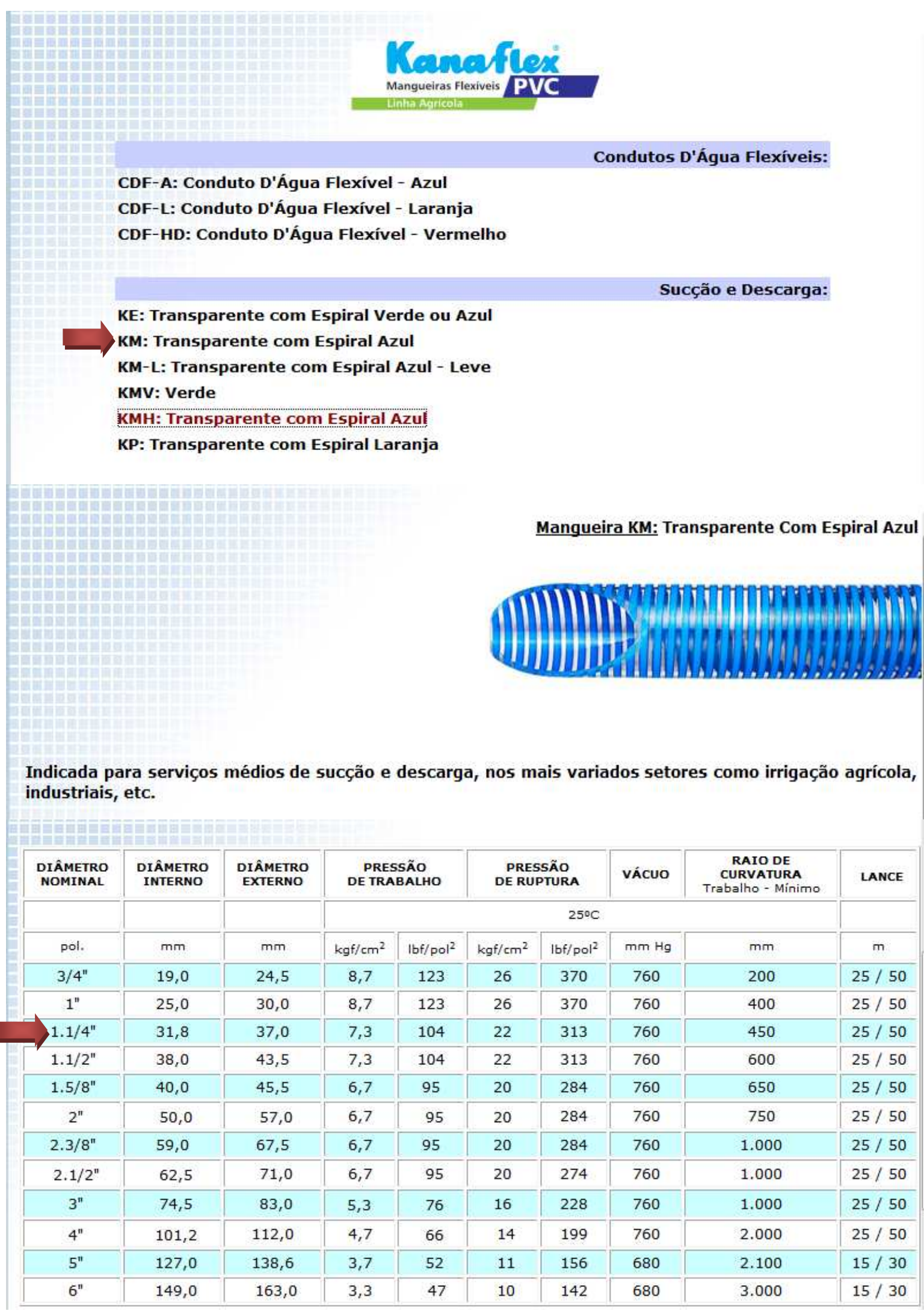


ANEXO C: Características Técnicas - Suportes da tubulação do novo PTS

\section{Eletrocalhas e Tampas}

Electrogutter and covers

Electrocanal y tapas

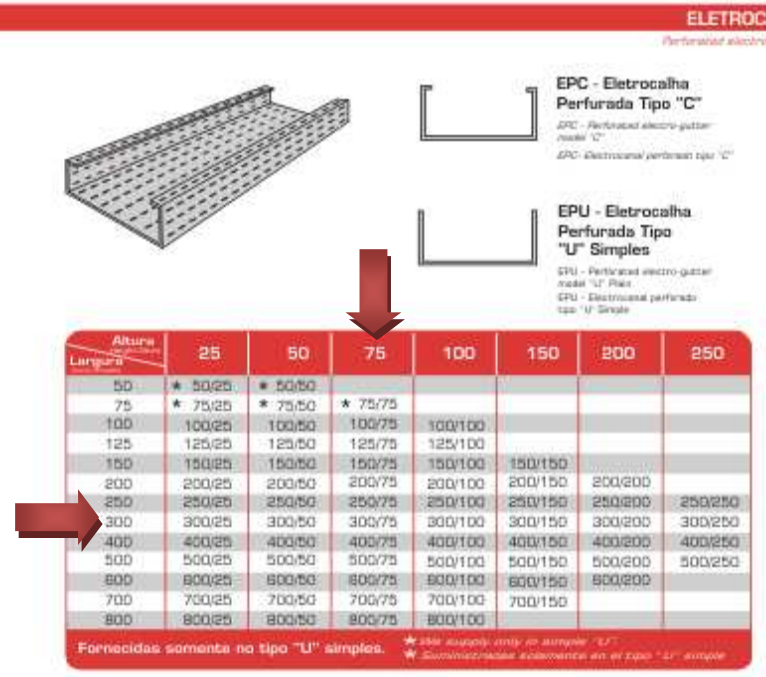


ANEXO D: Certificado de Calibração do Lab. de Metrologia Nuclear do IPEN

\title{
ipen
}

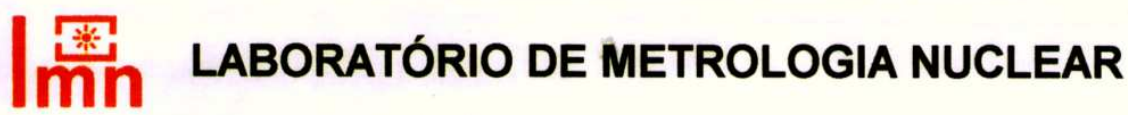

\author{
CENTRO DO REATOR DE PESQUISAS
}

\author{
CERTIFICADO DE CALIBRAÇÃO \\ $D E$ \\ DENSIDADE DE FLUXO DE NÊUTRONS
}

Certificado $n^{\circ}$ :

Data:

F-01/2008

30/01/2008

Destinatário:

Roberto Frajndlich (CRPq)

Fonte de nêutrons:

Reator IEA-R1 Potência: 2,0 MW

Reação utilizada:

${ }^{197} \mathrm{Au}(\mathrm{n}, \gamma){ }^{1978} \mathrm{Au}$

Tipo de amostra:

Au puro - folha

\begin{tabular}{|c|c|c|c|c|}
\hline Posição & $\begin{array}{c}\text { Tempo de } \\
\text { irradiação }\end{array}$ & $\begin{array}{c}\text { Data da } \\
\text { irradiação }\end{array}$ & $\begin{array}{c}\text { Densidade de Fluxo } \\
\text { de Nêutrons Térmicos } \\
10^{12}\left(\mathrm{~cm}^{-2} \mathrm{~s}^{-1}\right)\end{array}$ & $\begin{array}{c}\text { Incerteza* } \\
(\%)\end{array}$ \\
\hline Estação 4 & 10 min & $16 / 01 / 2008$ & 3,70 & 7,0 \\
\hline
\end{tabular}

*Nivel de confiança :68\%.

Observação: Temperatura do moderador considerada: $40^{\circ} \mathrm{C}$

Executores:

Dr. Mauro S. Dias

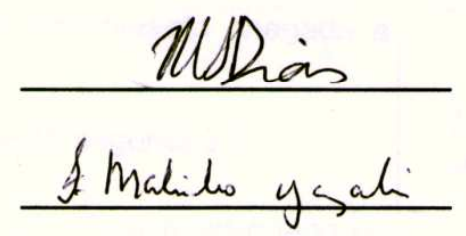

MSc. Ione Makiko Yamazaki

Responsável:

Dr. Mauro S. Dias

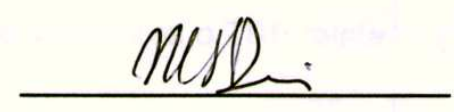

\footnotetext{
Comissão Nacional de Energia Nuclear Instituto de Pesquisas Energéticas e Nucleares Av. Prof. Lineu Prestes, 2242 Cidade Universitária - CEP 05508-000 Caixa Postal 11049 - CEP 05422-970 - Pinheiros - São Paulo - SP - Brasil Telefone: (011) 3133-8822 Fax: (0
e-mail: sac@ipen.br
} 
ANEXO E: Análise e Avaliação de Risco Operacional do Reator com o novo PTS

\section{IPEN-CNEN/SP \\ 22 SET 1438 墨 002242}

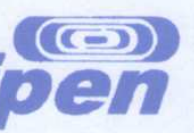

PROTOCOLO

\section{Memorando Interno CEN $n^{\circ}$ 068/2005}

DATA: 21 DE SETEMBRO DE 2005

PARA: ROBERTO FRAJNDLICH (CRPQ)

DE: ANTONIO TEIXEIRA E SILVA (CEN)

REFERÊNCIA: PROJETO SISTEMA PNEUMÁTICO

Prezado Senhor,

Informo que após análise no CEN, a implantação do projeto do novo Sistema Pneumático não deve agravar aspectos de segurança já definidos no RAS do Reator IEA-R1 para o Sistema Pneumático que se encontra hoje no reator. Solicitamos, entretanto, que este novo projeto seja incorporado ao RAS do Reator IEA-R1 nos mesmos moldes do que foi feito para o Sistema Pneumático que está sendo substituído.

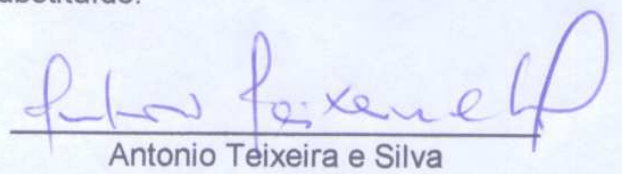

Gerente do Centro de Engenharia Nuclear

CEN 


\section{REFERÊNCIAS BIBLIOGRÁFICAS}

1. LIU, H. Pneumatic Capsule Pipeline - Basic Concept, Practical Considerations, and Current Research. In: MID-CONTINENT TRANSPORTATION SYMPOSIUM 2000 PROCEEDINGS, 15-16 may, 2000, Ames, lowa, USA. Proceedings... Ames: 2000, pp. 230-234.

2. LIU, H. Research, Development and Use of PCP in the United States of America. Japanese Journal of Multiphase Flow, Vol.21, nำ1, pp. 57-69, 2007.

3. MIGUEL, R. A. Otimização da Técnica de Análise Por Ativação Neutrônica Instrumental e Adequação do Software " $k_{0}$-Labsue" Método Paramétrico $k_{0}$. 2003. Dissertação (Mestrado) - Universidade Federal de Minas Gerais, Minas Gerais.

4. MARETTI, F. Jr. Influências na Ativação Neutrônica em Reatores. 1983.

Dissertação (Mestrado) - Universidade Federal de Minas Gerais, Minas Gerais.

5. LI, X.; HENKELMANN, R.; BAUMGÄRTNER, F. An Automated Fast Transfer System at the Research Reactor Munich. Nuclear Instruments and Methods in Physics Research, A 522 : 470-476, 2004.

6. CARVAlho, A. N. Projeto e Construção de Um Sistema Pneumático de Transferência de Amostras para o Gerador de Nêutrons. 1983. Monografia noㅡ 23, Curso de Introdução à Engenharia Nuclear - Universidade Federal de Pernambuco, Recife.

7. AEROCOM Transportes Pneumáticos. Apresenta aplicações do uso de Sistemas Pneumáticos de Transferência. Disponível em <http://www.aerocom.com.br/aplicacoes.html>. Acesso em: 06 abr. 2010.

8. SUMIYA, L. C. do A. Estudo de parâmetros relevantes na irradiação de 124$X e$, visando a otimização na obtenção de 123-I ultra puro no Ciclotron Cyclone-30 do IPEN-CNEN/SP. 2006. Tese (Doutorado) - Instituto de Pesquisas Energéticas e Nucleares, São Paulo.

9. BODE, P.; HOFFMAN, E. L.; LINDSTROM, R. M.; PARRY, S. J.; ROSENBERG, R. J. Practical Aspects of Operating a Neutron Activation Analysis Laboratory. Vienna, (Austria): AIEA International Atomic Energy Agency, 1990. (IAEA-TECDOC-564).

10. ZANDI, I; GIMM, K. K. Transport of Solid Commodities Via Freight Pipeline Freight Pipeline Technology - Volume II. Philadelphia, (USA): U.S. Department of Transportation, 1976. (DOT-TST-76T-36). 
11. COHEN, R. A. The Pneumatic Mail Tubes: New York's Hidden Highway and Its Development. In: $1^{\text {st }}$ INTERNATIONAL SYMPOSIUM ON UNDERGROUND FREIGHT TRANSPORT BY CAPSULE PIPELINES AND OTHER TUBE/TUNNEL SYSTEMS, 2-3 september, 1999, Columbia, Missouri, USA. Proceedings... Missouri: 1999, pp. 189-202.

12. KIRA, C. S. Estudo da composição mineral e dos elementos-traço essenciais em amostras de leite e produtos lácteos por espectrometria de emissão atômica com plasma induzido e análise por ativação com nêutrons. 2002. Dissertação (Mestrado) - Instituto de Pesquisas Energéticas e Nucleares, São Paulo.

13. ARINE, D. R. Análise de águas de superfície e de sedimentos de rios da região de Iperó, SP, por espectrometria de absorção atômica e por ativação neutrônica. 2000. Dissertação (Mestrado) - Instituto de Pesquisas Energéticas e Nucleares, São Paulo.

14. FUGA, A.; SAIKI, M.; MARCELLI, M. P. Análise de liquens por ativação neutrônica para estudo da poluição atmosférica da cidade de São Paulo.

In: INTERNATIONAL NUCLEAR ATLANTIC CONFERENCE-INAC 2005, 28 aug 2 sep, 2005, Santos, SP, Brasil. Anais... Santos: INAC, 2005.

15. SEO, D.; SAIKI, M.; CATHARINO, M. G. M.; MOREIRA, E. G.; VASCONCELOS, M. B.A. Aplicação da irradiação curta na análise por ativação com nêutrons de amostras de mexilhão. In: INTERNATIONAL NUCLEAR ATLANTIC CONFERENCE-INAC 2007, 30 sep - 5 oct, 2007, Santos, SP, Brasil. Anais... Santos: INAC, 2007.

16. SEO, D.; VASCONCELOS, M. B. A.; SAIKI, M.;CATHARINO, M. G. M.; MOREIRA, E. G.; SOUSA, E. C. P. M.; PEREIRA, C. D. S. Estabelecimento de procedimento para determinação de vanádio em mexilhões pelo método de análise por ativação com nêutrons. In: INTERNATIONAL NUCLEAR ATLANTIC CONFERENCE-INAC 2007, 27 sep - 2 oct, 2009, Rio de Janeiro, RJ, Brasil. Anais... Rio de Janeiro: INAC, 2009.

17. SEO, D.; VASCONCELOS, M. B. A.; SAIKI, M.;CATHARINO, M. G. M.; MOREIRA, E. G.; SOUSA, E. C. P. M.; PEREIRA, C. D. S. Active biomonitoring of magnesium and manganese using the Perna perna mussel collected in the north shore of São Paulo, Brasil. In: INTERNATIONAL NUCLEAR ATLANTIC CONFERENCE-INAC 2007, 27 sep - 2 oct, 2009, Rio de Janeiro, RJ, Brasil. Anais... Rio de Janeiro: INAC, 2009.

18. OLIVEIRA, L. C.; ZAMBONI, C. B.; VILELA, E. C. The potassium reference value in whole blood using nuclear activation. In: INTERNATIONAL NUCLEAR ATLANTIC CONFERENCE-INAC 2005, 28 aug - 2 sep 2005, Santos, SP, Brasil. Anais... Santos: INAC, 2005 
19. SIMPSON, J. D.; CHICHESTER, J. R.; HILL J. R. The A-711 high yield neutron generator and automated pneumatic transfer system for fast neutron activation analysis. Nuclear Instruments and Methods in Physics Research, B 241: 228-231, 2005.

20. JANG, S. Y.; KIM, C. H.; REECE W. D.; BRABY, L. A. Filtered fast neutron irradiation system using Texas A\&M University Nuclear Science Center Reactor. Nuclear Instruments and Methods in Physics Research, A 530: 493-504, 2004.

21. FELICISSIMO, M. P.; PEIXOTO, J. L.; MUNITA, C. S. Preliminary chemical composition study of pré-colonial ceramics from pantanal sul mato-grossense by nêutron activation analysis. In: INTERNATIONAL NUCLEAR ATLANTIC CONFERENCE-INAC 2005, 28 aug - 2 sep, 2005, Santos, SP, Brasil. Anais... Santos: INAC, 2005

22. ARMELIN, M. J. A.; PRIMAVESI, O.; SAIKI, M. Effect of limming and and fertilizer on mineral content and productivity of Brachiaria Decumbens grass forage.

Journal of Radioanalytical and Nuclear Chemistry, Vol. 271, nำ1, 221-224, 2007.

23. ARMELIN, M. J. A.; PRIMAVESI, O.; SAIKI, M. Limestone doses affecting mineral contents in tropical grass forage. Journal of Radioanalytical and Nuclear Chemistry, Vol. 264, nำ 1, 29-31, 2005.

24. LIU, H. Use of pneumatic capsule pipeline for both underground freight transport and tunnel construction. In: INTERNATIONAL ACADEMIC CONFERENCE ON UNDERGROUND SPACE - IACUS 2006, 18-19 nov, 2006, Beijing, China. Proceedings... Beijing: IACUS, 2006.

25. LIU, H; KOSUGI, S. Use of pneumatic capsule pipeline for underground tunneling. In: $12^{\text {th }}$ INTERNATIONAL SYMPOSIUM ON FREIGHT PIPELINES, 20-24 sep, 2004, Prague, Czech Republic. Proceedings... Prague: ISFP, 2004.

26. HANE, K.; OKUTSU, K.; MATSUI, N.; KOSUGI, S. Applicability of pneumatic capsule pipeline system to radioactive waste diposal facility. In: WM'02 CONFERENCE, 24-28 feb, 2002, Tucson, AZ, Estados Unidos. Proceedings... Tucson: WM, 2002.

27. KOSUGI, S.; SAITOU, K.; MATSUI, N.; TOMITA, Y. Development of vertical pneumatic capsule pipeline system for deep underground. In: $2^{\text {nd }}$ IINTERNATIONAL SYMPOSIUM ON UNDERGROUND FREIGHT TRANSPORTATION BY CAPSULE PIPELINES AND OTHER TUBE/ Tunnel Systems(2000). 
28. MARIA, S. P. Estudo das características de distribuição de elementos terras raras em SOLANUM LYCOCARPUM em diferentes ambientes tropicais do Brasil por ativação neutrônica. 2001. Dissertação (Mestrado) - Instituto de Pesquisas Energéticas e Nucleares, São Paulo.

29. FRAZÃO, S. V. Estudo sobre a determinação de elementos traço em cabelos humanos pelo método de análise por ativação com nêutrons. 2008. Dissertação (Mestrado) - Instituto de Pesquisas Energéticas e Nucleares, São Paulo.

30. SILVA, N. C.; FIGUEIREDO, A. M. G.; RIBEIRO, A. P.; NETO, G. M. N.; CAMARGO, S. P.; TICIANELLI, R. B. Concentração de metais em solos adjacentes à avenida Marginal do Rio Tietê, São Paulo. In: INTERNATIONAL NUCLEAR ATLANTIC CONFERENCE-INAC 2009, 27 set - 2 out 2009, Rio de Janeiro, RJ, Brasil. Anais... Rio de Janeiro: INAC, 2009.

31. AGUIAR, R. O.; ZAMBONI, C. B.; MEDEIROS, J. A. G. Analisys of Ca and Mg in blood of golden hamster using NAA technique. In: INTERNATIONAL NUCLEAR ATLANTIC CONFERENCE-INAC 2009, 27 set - 2 out 2009, Rio de Janeiro, RJ, Brasil. Anais... Rio de Janeiro: INAC, 2009.

32. METAIRON, S.; ZAMBONI, C. B.; MEDEIROS, I. M. M. A. Analisys of inorganic elements in blood of albino rabbit using NAA. In: INTERNATIONAL NUCLEAR ATLANTIC CONFERENCE-INAC 2009, 27 set - 2 out 2009, Rio de Janeiro, RJ, Brasil. Anais... Rio de Janeiro: INAC, 2009.

33. ZAMBONI, C. B.; OLIVEIRA, L. C.; MEDEIROS, J. A. G.; AZEVEDO, M. R.; VILELA, E. C.; SANT'ANNA, O. A.; DALAQUA, L. Determination of reference values of elements in whole blood using nuclear methodology.

In: INTERNATIONAL NUCLEAR ATLANTIC CONFERENCE-INAC 2007, 30 sep - 5 oct, 2007, Santos, SP, Brasil. Anais... Santos: INAC, 2007.

34. ZAMBONI, C. B.; SUZUKI, M. F.; METAIRON, S.; CARVALHO, M. D. F.; SANT'ANNA, O. A. Investigation of whole blood of SJL/J mice using neutron activation analysis. Journal of Radioanalytical and Nuclear Chemistry, Vol. 281, 97-99, 2009.

35. AGUIAR, R. O.; ZAMBONI, C. B.; MEDEIROS, J. A. G. Trace elements at whole blood of golden hamster using semi parametric NAA technique.

In: INTERNATIONAL NUCLEAR ATLANTIC CONFERENCE-INAC 2007, 30 sep - 5 oct, 2007, Santos, SP, Brasil. Anais... Santos: INAC, 2007.

36. OLIVEIRA, L. C. Estudo da distribuição de íons e metais em sangue via metodologia nuclear. 2008. Tese (Doutorado) - Instituto de Pesquisas Energéticas e Nucleares, São Paulo. 
37. OLIVEIRA, L. C.; ZAMBONI, C. B. The magnesium reference value in whole blood using nuclear activation. In: INTERNATIONAL NUCLEAR ATLANTIC CONFERENCE-INAC 2009, 27 set - 2 out 2009, Rio de Janeiro, RJ, Brasil. Anais... Rio de Janeiro: INAC, 2009.

38. TRINDADE, C. E.; SAIKI, M.; SUMITA, N. M.; JALUUL, O.; VASCONCELLOS, M. B. A.; JACOB, W. Comparative study between trace element concentrations in human whole blood and serum samples. In: INTERNATIONAL NUCLEAR ATLANTIC CONFERENCE-INAC 2007, 30 sep - 5 oct, 2007, Santos, SP, Brasil. Anais... Santos: INAC, 2007.

39. AGUIAR, R. O. Determinação de elementos em sangue de hamster dourado usando AAN. 2009. Dissertação (Mestrado) - Instituto de Pesquisas Energéticas e Nucleares, São Paulo.

40. BAPTISTA, T. S.; ZAMBONI, C. B.; MEDEIROS, J. A. G.; FREITAS, M. G.; HIGASHI, H. G.; MARCELINO, J. R. Neutron activation analysis of $\mathrm{Cl}, \mathrm{K}$ and $\mathrm{Na}$ content in whole blood of horses used in hyperimmune sera production. In: INTERNATIONAL NUCLEAR ATLANTIC CONFERENCE-INAC 2009, 27 set 2 out 2009, Rio de Janeiro, RJ, Brasil. Anais... Rio de Janeiro: INAC, 2009.

41. BAPTISTA, T. S. Valores de referência de elementos em sangue de cavalos da raça crioula via metodologia nuclear. 2010. Dissertação (Mestrado) Instituto de Pesquisas Energéticas e Nucleares, São Paulo.

42. OLIVEIRA, L. C.; ZAMBONI, C. B.; ZAHN, G. S.; MASCHIO, M. A. The reference value for blood sodium in inhabitants of Brazil: harmonization of statistical treatment. In: INTERNATIONAL NUCLEAR ATLANTIC CONFERENCE-INAC 2007, 30 sep - 5 oct, 2007, Santos, SP, Brasil. Anais... Santos: INAC, 2007.

43. OLIVEIRA, L. C.; ZAMBONI, C. B.; GENEZINI, F. A.; FIGIEIREDO, A. M. G.; ZAHN, G. S. Use of thermal neutrons to perform clinical analyses in blood and urine samples. Journal of Radioanalytical and Nuclear Chemistry, Vol. 263, nํㅜ 3, 783-786, 2005.

44. GENEZINI, F. A.; ZAHN, G. S.; ZAMBONI, C. B. Determination of Half Life of the ${ }^{155} \mathrm{Sm}$ beta-decay. In: XXXII Reunião de Trabalho sobre Física Nuclear no Brasil, 2010, Águas de Lindóia. AIP Conference. Proceedings... New York : American Institute of Physics, 2010, v. 1245, p. 163-166.

45. RAELE, M. P.; ZAMBONI, C. B.; ZAHN, G. S.; GENEZINI, F. A. Decay of ${ }^{155} \mathrm{Sm}$. Brazilian Journal of Physics, São Paulo, Vol. 35, № 3B, 839-842, 2005.

46. SILVA, A. C. O.; GENEZINI, F. A.; ZAMBONI, C. B.; ZAHN, G. S.; CRUZ, M. T. F. The half-life of Mo-101 and Tc-101 beta- decay. In: XXXI Reunião de Trabalho sobre Física Nuclear no Brasil, 2008, São Sebastião. Programa e Resumos , 2008. p. 37-38. 
47. BATISTA, W. F.; GENEZINI, F. A.; ZAMBONI, C. B.; ZAHN, G. S. Half-Life of Te-127. In: XXXI Reunião de Trabalho sobre Física Nuclear no Brasil, 2008, São Sebastião. Programa e Resumos, 2008. p. 38-38.

48. ZAHN, G. S.; GENEZINI, F. A.; OLIVA, J. W. M.; ZAMBONI, C. B. The half life of the ${ }^{193}$ Os beta-decay. In: XXXII Reunião de Trabalho sobre Física Nuclear no Brasil, 2010, Águas de Lindóia. AIP Conference. Proceedings... New York : American Institute of Physics, 2010, v. 1245, p. 128-131.

49. ZAHN, G. S.; ZAMBONI, C. B.; GENEZINI, F. A.; RAELE, M. P.; CHÁVEZ, J. Y. Z., CRUZ, M. T. F. Investigation of Excited Levels in ${ }^{193}$ Ir from the Beta Decay of ${ }^{193}$ Os. Brazilian Journal of Physics, São Paulo, v. 35, no 3B, 843-846, 2005.

50. GENEZINI, F. A.; RAELE, M. P.; ZAHN, G. S.; ZAMBONI, C. B. Multiparametric coincidence measurements of ${ }^{155} \mathrm{Sm} \beta^{-}$decay. In: INTERNATIONAL NUCLEAR ATLANTIC CONFERENCE-INAC 2007, 30 sep - 5 oct, 2007, Santos, SP, Brasil. Anais... Santos: INAC, 2007.

51. ZAHN, G. S. Estudo do decaimento $\beta^{-}$do ${ }^{193}$ Os. 2006. Tese (Doutorado) Instituto de Pesquisas Energéticas e Nucleares, São Paulo.

52. ZAHN, G. S.; ZAMBONI, C. B.; GENEZINE, F. A.; CHÁVES, J. Y. Z.; CRUZ, M. T. F. Investigation of the new $960 \mathrm{keV}$ level in ${ }^{193} \mathrm{Ir}$ using a multiparametric detection system. In: INTERNATIONAL NUCLEAR ATLANTIC CONFERENCE-INAC 2005, 28 aug - 2 sep, 2005, Santos, SP, Brasil. Anais... Santos: INAC, 2005

53. ZAHN, G. S.; ZAMBONI, C. B.; OLIVEIRA, L. C. Thermal neutron activation cross section for ${ }^{48} \mathrm{Ca}$. In: INTERNATIONAL NUCLEAR ATLANTIC CONFERENCEINAC 2005, 28 aug - 2 sep, 2005, Santos, SP, Brasil. Anais... Santos: INAC, 2005

54. KOVACS, L.; ZAMBONI, C. B.; DALAQUA, L. The determination of thermal neutron cross section of ${ }^{81} \mathrm{Br}$. In: INTERNATIONAL NUCLEAR ATLANTIC CONFERENCE-INAC 2009, 27 set - 2 out 2009, Rio de Janeiro, RJ, Brasil. Anais... Rio de Janeiro: INAC, 2009.

55. ZAHN, G. S.; GENEZINE, F. A.; ZAMBONI, C. B.;CRUZ, M. T. F. Gamma transition intensity determination using multidetector coincidence data. Nuclear Instruments and Methods in Physics Research, A 605: 339-343, 2009.

56. ZAHN, G. S.; ZAMBONI, C. B.; GENEZINI, F. A.; RAELE, M. P. New gamma transitions in ${ }^{193}$ Ir from the beta decay of ${ }^{193}$ Os. Brazilian Journal of Physics, São Paulo, v. 34, no 3B, p. 843-846, 2004. 
57. BATISTA, W.; ZAMBONI, C. B. Gamma transitions in ${ }^{127}$ Te. In: INTERNATIONAL NUCLEAR ATLANTIC CONFERENCE-INAC 2009, 27 set - 2 out 2009, Rio de Janeiro, RJ, Brasil. Anais... Rio de Janeiro: INAC, 2009.

58. ZAHN, G. S.; GENEZINI, F. A.; ZAMBONI, C. B.; CRUZ, M. T. F. A new procedure to analyse angular correlation experimental data. In: IX International Conference on Nuclear Data for Science and Tecnology, 2007, Nice, France. Proceedings... p. 121-124.

59. GENEZINI, F. A.; ZAHN, G. S.; ZAMBONI, C. B.; CRUZ, M. T. F. An alternative method to determine ${ }^{235} U$ in environmental samples. In: IX International Conference on Nuclear Data for Science and Tecnology, 2007, Nice, France. Proceedings... p. 239-241.

60. MEDEIROS, I. M. M. A.; MEDEIROS, J. A. G.; ZAMBONI, C. B. Software for determination of the thermal neutron flux in a nuclear reactor.

In: INTERNATIONAL NUCLEAR ATLANTIC CONFERENCE-INAC 2009, 27 set 2 out 2009, Rio de Janeiro, RJ, Brasil. Anais... Rio de Janeiro: INAC, 2009.

61. OLIVEIRA, L. C.; ZAMBONI, C. B.; ZAHN, G. S.; GENEZINI, F. A. Evaluation of semi-parametric NAA results using standard reference materials. In: XXXI Reunião de Trabalho sobre Física Nuclear no Brasil, 2008, São Sebastião. Proceedings... p. 23-23.

62. MAIHARA, V. A.; MOURA, P. L. C.; FÁVARO, D. I. T.; VASCONCELLOS, M. B. A. Assessment of iodine content in Brazilian duplicate portion diets and table salt. Journal of Radioanalytical and Nuclear Chemistry, Vol. 278, nํ2, 391-393, 2008. 